UNIVERSIDADE DE SÃO PAULO

\author{
INSTITUTO DE QUÍMICA \\ INSTITUTO DE FÍSICA \\ INSTITUTO DE BIOCIÊNCIAS \\ FACULDADE DE EDUCAÇÃO
}

Jéssica da Silva Gaudêncio

ESTUDO DAS REPRESENTAÇÕES VISUAIS EM QUESTÕES DE QUÍMICA DOS EXAMES VESTIBULARES DE UNIVERSIDADES PÚBLICAS DO ESTADO DE SÃO PAULO 
Jéssica da Silva Gaudêncio

\section{ESTUDO DAS REPRESENTAÇÕES VISUAIS EM QUESTÕES DE QUIIMICA DOS EXAMES VESTIBULARES DE UNIVERSIDADES PÚBLICAS DO ESTADO DE SÃO PAULO}

Dissertação de Mestrado apresentada à Comissão do Programa de Pós-Graduação Interunidades em Ensino de Ciências, como requisito para obtenção do título de Mestre em Ensino de Ciências

Área de concentração: Ensino de Química

Orientador: Prof. Doutor Guilherme Andrade Marson

São Paulo

2015 


\section{FICHA CATALOGRÁFICA \\ Preparada pelo Serviço de Biblioteca e Informação do Instituto de Física da Universidade de São Paulo}

Gaudêncio, Jéssica da Silva

Estudo das representações visuais em questões de química dos exames vestibulares de universidades públicas do Estado de São Paulo. São Paulo, 2015.

Dissertação (Mestrado) - Universidade de São Paulo. Faculdade de Educação, Instituto de Física, Instituto de Química e Instituto de Biociências.

Orientador: Prof. Dr. Guilherme Andrade Marson

Área de Concentração: Ensino de Química

Unitermos: 1.Química (Estudo e ensino); 2. Ensino de química; 3.

Vestibular; 4. Universidade pública. 


\section{DEDICATÓRIA}

Dedico este mestrado a meu esposo Alan Matsushita, pelo apoio incondicional e compreensão em todas as etapas deste estudo. Por permanecer ao meu lado, me incentivando a percorrer este caminho, estendendo sua mão amiga nos momentos difíceis. 


\section{AGRADECIMENTOS}

A Deus pela vida.

Ao meu esposo Alan pelos apoios, conselhos e compreensão nos momentos difíceis, pela paciência e incentivo desde os primeiros momentos de curso.

Aos meus pais e irmão pelo apoio durante a realização dos meus estudos, e principalmente à minha sobrinha Amanda por momentos de alegrias e distrações.

À professora Lúcia, Celinha, Fátima e Leda pela ajuda e acolhimento em suas vidas, por dividirem seus espaços sempre com muito carinho e atenção, sendo fundamental para a conclusão desta etapa em minha vida.

A toda minha família e amigos, em especial ao João Gleden pela ajuda e parceria.

A todas as pessoas que direta ou indiretamente contribuíram para a realização deste trabalho. 


\section{RESUMO}

Esta pesquisa apresenta uma análise multifacetada para a classificação das representações visuais presentes em questões de química de exames vestibulares de cinco grandes universidades públicas paulistas: USP, UNICAMP, UFSCAR, UNESP e UNIFESP no período de 2007 a 2011. Os vestibulares da UFSCAR e UNIFESP utilizaram o exame do ENEM a partir de 2009 como processo de seleção, assim o exame também foi analisado. Foram encontradas 252 questões contendo representações visuais em provas de conhecimentos gerais e conhecimentos específicos. Alguns exemplos dessas representações incluem gráficos, fluxogramas, diagramas, tabelas, e equações químicas. As representações visuais foram analisadas quanto a suas relações com o texto, sua funcionalidade, conteúdos químicos envolvidos na questão e as habilidades cognitivas requisitadas. Os resultados indicam, de modo geral, que as representações visuais mais frequentes são as equações químicas e as representações bidimensionais da estrutura molecular, com predominância de conteúdos de química orgânica e físico-química. Quanto a relação texto e imagem, destaca-se a grande ocorrência de casos nos quais a integração texto e imagem é necessária para a resolução da questão. No tocante à funcionalidade das representações visuais, salienta-se que: i as provas envolvem em suas questões ilustrações que necessitam do conhecimento químico para suas interpretações; ii - há predominância de imagens menos realistas e mais interpretativas; iii - a grande ocorrência de etiquetas verbais nominativas. A ênfase em questões de memorização contendo representações visuais também foi investigada adotando-se o referencial de Zoller $(1993,1997,1999,2001)$ para classificar as questões quanto às habilidades cognitivas requisitadas: de alta ou baixa ordem. Os resultados indicam que questões que demandam habilidades cognitivas de baixa ordem são predominantes nas provas de conhecimentos gerais, e questões que demandam habilidades cognitivas de alta ordem em provas de conhecimentos específicos.

Palavras chave: ensino de química, representações visuais, vestibular e habilidades cognitivas. 


\begin{abstract}
This research presents a multifaceted analysis for the classification of visual representations present in chemical questions of entrance examinations of five biggest São Paulo public universities: USP, UNICAMP, UFSCAR, UNESP and UNIFESP from 2007 to 2011. Entrance examinations of UFSCAR and UNIFESP used the exam ENEM from 2009 as a selection process, so the test was analyzed too. 252 questions were found with visual representations in general knowledge and specific knowledge test. Some examples of these representations include graphics, flow charts, diagrams, tables, and chemical equations. The visual representations were analyzed for their relation with the text, its functionality, chemical content involved in the question and the required cognitive skills. The results indicate, generally, that the most frequent visual representations are the chemical equations and the two-dimensional representations of molecular structure with content predominance of organic chemistry and physicochemical. About the relation of text-image, there is a high occurrence of cases in which text and image integration is necessary for the resolution of the matter. Regarding the functionality of visual representations, it is noted that: $\mathrm{i}$ - the test involve in his questions, illustrations that requires chemical knowledge for their interpretations; ii there is predominance of less realistic and more interpretive images; iii - the high occurrence of nominative verbal labels. The emphasis on memorization questions containing visual representations was also investigated adopting the Zoller (1993, 1997, 1999, 2001) reference to classify the questions about the cognitive skills required: high or low order. The results indicate that questions that require lower order cognitive skills are prevalent in the tests of general knowledge, and questions that require higher order cognitive skills of specific evidence.
\end{abstract}

Keywords: chemistry teaching, visual representations, vestibular and cognitive skills. 


\section{LISTA DE ABREVIATURAS E SIGLAS}

CG - Conhecimentos Gerais

COMVEST - Comissão Permanente para os Vestibulares

DCN - Diretrizes Curriculares Nacionais

ES - Conhecimentos Específicos

ENEM - Exame Nacional do Ensino Médio

FAMERP - Faculdade de Medicina de São José do Rio Preto

FCMSC-SP - Faculdade de Ciências Médicas da Santa Casa de São Paulo

FIES - Fundo de Financiamento Estudantil

FUVEST - Fundação Universitária para o Vestibular

HOCS - Higher Order Cognitive Skills

IFES - Instituições Federais de Ensino Superior

INEP - Instituto Nacional de Estudos e Pesquisas Educacionais

LDB - Lei das Diretrizes e Bases da Educação Nacional

LOCS - Lower Order Cognitive Skills

MEC - Ministério da Educação e Desportos

REUNI - Programa de Apoio ao Plano de Reestruturação e Expansão das Universidades Federais

SISU - Sistema de Seleção Unificada

PROUNI - Programa Universidade para Todos

PCN - Parâmetros Curriculares Nacionais

PCNEM - Parâmetros Curriculares Nacionais para o Ensino Médio

USP - Universidade de São Paulo

UNICAMP - Universidade Estadual de Campinas

UNESP - Universidade Estadual de São Paulo

UFSCAR - Universidade Federal de São Carlos

UNIFESP - Universidade Federal de São Paulo

VUNESP - Fundação para o Vestibular da Universidade Estadual Paulista 


\section{LISTA DE FIGURAS}

Figura 1 - Dimensões representacionais (Fonte: JOHNSTONE, 1993, p. 703, tradução nossa) 30

Figura 2 - Representação pela Projeção de Fisher em 3D das moléculas a) cis-2-buteno e b) trans-2-buteno (FONTE: RAUPP, SERRANO E MOREIRA, 2009, p.69) 33

Figura 3 - Representação computacional em 3D das moléculas cis-2-buteno e o trans-2buteno respectivamente (Fonte: RAUPP, SERRANO E MOREIRA, 2009, p.70) 33

\section{LISTA DE QUADROS}

Quadro 1 - Diferentes fórmulas estruturais para as moléculas cis-2-buteno e trans-2buteno.

Quadro 2 - Exemplos de questões com habilidade cognitiva de baixa ordem de (LOCS) (ZOLLER e TSAPARLIS, 1997, p.120) 39

Quadro 3 - Exemplos de questões com habilidade cognitiva de alta ordem (HOCS). (ZOLLER e TSAPARLIS, 1997, p.120). 40

Quadro 4 - Exemplo de questão que envolve mais de um assunto químico (FUVEST/USP-(ES), 2009, questão 02). 66

Quadro 5 - Exemplo de questão que mobiliza habilidades cognitivas de baixa ordem (LOCS) (ENEM, 2011, questão 80).

Quadro 6 - Exemplo de questão que mobiliza habilidade cognitiva de alta ordem (COMVEST/UNICAMP-(ES), 2007, questão 02). 68

Quadro 7 - Exemplo de questão com representação de moléculas 3D (FUVEST/USP(CG), 2007, questão 23). 


\section{LISTA DE TABELAS}

Tabela 1 - Universo de questões analisadas em cada exame 42

Tabela 2 - Questões do exame vestibular da FUVEST/USP que tomaram parte deste trabalho

Tabela 3 - Questões do exame vestibular da COMVEST/UNICAMP que tomaram parte deste trabalho

Tabela 4 - Questões do exame vestibular da VUNESP/UNESP que tomaram parte deste trabalho 45

Tabela 5 - Questões do exame vestibular da VUNESP/UFSCAR que tomaram parte deste trabalho 46

Tabela 6 - Questões do exame vestibular da VUNESP/UNIFESP que tomaram parte deste trabalho

Tabela 7 - Questões do Exame Nacional do Ensino Médio (ENEM) que tomaram parte deste trabalho 48

Tabela 8 - Exemplos dos tipos de ilustração encontrados nas provas. 50

Tabela 9 - Exemplos de questões para as categorias de funcionalidade das ilustrações 54

Tabela 10 - Descrição e exemplos da categoria iconicidade das ilustrações 57

Tabela 11 - Descrição e exemplos da categoria etiquetas verbais presente nas ilustrações

Tabela 12 - Exemplos da categoria relação texto-imagem 62

Tabela 13 - Assuntos químicos que foram agrupados 65

Tabela 14 - Ocorrência dos tipos de ilustração encontrados nas questões da primeira e segunda fase dos exames vestibulares das cinco universidades paulistas e ENEM nos anos de 2007 a 2011.

Tabela 15 - Ocorrência dos tipos de ilustração encontrados em questões de conhecimentos gerais (primeira fase) dos exames vestibulares de cada universidade e ENEM nos anos de 2007 a 2011. 71

Tabela 16 - Ocorrência dos tipos de ilustração encontrados em questões de 
conhecimentos específicos (segunda fase) dos exames vestibulares de cada universidade nos anos de 2007 a 2011.

Tabela 17 - Resultado dos tipos de ilustração encontrado na primeira fase (CG) e segunda fase (ES) dos exames vestibulares da FUVEST/USP de 2007 a 2011

Tabela 18 - Resultado dos tipos de ilustração encontrado na primeira fase (CG) e segunda fase (ES) dos exames vestibulares da COMVEST/UNICAMP de 2007 a 2011.

Tabela 19 - Resultado dos tipos de ilustração encontrado na primeira fase (CG) e segunda fase (ES) dos exames vestibulares da VUNESP/UFSCAR de 2007 a 2011 ... 77 Tabela 20 - Resultado dos tipos de ilustração encontrado na primeira fase (CG) e segunda fase (ES) dos exames vestibulares da VUNESP/UNESP de 2007 a 2011...... 78 Tabela 21 - Resultado dos tipos de ilustração encontrado na primeira fase (CG) e segunda fase (ES) dos exames vestibulares da VUNESP/UNIFESP de 2007 a 2011... 80 Tabela 22 - Resultado dos tipos de ilustração encontrado para o ENEM nos anos 2010 e 2011.

Tabela 23 - Ocorrência para a funcionalidade das ilustrações encontrada nas questões da primeira e segunda fase dos exames vestibulares das cinco universidades paulistas e ENEM nos anos de 2007 a 2011 84

Tabela 24 - Ocorrência para a categoria funcionalidade das ilustrações encontrados em questões de conhecimentos gerais (primeira fase) dos exames vestibulares de cada universidade e ENEM nos anos de 2007 a 2011. 85

Tabela 25 - Ocorrência para a categoria funcionalidade das ilustrações encontrados em questões de conhecimentos específicos (segunda fase) dos exames vestibulares de cada universidade nos anos de 2007 a 2011.

Tabela 26 - Resultado para a categoria funcionalidade das ilustrações encontrado na primeira fase (CG) e segunda fase (ES) dos exames vestibulares da FUVEST/USP de 2007 a 2011 86

Tabela 27 - Resultado para a categoria funcionalidade das ilustrações encontrado na primeira fase (CG) e segunda fase (ES) dos exames vestibulares da COMVEST/UNICAMP de 2007 a 2011. 
Tabela 28 - Resultado para a categoria funcionalidade das ilustrações encontrado na primeira fase (CG) e segunda fase (ES) dos exames vestibulares da VUNESP/UFSCAR de 2007 a 2011 88

Tabela 29 - Resultado para a categoria funcionalidade das ilustrações encontrado na primeira fase (CG) e segunda fase (ES) dos exames vestibulares da VUNESP/UNESP de 2007 a 2011

Tabela 30 - Resultado para a categoria funcionalidade das ilustrações encontrado na primeira fase (CG) e segunda fase (ES) dos exames vestibulares da VUNESP/UNIFESP de 2007 a 2011 90

Tabela 31 - Resultado para a categoria funcionalidade das ilustrações encontrado no exame do ENEM nos anos 2010 e 2011.

Tabela 32 - Ocorrência para o grau de iconicidade encontrados nas questões da primeira e segunda fase dos exames vestibulares das cinco universidades paulistas e ENEM nos anos de 2007 a 2011.

Tabela 33 - Ocorrência para a categoria grau de iconicidade das ilustrações encontrados em questões de conhecimentos gerais (primeira fase) dos exames vestibulares de cada universidade e ENEM nos anos de 2007 a 2011.

Tabela 34 - Ocorrência para a categoria grau de iconicidade das ilustrações encontrados em questões de conhecimentos específico (segunda fase) dos exames vestibulares de cada universidade nos anos de 2007 a 2011.

Tabela 35 - Resultado para a categoria grau de iconicidade das ilustrações encontrado na primeira fase (CG) e segunda fase (ES) dos exames vestibulares da FUVEST/USP de 2007 a 2011 95

Tabela 36 - Resultado para a categoria grau de iconicidade das ilustrações encontrado na primeira fase (CG) e segunda fase (ES) dos exames vestibulares da COMVES/UNICAMP de 2007 a 2011 96

Tabela 37 - Resultado para a categoria grau de iconicidade das ilustrações encontrado na primeira fase (CG) e segunda fase (ES) dos exames vestibulares da VUNESP/UFSCAR de 2007 a 2011

Tabela 38 - Resultado para a categoria grau de iconicidade das ilustrações encontrado na primeira fase (CG) e segunda fase (ES) dos exames vestibulares da 
Tabela 39 - Resultado para a categoria grau de iconicidade das ilustrações encontrado na primeira fase (CG) e segunda fase (ES) dos exames vestibulares da VUNESP/UNIFESP de 2007 a 2011. 99

Tabela 40 - Resultado para a categoria grau de iconicidade das ilustrações encontrado para as provas do ENEM nos anos de 2010 e 2011.

Tabela 41 - Ocorrência para as etiquetas verbais encontradas nas questões da primeira e segunda fase dos exames vestibulares das cinco universidades paulistas e ENEM nos anos de 2007 a 2011. 102

Tabela 42 - Ocorrência para as etiquetas verbais das ilustrações encontradas em questões de conhecimentos gerais (primeira fase) dos exames vestibulares de cada universidade e ENEM nos anos de 2007 a 2011.

Tabela 43 - Ocorrência para as etiquetas verbais das ilustrações encontradas em questões de conhecimentos específicos (segunda fase) dos exames vestibulares de cada universidade nos anos de 2007 a 2011.

Tabela 44 - Resultado para as etiquetas verbais encontradas na primeira fase (CG) e segunda fase (ES) dos exames vestibulares da FUVEST/USP de 2007 a 2011 104 Tabela 45 - Resultado para as etiquetas verbais encontradas na primeira fase (CG) e segunda fase (ES) dos exames vestibulares da COMVEST/UNICAMP de 2007 a 2011.

Tabela 46 - Resultado para as etiquetas verbais encontradas na primeira fase (CG) e segunda fase (ES) dos exames vestibulares da VUNESP/UFSCAR de 2007 a 2011. 106 Tabela 47 - Resultado para as etiquetas verbais encontradas na primeira fase (CG) e segunda fase (ES) dos exames vestibulares da VUNESP/UNESP de 2007 a 2011 .... 107 Tabela 48 - Resultado para as etiquetas verbais encontradas na primeira fase (CG) e segunda fase (ES) dos exames vestibulares da VUNESP/UNIFESP de 2007 a 2011.. 108 Tabela 49 - Resultado para as etiquetas verbais encontradas no exame do ENEM nos anos 2010 e 2011. 109

Tabela 50 - Ocorrência para a relação texto-imagem encontrada nas questões da primeira e segunda fase dos exames vestibulares das cinco universidades paulistas e 
ENEM nos anos de 2007 a 2011.

Tabela 51 - Ocorrência para a relação texto-imagem encontrada em questões de conhecimentos gerais (primeira fase) dos exames vestibulares de cada universidade e ENEM nos anos de 2007 a 2011

Tabela 52 - Ocorrência para a relação texto-imagem encontrada em questões de conhecimentos específicos (segunda fase) dos exames vestibulares de cada universidade nos anos de 2007 a 2011

Tabela 53 - Resultado para a relação texto-imagem das ilustrações encontrado na primeira fase (CG) e segunda fase (ES) dos exames vestibulares da FUVEST/USP de 2007 a 2011

Tabela 54 - Resultado para a categoria relação texto-imagem das ilustrações encontrado na primeira fase (CG) e segunda fase (ES) dos exames vestibulares da COMVEST/UNICAMP de 2007 a 2011. 113

Tabela 55 - Resultado para a categoria relação texto-imagem das ilustrações encontrado na primeira fase (CG) e segunda fase (ES) dos exames vestibulares da VUNESP/UFSCAR de 2007 a 2011

Tabela 56 - Resultado para a relação texto-imagem das ilustrações encontrado na primeira fase (CG) e segunda fase (ES) dos exames vestibulares da VUNESP/UNESP de 2007 a 2011

Tabela 57 - Resultado para a relação texto-imagem das ilustrações encontrado na primeira fase (CG) e segunda fase (ES) dos exames vestibulares da VUNESP/UNIFESP de 2007 a 2011

Tabela 58 - Resultado para a relação texto-imagem das ilustrações encontrado no exame do ENEM nos anos 2010 e 2011.

Tabela 59 - Ocorrência para os assuntos químicos das questões da primeira e segunda fase dos exames vestibulares das cinco universidades paulistas e ENEM nos anos de 2007 a 2011 119

Tabela 60 - Ocorrência para os assuntos químicos encontrados nas questões de conhecimentos gerais (primeira fase) dos exames vestibulares de cada universidade e ENEM nos anos de 2007 a 2011 
Tabela 61 - Ocorrência para os assuntos químicos encontrados nas questões de conhecimentos específicos (segunda fase) dos exames vestibulares de cada universidade nos anos de 2007 a 2011.

Tabela 62 - Resultado para os assuntos químicos encontrados na primeira fase (CG) e segunda fase (ES) dos exames vestibulares da FUVEST/USP de 2007 a 2011.

Tabela 63 - Resultado para os assuntos químicos encontrados na primeira fase (CG) e segunda fase (ES) dos exames vestibulares da COMVEST/UNICAMP de 2007 a 2011.

Tabela 64 - Resultado para os assuntos químicos encontrados na primeira fase (CG) e segunda fase (ES) dos exames vestibulares da VUNESP/UFSCAR de 2007 a 2011. . 123 Tabela 65 - Resultado para os assuntos químicos encontrados na primeira fase (CG) e segunda fase (ES) dos exames vestibulares da VUNESP/UNESP de 2007 a 2011 .... 124 Tabela 66 - Resultado para os assuntos químicos encontrados na primeira fase (CG) e segunda fase (ES) dos exames vestibulares da VUNESP/UNIFESP de 2007 a 2011.. 125 Tabela 67 - Resultado para os assuntos químicos encontrado no exame do ENEM nos anos 2010 e 2011.

Tabela 68 - Ocorrência para as questões que demandam HOCS e LOCS da primeira e segunda fase dos exames vestibulares das cinco universidades paulistas e ENEM nos anos de 2007 a 2011.

Tabela 69 - Ocorrência para as questões que demandam HOCS e LOCS encontradas em questões de conhecimentos gerais (primeira fase) dos exames vestibulares de cada universidade e ENEM nos anos de 2007 a 2011.

Tabela 70 - Ocorrência para as questões que demandam HOCS e LOCS encontradas em questões de conhecimentos específicos (segunda fase) dos exames vestibulares de cada universidade nos anos de 2007 a 2011. 128

Tabela 71 - Ocorrência para as questões que demandam HOCS e LOCS encontrada na primeira fase (CG) e segunda fase (ES) dos exames vestibulares da FUVEST/USP de 2007 a 2011 129

Tabela 72 - Ocorrência para as questões que demandam HOCS e LOCS encontrada na primeira fase (CG) e segunda fase (ES) dos exames vestibulares da 
COMVEST/UNICAMP de 2007 a 2011.

Tabela 73 - Ocorrência para as questões que demandam HOCS e LOCS encontrada na primeira fase (CG) e segunda fase (ES) dos exames vestibulares da VUNESP/UFSCAR de 2007 a 2011

Tabela 74 - Ocorrência para as questões que demandam HOCS e LOCS encontrada na primeira fase (CG) e segunda fase (ES) dos exames vestibulares da VUNESP/UNESP de 2007 a 2011

Tabela 75 - Ocorrência para as questões que demandam HOCS e LOCS encontrada na primeira fase (CG) e segunda fase (ES) dos exames vestibulares da VUNESP/UNIFESP de 2007 a 2011 134

Tabela 76 - Ocorrência para as questões que demandam HOCS e LOCS encontrada no exame do ENEM nos anos 2010 e 2011

Tabela 77 - Prova típica Eixo 1 - a representação visual em si: Categorias mais frequentes para as provas de conhecimentos gerais (CG) e conhecimentos específicos (ES).

Tabela 78 - Prova típica Eixo 3 - a questão de química no vestibular como um todo: Categorias mais frequentes para as provas de conhecimentos gerais (CG) e conhecimentos específicos (ES). 


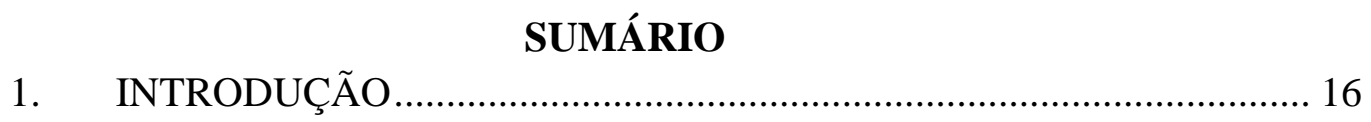

1.1 Exame vestibular no Brasil .......................................................... 16

1.2 Exame de seleção e alternativas......................................................... 18

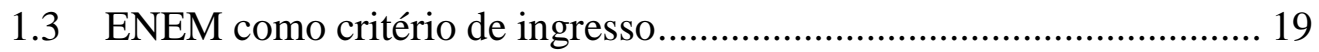

1.4 O vestibular nas Universidades Públicas em São Paulo ...................... 21

1.5 O vestibular como norteador do ensino médio .................................... 22

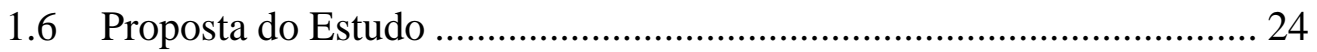

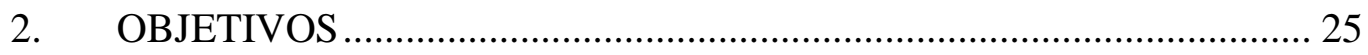

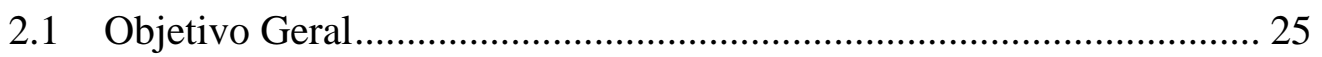

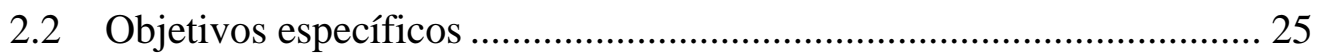

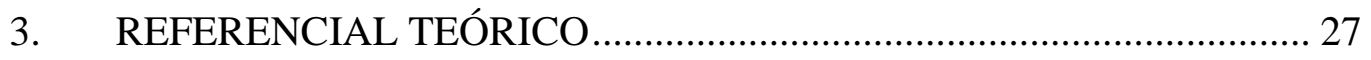

3.1 Eixo 1 - A ilustração em si............................................................ 29

3.2 Eixo 2 - A Relação entre a representação visual e seu entorno na questão. 35

3.3 Eixo 3 - A questão de química como um todo................................... 37

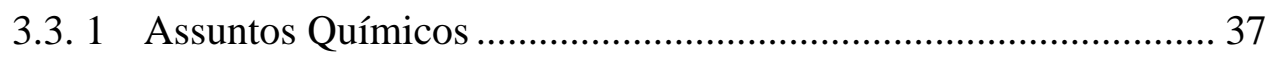

3.3. 2 Habilidades Cognitivas de Alta e Baixa Ordem segundo Zoller.. 38

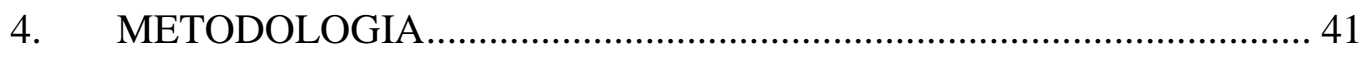

4.1 Universo da pesquisa ............................................................... 41

4.1.1 Fundação Universitária para o Vestibular (FUVEST).................. 42

4.1.2 Comissão permanente para os vestibulares (COMVEST) ............. 43 
4.1.3 Fundação para o Vestibular da Universidade Estadual Paulista (VUNESP).

4.1.4 Exame Nacional do Ensino Médio (ENEM)

4.2 Critérios de Análise e suas Categorias 48

4.3 Descrição das Categorias 49

4.3.1 Eixo 1 - A ilustração em si 49

4.3.3.1 Assuntos químicos envolvidos nas questões 64

4.3.3.2 Habilidades cognitivas requisitadas nas questões segundo Zoller .66

5. RESULTADOS E DISCUSSÃO 69

5.1 Eixo 1 - A representação visual em si 69

5.2 Eixo 2 - A Relação entre a representação visual e seu entorno na questão 110

5.3 Eixo 3 - A questão de química no vestibular como um todo 119

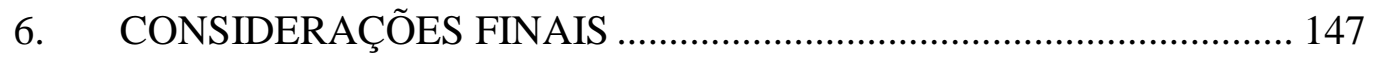

7. REFERÊNCIAS BIBLIOGRÁFICAS .............................................. 152 


\section{INTRODUÇÃO}

\subsection{Exame vestibular no Brasil}

O ensino superior no Brasil teve origem a partir de 1808, na forma de cursos superiores isolados criados pela iniciativa de D. João VI, sendo no Rio de Janeiro: o Curso de Engenharia da Academia Real da Marinha (1808) e da Academia Militar (1810), o Curso de Cirurgia e Anatomia (1808) e Medicina (1809), e na Bahia: o Curso de Cirurgia (1808), Economia (1808), Agricultura (1810), Química (industrial, geologia e mineralogia (1817)) e o Curso de Desenho Técnico Industrial (1818) (SAVIANI, 2010; MARTINS, 2002).

As universidades brasileiras só começaram a se caracterizar a partir do Decreto 19.851, de 11 de abril de 1931, que estabeleceu o Estatuto das Universidades Brasileiras, dispondo que o ensino superior no Brasil obedeceria a um sistema universitário regido por uma série de regulamentos (SAVIANI, 2010). Deste modo, com o passar do tempo, o sistema brasileiro de seleção à universidade marcou vários acontecimentos que envolveram o sistema educacional, além das questões políticas, econômicas e sociais (AMAURO, 2010).

O vestibular no Brasil teve início no governo de Hermes da Fonseca, com uma série de promulgações de decretos. Dentre estes, se destacam o de $\mathrm{n}^{\circ} 8.661$ que aprovou os regulamentos para as faculdades de medicina, e o de $\mathrm{n}^{\circ} 8.662$ que aprovou os das faculdades de direito. Em 5 de abril de 1911, no Decreto $n^{\circ} 8.659$ encontrava-se o exame de admissão ao ensino superior (Lei Orgânica do Ensino Superior e do Fundamental da República) . O artigo 65 deste Decreto, segundo Netto (1986, p. 41) estabelece:

\footnotetext{
Para concessão da matrícula, o candidato passará por um exame que habilite a um juízo de conjunto sobre o seu desenvolvimento intelectual e capacidade para empreender eficazmente o estudo das matérias que constituem o ensino da faculdade. [...] este exame constará de prova escrita em vernáculo, que revele a cultura mental que se quer verificar e de uma prova oral sobre línguas e ciências.
}

O nome vestibular é derivado da palavra "vestíbulo", que significa "entrada a um edifício", e pode ser entendido como a porta de entrada para as universidades (ALVES, 2007). Com um entendimento original, pode-se predizer que os exames de admissão às instituições de ensino superior faziam uma descrição do desenvolvimento racional e 
intelectual dos candidatos, não sendo compatível com o objetivo básico de ensino secundário, que seria conferir aos alunos uma formação humanista, desenvolvendo habilidades nas áreas de ciências, letras e artes, potencializando a formação de um cidadão crítico, responsável e consciente de seus atos (NETTO, 1986).

As mudanças significativas ao longo da história, como no conteúdo e na execução do vestibular, ocorreram após o ano de 1968, a partir da Reforma Universitária. Houve a modernização de uma parte significativa das universidades federais e estaduais, proporcionando a articulação das atividades de ensino e extensão, a abolição das cátedras vitalícias, introdução do regime departamental e a institucionalização da carreira acadêmica (MARTINS, 2009).

Em 1971, a partir do Decreto $\mathrm{n}^{\mathrm{o}} 68.908$, no Artigo $8^{\circ}$, foi concretizado que a proposta de unificação do vestibular (em relação aos conteúdos que abrangessem os conhecimentos comuns às variadas formas de educação) seria definida por organizações especializadas, públicas ou privadas. Neste mesmo Decreto, instituiu-se o "vestibular classificatório", em que os candidatos seriam admitidos até o número máximo limite de vagas fixadas no edital (LELIS, 1985), aumentando o caráter discriminatório e seletivo da prova. Assim, o vestibular cumpre um novo papel: o instrumento que abre as portas da universidade.

A adoção do vestibular classificatório aumentou o nível de dificuldade das provas assim como seu caráter seletivo. As questões objetivas (múltipla escolha) foram implantadas nos concursos vestibulares a partir de 1965, com a possibilidade de identificar comportamentos simples e complexos quando bem elaboradas. Porém, a transposição imediata das questões de exames vestibulares para os livros didáticos utilizados em sala de aula estimulam metodologias de ensino que privilegiam a memorização dos assuntos (AMAURO, 2010).

No final do século XX e no início do século XXI aconteceram diversas reformas no ensino, como a alteração da forma de vestibular, porém, sem alterar a essência do processo seletivo, que, segundo Amauro (2010, p. 20) seria: “a adoção de critérios de desempenho acadêmico, pautado nos conteúdos de ensino, bem como o caráter classificatório das provas", propiciando para cada universidade a preferência de elaboração de suas provas. 


\subsection{Exame de seleção e alternativas}

A seleção do vestibular ocorre da delimitação prévia das vagas oferecidas pelas instituições e da definição de um perfil de conhecimentos adquiridos ou potencializados ao longo da educação básica (NETO, 1995).

$\mathrm{O}$ crescimento do ensino superior brasileiro é insuficiente quando confrontado às expectativas da população. Mesmo com o aumento do investimento público e privado no ensino superior, ainda existe uma redução do crescimento da matrícula, fazendo-se persistir desafios e problemas. Dentre estes, pode-se citar a expansão do crescimento da matrícula juntamente com a democratização do acesso, a diferenciação da oferta em relação das demandas sociais e econômicas (cotas) e a excelência e qualidade da formação que é oferecida (TANEGUTI, 2013).

Em 2011 o Brasil possuía 2.181.501 vagas em cursos de graduação e um total de 5.442.581 candidatos inscritos, independentemente da instituição ser pública ou privada (TANEGUTI, 2013). Isto mostra que o número de vagas é insuficiente para a grande demanda existente no país.

A oferta e a demanda por vagas no ensino superior do Brasil variam nas regiões do país. Resultados do relatório técnico elaborado pelo Ministério da Educação (MEC) para o ano de 2011 (ALVAREZ, 2013) mostram que a região sudeste (Espírito Santo, Minas Gerais, Rio de Janeiro e São Paulo) acolhem 1.157 instituições de ensino superior representando $49 \%$ da totalidade do país. Esta região é a que mais disponibiliza o número de vagas em instituições de ensino superior, com 1.435.401 vagas, porém possuindo o maior número de candidatos, com 2.488.807. Assim, a região sudeste é a que possui maior número de vagas, mas também maior número de candidatos (TANEGUTI, 2013).

A Lei de Diretrizes e Bases da Educação Nacional (LDB no 9394/96) não obriga a adoção dos vestibulares como único instrumento de seleção de candidatos para o ensino superior. Estabelece que haja algum processo de seleção e a exigência de conclusão do ensino médio. Deste modo, as instituições de ensino superior podem optar por seleções de admissão alternativas (AMAURO, 2010).

Muitas iniciativas têm sido oferecidas com o propósito de expansão do ensino 
superior, como o Programa de Apoio ao Plano de Reestruturação e Expansão das Universidades Federais (REUNI) ${ }^{1}$ que busca ampliar o acesso e a permanência na educação superior. $\mathrm{O}$ Programa Universidade para Todos (PROUNI) ${ }^{2}$ é um programa do Ministério da Educação, que oferece bolsas de estudos parciais ou integrais para estudantes em instituições privadas de ensino superior. Existe também o Fundo de Financiamento Estudantil (FIES) ${ }^{3}$, criado em 1999, que é um programa destinado a financiar a graduação na educação superior de estudantes que não possuem condições de arcar integralmente com os custos de sua formação em instituições de ensino superior não gratuitas, mas com avaliação positiva pelo MEC.

A ideia da adoção de formas alternativas para o ingresso no ensino superior tem sido defendida por diversos educadores, entre eles Barros (1985) sugere a substituição do vestibular por uma prova contínua realizada ao longo de um ano escolar integral, em que o candidato seria testado pela sua motivação e evocação acadêmica, através de atividades em cursos profissionais elaborados e supervisionados pela universidade. Desta forma, os estudantes teriam acesso ao ensino profissionalizante, e somente depois, se escolhido, já com maturidade suficiente, aprofundaria seus estudos de natureza abrangente. Esta alternativa teria a vantagem (teoricamente) de não deixar milhares de estudantes de fora da universidade, assim como ocorre pelo exame vestibular, porém ainda não resolve a enorme procura por vagas.

Para Amauro (2010), uma alternativa seria a criação de cursos pré-universitários para a seleção de candidatos ao ensino superior. Porém, a adoção desta opção pode levar em conta fatos como a substituição do ensino médio por estes cursos, sendo que para isso seria necessário que o Estado ofertasse números suficientes de vagas para todo o território nacional, não aumentando o número de vagas nas universidades públicas.

\subsection{ENEM como critério de ingresso}

Em 1998 o MEC instituiu o Exame Nacional do Ensino Médio (ENEM) realizado

\footnotetext{
${ }^{1}$ Programa de Apoio ao Plano de Reestruturação e Expansão das Universidades Federais (REUNI). Ministério da Educação. Disponível em: < http://reuni.mec.gov.br/> Acesso em: jun. 2014.

${ }^{2}$ ProUni. Ministério da Educação. Disponível em : <http://siteprouni.mec.gov.br/o_prouni.php〉 Acesso em: jun. 2014.

${ }^{3}$ Programa de Financiamento Estudantil (FIES). Ministério da Educação. Disponível em:

<http://sisfiesportal.mec.gov.br/fies.html〉 Acesso em: jun. 2014.
} 
pelo Instituto Nacional de Estudos e Pesquisas Educacionais (INEP) ${ }^{4}$, como instrumento de verificação de aprendizado para os alunos concluintes do ensino médio, contribuindo para a melhoria da qualidade da educação.

Conforme consta nos Parâmetros Curriculares Nacionais para o Ensino Médio (PCNEM+) (BRASIL, 2002, p. 15):

O Exame Nacional do Ensino Médio (ENEM) aponta cinco competências gerais: dominar diferentes linguagens, desde idiomas até representações matemáticas e artísticas; compreender processos, sejam eles sociais, naturais, culturais ou tecnológicos; diagnosticar e enfrentar problemas reais; construir argumentações; e elaborar proposições solidárias.

O ENEM foi apresentado pelo governo como uma proposta inovadora. A premissa é que, por envolver em suas provas a transdisciplinaridade e a contextualização dos assuntos abordados, seria uma tentativa de não privilegiar exclusivamente processos cognitivos relacionados a lembrança e o reconhecimento de datas, fatos, leis, fórmulas, equações e regras definidas (AMAURO, 2010).

A partir de 2009, o ENEM passou a ser utilizado também como mecanismo de seleção para o ingresso no ensino superior. Mudanças foram implantadas no exame a fim de contribuir para a democratização de oportunidades de acesso às vagas em Instituições Federais de Ensino Superior (IFES), e induzir a reestruturação dos currículos do ensino médio.

Strucchi (2006) salienta que o Exame Nacional do Ensino Médio (ENEM) é de fato uma opção de substituição do exame vestibular. Assim, nos dias atuais muitas universidades estão utilizando a nota do ENEM como fase única de seleção, que é realizada através do Sistema de Seleção Unificada (SISU) ${ }^{5}$. Para que isto ocorra, o candidato deve fazer a prova do ENEM e posteriormente inscrever-se no SISU, escolhendo as faculdades e os cursos de sua preferência, sendo a nota de corte definida pelas próprias instituições de ensino superior e institutos tecnológicos.

\footnotetext{
${ }^{4}$ Instituto Nacional de Estudos e Pesquisas Educacionais Anísio Teixeira (INEP). Disponível em: <http://portal.inep.gov.br/web/enem/sobre-o-enem>. Acesso em: jun. 2014.

5 Sistema de seleção Unificada (SISU). Ministério da Educação. Disponível em: 〈http://sisu.mec.gov.br〉. Acesso em: jun. 2014.
} 
A utilização dos resultados do ENEM também pode ser combinada com o vestibular da instituição, sendo a primeira fase constituída pela nota do ENEM, e a segunda fase uma prova específica da instituição. Outra forma seria como fase única para as vagas remanescentes do vestibular, as quais não fossem ocupadas no ano anterior seriam preenchidas por candidatos que alcançassem uma porcentagem de acertos no ENEM, sendo isto definido por cada universidade. O exame também é utilizado em programas oferecidos pelo Governo Federal, tais como o PROUNI, em que a seleção dos candidatos é realizada com base nas notas do exame.

\subsection{O vestibular nas Universidades Públicas em São Paulo}

Os exames vestibulares de universidades como Universidade de São Paulo (USP), Universidade Estadual de Campinas (UNICAMP), Universidade Estadual Paulista (UNESP), Universidade Federal de São Carlos (UFSCAR) e Universidade Federal de São Paulo (UNIFESP) utilizam diferentes formas de seleção, contando com equipes de docentes que preparam e aplicam o exame e corrigem as provas dissertativas.

\section{FUVEST}

A Fundação Universitária para o Vestibular (FUVEST) ${ }^{6}$ foi criada em 20 de abril de 1976, sendo uma fundação de direito privado e sem fins lucrativos. Sua finalidade é organizar e realizar os exames vestibulares de instituições de ensino superior como a Universidade de São Paulo (USP) e Faculdade de Ciências Médicas da Santa Casa de São Paulo (FCMSC-SP).

\section{VUNESP}

A Fundação para o Vestibular da Universidade Estadual Paulista (VUNESP) ${ }^{7}$ é uma fundação com personalidade jurídica de direito privado, sem fins lucrativos, criada em 26 de

\footnotetext{
${ }^{6}$ Fundação Universitária para o Vestibular. Disponível em: 〈http://www.fuvest.br/〉. Aceso em: jun. 2014.

${ }^{7}$ Fundação Vunesp. Disponível em: 〈http://www.vunesp.com.br/internas/quem.html $>$. Acesso em: jun.2014.
} 
outubro de 1979 pelo Conselho Universitário da UNESP.

As principais atividades da VUNESP são: organizar, planejar, executar e supervisionar o concurso vestibular da UNESP, realizar vestibulares e concursos diversos para outras instituições públicas como UFSCAR e UNIFESP, promover atividades de pesquisa e extensão de serviços à comunidade, e desenvolver outras atividades compatíveis com suas finalidades.

\section{COMVEST}

O vestibular da Universidade de Campinas (UNICAMP) foi realizado pela Fundação Universitária para o Vestibular (FUVEST) até o ano de 1986. No ano seguinte (1987), a UNICAMP criou seu próprio processo de seleção: a Comissão Permanente para os Vestibulares (COMVEST) ${ }^{8}$, com questões diferenciadas e de caráter dissertativo. Atualmente a comissão realiza concursos públicos e exames para outras instituições, como por exemplo, o vestibular da Faculdade de Medicina de São José do Rio Preto (FAMERP) 9 .

\section{$1.5 \mathrm{O}$ vestibular como norteador do ensino médio}

$\mathrm{O}$ vestibular se presta à finalidade específica de seleção para o ensino superior. $\mathrm{O}$ uso da sua adoção como parâmetro norteador do ensino é considerada inapropriada segundo Amauro (2010), por interferir no objetivo principal do ensino médio, de modo a privilegiar a preparação para o exame em detrimento dos objetivos formativos estabelecidos para o ensino médio na LDB.

Existe uma concepção de que o vestibular se torna amplamente em um instrumento normativo e orientador do sistema educacional. Os que são adeptos desta concepção observam uma grande influência do vestibular sobre o ensino fundamental e médio e até mesmo sobre o ensino superior (NETTO, 1978; SILVA et al., 2010).

\footnotetext{
${ }^{8}$ Comissão Permanente para o Vestibular. Disponível em: http://www.comvest.unicamp.br/>. Acesso em: jun. 2014.

${ }^{9}$ Comissão Permanente para o Vestibular. Disponível em:

$\langle$ http://www.comvest.unicamp.br/cursos/medicina famerp.html〉. Acesso em: jun. 2014.
} 
Deste modo, destaca-se a grande influência que o vestibular exerce nas propostas de ensino das escolas de ensino fundamental e principalmente ensino médio. Muitos pais desejam que seus filhos sejam aprovados em uma instituição de ensino superior, e depositam na escola esta expectativa, a ponto de avaliar seu desempenho como meio preparatório para o vestibular. Assim, a escola altera seus planejamentos para se adequar aos assuntos abordados nas provas, tornando o vestibular um parâmetro para o currículo e a metodologia de ensino. Em consequência disto, muitos professores modificam suas aulas buscando subsídios que fortaleçam o ensino voltado para resoluções de questões de provas vestibulares.

O problema em questão não é o vestibular em si, mas torná-lo como principal eixo norteador do ensino médio, a tal ponto que esta etapa fundamental da formação para a vida cidadã subverta-se ao propósito estreito de preparação para um exame. Este risco em que incorrem milhares de instituições de ensino no país vai de encontro à função de educação básica tal qual concebida em documentos como os Parâmetros Curriculares Nacionais para o Ensino Médio (PCNEM+): formar um aluno crítico que saiba usar o conhecimento científico no exercício da cidadania, para além da memorização (BRASIL, 2002).

Passada mais de uma década da publicação dos Parâmetros Curriculares Nacionais (PCN), no senso comum sobre o bom ensino, prevalece ainda nos dias de hoje a ideia de que a melhor escola é aquela que aprova mais estudantes nos vestibulares mais concorridos (SCHWARTZMAN, 2010; ALVES, 2007).

Não se leva em conta a finalidade destas provas e nem a sua utilização como possível sinalizador/indicador de melhorias do processo de ensino-aprendizagem e avaliação do ensino básico (AMAURO, 2010; NETO, 1995). Sobretudo, não se questiona que sua adoção como instrumento de avaliação de aprendizado no contexto do ensino médio é limitada. Mesmo quando aplicadas em modo dissertativo, o caráter eminentemente somativo de tais "provas" dificultam, quando não impedem, o diagnóstico e acompanhamento da aprendizagem, tornando hermética ao professor qualquer informação sobre os processos mentais dos alunos em sua apropriação do conhecimento.

O método consolidado de preparação para o vestibular é notoriamente fundamentado em apostilas as quais determinam com grande rigidez o passo com que o conteúdo deve ser disposto aos estudantes. Trata-se de um mecanismo em que o papel do 
professor fica reduzido, podendo, inclusive, este ser substituído a qualquer ponto do ano letivo com um mínimo de prejuízo para o progresso da transmissão de conteúdos.

\subsection{Proposta do Estudo}

As motivações do presente estudo são: a influência do vestibular sobre o ensino de Química; a grande importância do uso das visualizações no processo de ensinoaprendizagem dos conteúdos químicos; e o fato de que os exames vestibulares das maiores instituições de ensino superior público do país cada vez mais empregam imagens (tabelas, gráficos, diagramas, figuras e esquemas) em seus exames (GIBIN e FERREIRA, 2013). Assim, torna-se relevante caracterizar as representações visuais presentes nas questões de Química dos vestibulares de universidades públicas paulistas.

Fazer um estudo sobre as questões de química nas provas de vestibulares pode trazer informações relevantes para professores, alunos e instituições nos três níveis educacionais, mostrando e informando a sociedade escolar, a comunidade e a família, (AMAURO, 2010), além de haver poucos estudos sobre esta temática em comparação com outras temáticas tratadas na literatura.

Os resultados oriundos deste estudo poderão, em princípio, indicar pontos a serem contemplados pelas equipes que preparam os exames, de modo que se possa explorar o pleno potencial das representações visuais como meios para a mobilização de habilidades cognitivas para além da interpretação direta e da associação de informações memorizadas. Este movimento, além de repercutir no ensino médio, pode ainda repercutir positivamente no ensino superior, uma vez que as questões usadas como mecanismo de seleção poderiam incluir habilidades mobilizadas na interpretação de representações visuais e no trânsito entre as dimensões submicroscópica, macroscópica e simbólica dos conhecimentos químicos. 


\section{OBJETIVOS}

\subsection{Objetivo Geral}

O objetivo geral deste trabalho é caracterizar o uso de representações visuais apresentadas nas questões de química em provas de vestibulares das seguintes Universidades Públicas do Estado de São Paulo: Universidade de São Paulo, Universidade Estadual de Campinas, Universidade Estadual Paulista, Universidade Federal de São Carlos, Universidade Federal de São Paulo nos anos de 2007 a 2011 e também o Exame Nacional do Ensino Médio, nos anos de 2010 e 2011.

\subsection{Objetivos específicos}

A consecução do objetivo geral de trabalho foi articulada através dos seguintes objetivos específicos, por meio de três grandes eixos analíticos:

\section{Eixo 1: A ilustração em si}

- Destacar quais os tipos de ilustrações mais presentes nas provas de química de exames vestibulares;

- Analisar o grau de funcionalidade e iconicidade atribuído à ilustração;

- Identificar a presença de etiquetas verbais nas ilustrações estudadas;

\section{Eixo 2: A Relação entre a representação visual e seu entorno na questão}

- Analisar quais as relações existentes entre o texto da questão e a imagem ali presente; 


\section{Eixo 3: A questão de química como um todo}

- Identificar os assuntos químicos presentes nas questões que contém representações visuais;

- Analisar as questões quanto às habilidades cognitivas requeridas, segundo as pesquisas de Zoller em habilidades de alta ordem cognitiva e baixa ordem cognitiva. 


\section{REFERENCIAL TEÓRICO}

Esta pesquisa se articula por meio de uma análise multifacetada das representações visuais presentes em questões dos exames vestibulares. Esta abordagem visa dispor um panorama amplo de identificação de fatores que norteiam o emprego de representações visuais nas questões de química dos exames analisados. Assim, optou-se por incluir um referencial diverso que leva em conta as funções das representações visuais e suas relações com o texto, e também a análise das habilidades cognitivas requisitadas nas questões segundo referencial que as classifica em alta ordem cognitiva e baixa ordem cognitiva. Partindo-se deste princípio, o trabalho de pesquisa e discussão de seus resultados foi organizado nos seguintes eixos analíticos:

- Eixo 1 - A ilustração em si - Compreende a ilustração analisada quanto à informação química e sua complexidade enquanto continente simbólico desta informação;

- Eixo 2 - A Relação entre a representação visual e seu entorno na questão Abrange a representação visual como paratexto e suas categorias;

- Eixo 3 - A questão de química como um todo - Envolve os assuntos químicos abordados e as habilidades cognitivas mobilizadas na resolução da questão vestibular.

\section{Imagens e Ilustrações}

As representações visuais voltadas para o ensino de ciências proporcionam um meio de visualização para fenômenos macroscópicos ou submicroscópicos. Mas não somente isso, as representações podem ser utilizadas para exibir dados, organizar informações complexas, e promover um entendimento comum dos fenômenos científicos, podendo ser utilizadas para apresentar múltiplas relações e processos que tornam-se difíceis de descrever. Alguns exemplos dessas representações são imagens de gráficos, fluxogramas 
e tabelas, no qual podem ser utilizadas para a organização de ideias e exposição de informações científicas (COOK, 2006).

A definição do termo imagem pode apresentar inúmeros significados, pois depende da área do conhecimento e do contexto a ser empregado (GIBIN e FERREIRA, 2013). Contudo torna-se conveniente para este estudo fazer a distinção entre imagem e ilustração (PERALES, 2006 p.14, tradução nossa):

\footnotetext{
- Imagem: representação de seres, objetos ou fenômenos, seja com características gráficas (em papel ou audiovisual) ou mentais (a partir de um processo de abstração mais ou menos complexo).

- Ilustração: se trata de uma imagem mais específica, de caráter exclusivamente gráfico, e que acompanha o texto escrito com a intenção de complementar a informação fornecida.
}

Assim, esta pesquisa analisou questões de química contendo ilustrações, já que estas se complementam ao texto das questões com sentido de apoio para a sua resolução. Contudo, considera-se que as ilustrações contêm imagens que são representações visuais dos conceitos científicos apresentados. 


\subsection{Eixo 1 - A ilustração em si}

No processo de ensino-aprendizagem em ciências utilizam-se as representações visuais, como imagens gráficas para exibir dados e informações complexas sobre fenômenos científicos, proporcionando a partir disto, a ilustração destes fenômenos invisíveis ou até mesmo visíveis, mas demasiadamente pequeno, grande, rápido ou lento para se observar a olho nu, o que torna a sua compreensão difícil (COOK, 2006). Muitas vezes a própria conceitualização do conhecimento científico necessita da visualização para a sua compreensão, mostrando que as imagens desempenham uma importante função no ensino de ciências, principalmente para conceitos abstratos que envolvem a dimensão representacional submicroscópica (SILVA, et al 2006).

Dentre outros recursos didáticos, os livros didáticos utilizados na química são um importante instrumento de apoio pedagógico, exercendo uma influência marcante no processo de ensino-aprendizagem (CAMPOS e CACHAPUZ, 1997). Muitos destes recursos envolvem o uso de imagens para melhor facilitação do conhecimento químico pelo leitor, podendo também possuir outras finalidades, como, atrair e despertar o interesse do leitor e descrever fenômenos a partir do desenvolvimento da capacidade humana de processamento da informação visual ou espacial (PERALES e JIMÉNES, 2002).

No meio científico as imagens desempenham um papel de representação gráfica de fenômenos, na tentativa de buscar explicações e representações da realidade (GIBIN e FERREIRA, 2013). Porém estudos, como o realizado por Gibin, Kill e Ferreira (2009) mostram que o uso da imagem é pouco explorado em sala de aula durante atividades de ensino, inclusive por não serem autoexplicativas. Desta forma, estudantes podem apresentar diferentes compreensões sobre uma mesma imagem. 


\section{Representações Visuais no Ensino de Química}

Em especial na química, as diferentes formas de representações podem ser convenientemente tratadas em dimensões distintas. Segundo Johnstone (1993), os conceitos químicos podem ser relacionados a três componentes básicos, cada qual correspondente a uma dimensão representacional: a dimensão macroscópica, referente ao visível (a observação de um objeto ou fenômeno), a dimensão submicroscópica, representado pelas moléculas e átomos, e a dimensão simbólica, referente aos cálculos matemáticos, equações e estequiometria (Figura 1).

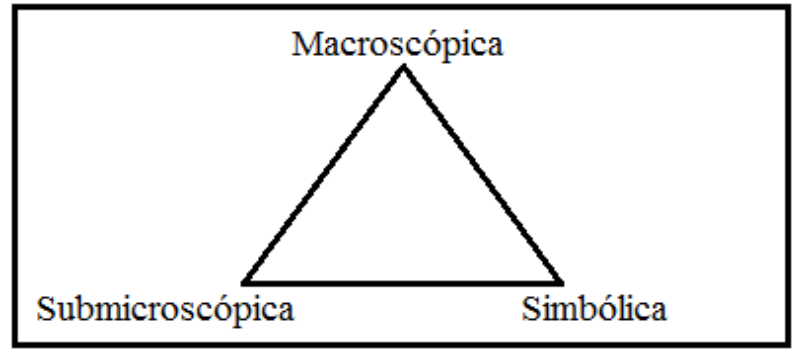

Figura 1 - Dimensões representacionais (Fonte: JOHNSTONE, 1993, p. 703, tradução nossa)

Diversos estudos reportam que, no processo de aprendizagem de conceitos químicos, muitos estudantes não conseguem transladar de uma dimensão representacional para outra, trazendo grandes dificuldades de aprendizagem nesta disciplina. Assim, almeja-se que os alunos compreendam os conceitos a partir destas três dimensões representacionais, mas para que isto ocorra, os professores necessitam buscar meios e representações adequadas para facilitar a visualização dos fenômenos químicos (TREAGUST, CHITTLEBOROUGH e MAMIALA, 2003; CHITTLEBOROUGH e TREAGUST, 2008; CHANDRASEGARAN, TREAGUST e MOCERINO, 2009; ADADAN, IRVING e TRUNDLE, 2009; HAND e CHOI, 2010).

Raupp, Serrano e Moreira (2009) trazem um exemplo da dificuldade que os estudantes apresentam ao transitar entre as diferentes representações: o caso da isomeria geométrica, em que diferentes compostos apresentam a mesma fórmula molecular sendo diferenciado apenas por sua estrutura tridimensional. O estudo deste conceito, dentro do 
meio científico e acadêmico, envolve o uso extensivo de representações, principalmente fórmulas estruturais tridimensionais (3D) ou modelos perceptíveis no espaço tridimensional, os quais permitem uma melhor visualização do que estruturas planares bidimensionais (2D).

Um exemplo é o caso das moléculas cis-2-buteno e o trans-2-buteno. A representação das moléculas em 2D pode dificultar a compreensão dos estudantes, principalmente quando há necessidade de diferenciação dos isômeros. A projeção de Fisher é excelente para representar bidimencionalmente uma molécula orgânica tridimensional por projeção (BRECHER, 2006). Porém, nas figuras em 3D, o estudante pode observar a geometria da molécula através da visualização externa para compreender a disposição dos átomos, diferente da representação de Fisher, em que o estudante terá que realizar operações internas (mentais) para compreender a estrutura da molécula, fazendo a conversão da Projeção de Fisher em tridimensional (RAUPP, SERRANO e MOREIRA, 2009).

O quadro 1 ilustra os diferentes modos de representação das fórmulas estruturais para moléculas cis-2-buteno e trans-2-buteno. 
Quadro 1 - Diferentes fórmulas estruturais para as moléculas cis-2-buteno e trans-2-buteno.

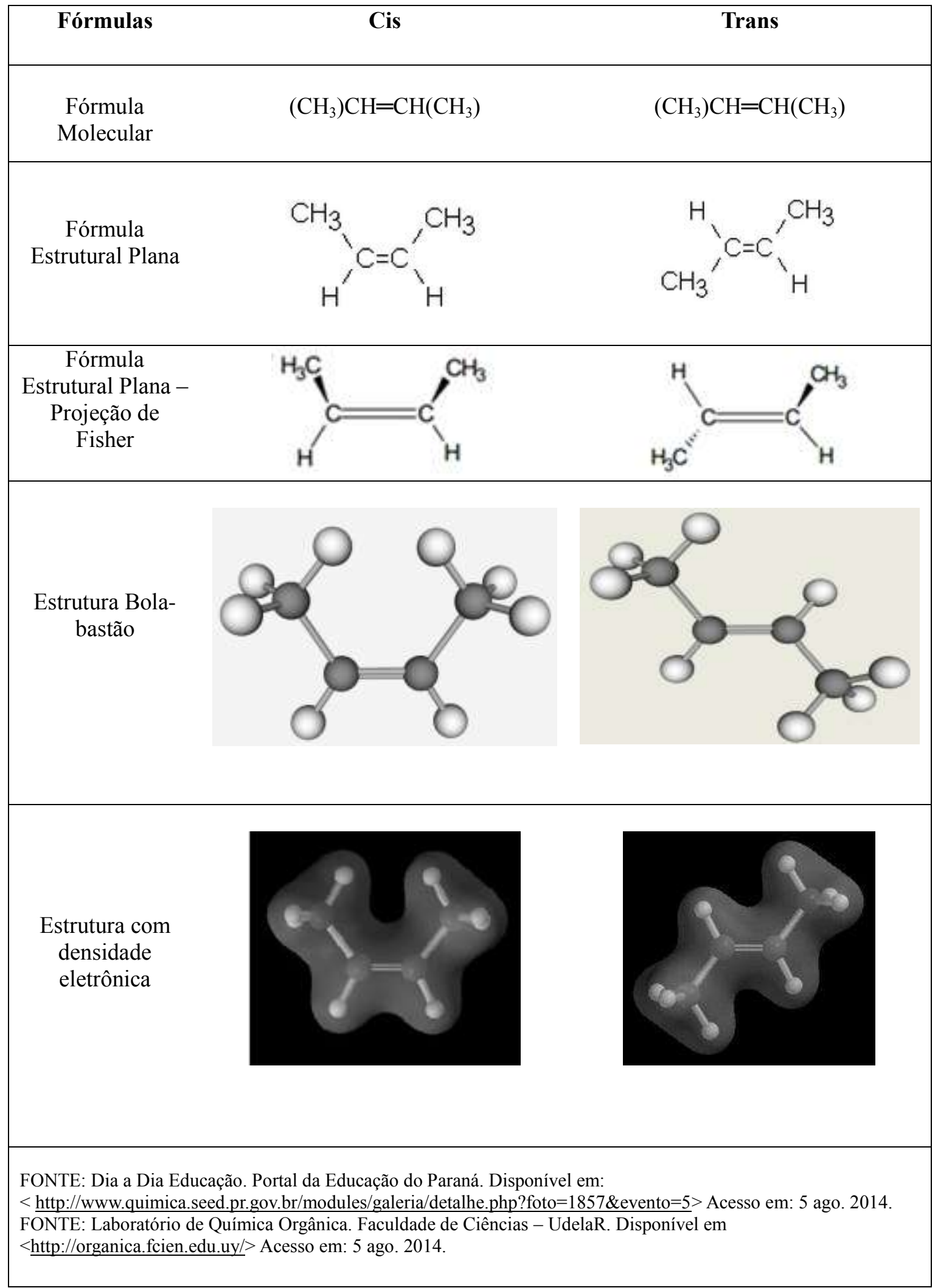


A figura 2 ilustra as moléculas em representação 3D em papel, de modo simples, através da Projeção de Fisher.

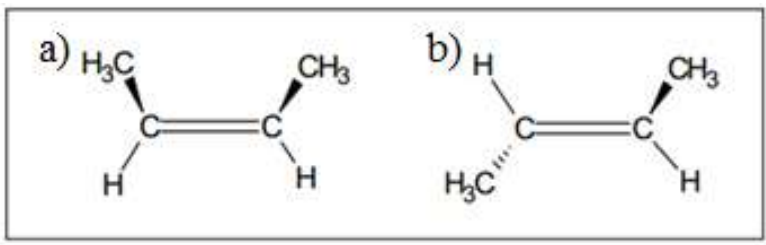

Figura 2 - Representação pela Projeção de Fisher em 3D das moléculas a) cis-2-buteno e b) trans-2-buteno (FONTE: RAUPP, SERRANO E MOREIRA, 2009, p.69)

Porém, nos dias de hoje dispomos de meios tecnológicos computacionais que nos permitem representar moléculas em 3D, como apresentado na figura 3 para as mesmas moléculas.

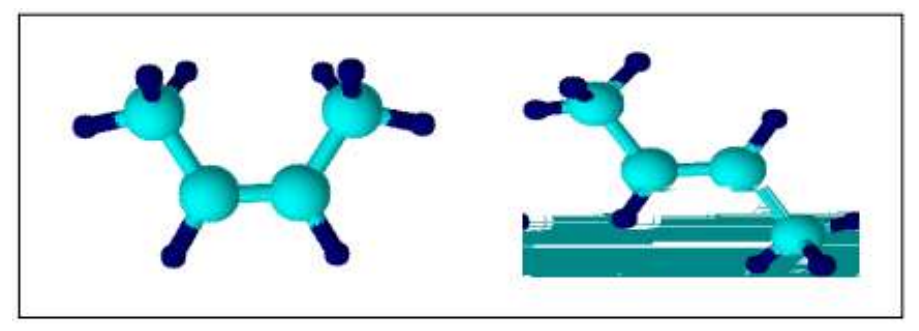

Figura 3 - Representação computacional em 3D das moléculas cis-2-buteno e o trans-2buteno respectivamente (Fonte: RAUPP, SERRANO E MOREIRA, 2009, p.70)

O exemplo reforça a ideia de que o uso de imagens pode auxiliar os estudantes na transição entre as dimensões representacionais, principalmente para a compreensão da estrutura da matéria, que exige uma elevada capacidade de abstração, já que o estudo envolve a parte submicroscópica da matéria (moléculas, átomos e suas partículas constituintes). Portanto, uma das principais funções das representações visuais na química é promover esta transição, auxiliando os estudantes na compreensão dos conceitos abstratos, permitindo o desenvolvimento de habilidades de interpretação de fenômenos científicos em nível molecular (SILVA, BRAIBANTE e PAZINATO, 2013). 


\section{Funções das imagens em livros didáticos}

Olim (2010) explana que as imagens encontradas em materiais didáticos nem sempre se referem ao visível (nível macroscópico), mas podem ser definidas como signos em que se pode encarnar uma ideia ou uma representação mental de algum objeto/desejo, a fim de transmiti-lo em forma de mensagem.

Perales e Jiménez (2002, p. 372, tradução nossa) destacam quais as funções didáticas das imagens, que seriam:

- Ilustrar os livros, ou seja, torná-los mais atrativos para despertar o interesse dos leitores;

- Descrever situações ou fenômenos baseando-se na capacidade humana de processar a informação visual e sua vantagem frente aos textos escritos na estimulação dos modelos mentais;

- Explicar as situações descritas. Isto é, neste caso as ilustrações não mostram apenas o mundo, mas também o que o transforma com a intenção de evidenciar relações ou ideias não evidentes por si mesmas, a fim de facilitar sua compreensão por parte do leitor.

Perales e Jiménez (2002) apresentam uma taxonomia de categorização para estudar as ilustrações presentes nos livros e textos didáticos. Nesta análise, supõe-se considerar os aspectos formais e semânticos das ilustrações. Os aspectos formais referem-se à sua disposição no texto, e os aspectos semânticos no significado que passam ao leitor.

Existem diferenças em vários aspectos e possibilidades das ilustrações serem analisadas, como: a "função da sequência didática" em que aparece, o "grau de iconicidade", a "funcionalidade" e as "etiquetas verbais".

A "função da sequência didática" investiga o modo em que as imagens são utilizadas no decorrer do texto. Para isso os autores estabeleceram seis categorias que podem aparecer as ilustrações: evocação, definição, aplicação, descrição, interpretação e problematização.

Para o "grau de iconicidade", as categorias são: fotografia, desenho figurativo, 
desenho figurativo com signos e, dentro desta, se inclui a ilustração figurativa com signos normalizados, desenhos esquemáticos, desenhos esquemáticos com signos e descrição em signos normalizados. A função desta categoria é determinar o grau de complexidade que a imagem possui.

A "funcionalidade" das ilustrações corresponde ao que pode ser feito com as imagens. As categorias são: inoperantes, operativas elementares e sintáticas.

As "etiquetas verbais" referem-se a textos inclusos dentro das ilustrações. Estas podem não ter etiquetas, serem nominativas ou relacionais.

A aplicação desta taxonomia permite a investigação de uma ampla análise de categorias, facilitando a análise das formas de representações visuais presentes em materiais didáticos.

\subsection{Eixo 2 - A Relação entre a representação visual e seu entorno na questão}

Segundo Vergnaud (1982), a representação simbólica é fundamental para o ensino, não sendo apenas uma linguagem que admite a conceitualização, mas que representa o problema e ajuda os estudantes em sua resolução. Logo, a diversidade simbólica da linguagem química torna-se um fator determinante sobre a forma como estudantes se apropriam deste conhecimento.

Contudo, isoladamente a representação visual em si não é capaz de atribuir significado aos conceitos, o que em última instância se dá no plano simbólico através de palavras associadas às analogias visuais. Desta forma, entender o entorno textual de uma imagem e sua articulação com a mesma é fundamental. Nesta concepção, as representações visuais podem ser tratadas como paratexto, isto é, tudo aquilo que rodeia o texto principal e que pode condicionar a leitura ajudando o leitor na construção ou reconstrução do sentido do texto. Assim, o paratexto pode ajudar o leitor na conexão com uma especialidade gráfica, como letras, gráficos, imagens, etc., tornando-se necessária a consciência da sua existência para se alcançar o significado preciso da informação (DIAZ e PANDIELLA, 2007).

Um exemplo comum de paratexto são as ilustrações. A imagem passará a se transformar em uma ilustração quando entra no texto e "ilumina", esclarece o real sentido do 
que se quer entender. Às vezes, a ilustração pode se tornar um adorno, porém existem conceitos para os quais não se consegue uma explicação apenas com palavras (DIAZ e PANDIELLA, 2007), como no caso do conceito de isomeria, discutido anteriormente.

As categorias estabelecidas para analisar a "relação da imagem com o texto principal", de acordo com a taxonomia empregada por Perales e Jiménez (2002) são: conotativa, denotativa e sinótica. A relação texto-imagem envolve atividades em dois distintos subsistemas. O primeiro é o verbal (sistema especializado de forma direta com a linguagem) e o segundo é o não verbal-imaginário (sistema especializado em trabalhar com a forma não linguística de eventos e objetos). A articulação das informações visuais e verbais (que pode ser texto ou áudio) pode ser entendida pela teoria da dupla codificação (Dual Coding Theory - TCD) de Paivio (2006). De acordo com esta teoria, as informações visuais e verbais são processadas independentemente nos subsistemas da memória. Quando as representações verbais e visuais estão relacionadas, estas são mais benéficas ao aprendizado de que quando aparecem somente em um desses subsistemas. Portanto aprender a partir de textos juntamente com gráficos é mais rico do que aprender com esses elementos isolados (COOK, 2006).

A partir deste contexto, sabe-se que em muitos materiais didáticos as imagens não encontram-se isoladas, mas intercaladas com textos descritivos ou explicativos. Para entender como as ilustrações auxiliam na compreensão do texto conceitual, devemos estudar como e quando aparecem, e identificar suas relações mútuas, como por exemplo, a relação dos textos com as imagens e o uso de textos dentro das imagens (etiquetas verbais) (PERALES e JIMÉNEZ, 2002). Portanto, é razoável incluir este tipo de análise nas imagens presentes nas questões vestibulares. 


\subsection{Eixo 3 - A questão de química como um todo}

Neste eixo leva-se em consideração os conteúdos e assuntos químicos e as habilidades cognitivas mobilizadas na resolução da questão.

\subsection{Assuntos Químicos}

Com o passar dos anos, muitas reformas educacionais foram implantadas em nosso país (Lei das Diretrizes e Bases (LDB), Diretrizes Curriculares Nacionais (DCN), Parâmetros Curriculares Nacionais (PCN), Parâmetros Curriculares Nacionais para o Ensino Médio (PCNEM)), apresentando novos conteúdos, propostas metodológicas, conceitos de avaliação, dentre outros (GUIMARÃES et al, 2009).

Tendo em vista que boa parte dos ingressos nas universidades públicas de São Paulo é oriunda do sistema educacional de São Paulo, para os fins deste trabalho adotou-se o currículo oficial do Estado de São Paulo como fonte para o sistema classificatório dos assuntos químicos presentes nas questões.

Segundo o currículo do estado de São Paulo (2011) os assuntos químicos propostos para o ensino de química na $1^{\mathrm{a}}$ série do ensino médio são:

- evidências macroscópicas das transformações químicas;

- reconhecimento das substâncias (reagentes e produtos) por suas propriedades características;

- relações quantitativas (leis de Lavoisier e Proust);

- modelo atômico de Dalton como primeira explicação para os fatos (conceito de átomo, massa atômica e símbolos químicos);

- equações químicas e seu balanceamento;

- primeira leitura da tabela periódica (identificação de elementos químicos e massas atômicas). 
Na $2^{\mathrm{a}}$ série os conteúdos são:

- estudo das soluções;

- estequiometria;

- aspectos termoquímicos e eletroquímicos;

- estrutura atômica relativos aos modelos de Rutherford e Bohr;

- ligações químicas.

E os conteúdos para a $3^{\mathrm{a}}$ série são:

- cinética química;

- equilíbrio químico;

- química orgânica.

\subsection{Habilidades Cognitivas de Alta e Baixa Ordem segundo Zoller}

O professor e pesquisador Uri Zoller tem contribuído para o enriquecimento dos estudos realizados sobre as habilidades cognitivas. $\mathrm{O}$ autor defende a ideia de que a melhora das habilidades cognitivas desenvolvidas pelos alunos fará com que os objetivos desejados para o processo de ensino-aprendizagem sejam alcançados (SUART e MARCONDES, 2008).

Zoller et al. (2002) define duas categorias para as habilidades cognitivas: as habilidades cognitivas de baixa ordem (LOCS - Lower Order Cognitive Skills) e as habilidades cognitivas de alta ordem (HOCS - Higher Order Cognitive Skills).

As LOCS podem ser caracterizadas pela capacidade de conhecer, recordar informações e/ou aplicar conhecimentos ou algorítmicos memorizados. As HOCS são referidas como capacidades orientadas para a investigação, resoluções de problemas, tomada de decisões e o desenvolvimento de raciocínio crítico (SUART e MARCONDES, 2008). Zoller (1993) ainda inclui em sua definição de HOCS a capacidade dos indivíduos elaborarem perguntas que abrangem um conhecimento adicional, partindo da tomada de decisões com pensamento racional, lógico e reflexivo através de uma ação responsável. 
Segundo Zoller (1993, 1997, 1999, 2001), as resoluções de questões de química demandam dos alunos diferentes habilidades cognitivas em variados níveis de complexidade, os quais estão relacionados com a dificuldade da questão (perguntas, grupos de perguntas e problemas). Zoller propõe que estas demandas cognitivas para a resolução de um problema podem também ser classificadas como habilidade cognitiva de alta ordem e habilidade cognitiva de baixa ordem.

Assim, de forma correspondente à definição de LOCS e HOCS, questões que mobilizam habilidades cognitivas de baixa ordem são aquelas que exigem a memorização de informações e conhecimentos, cuja resolução basta uma aplicação de forma simplificada da teoria conhecida pelo estudante, o qual pode ser resolvido por processos algorítmicos (processo de conhecimento mecanizado, que é reconhecido pelo estudante, mas não compreendido) (ZOLLER e TSAPARLIS, 1997). O quadro 2 apresenta exemplos de questões LOCS.

Quadro 2 - Exemplos de questões com habilidade cognitiva de baixa ordem de (LOCS) (ZOLLER e TSAPARLIS, 1997, p.120)

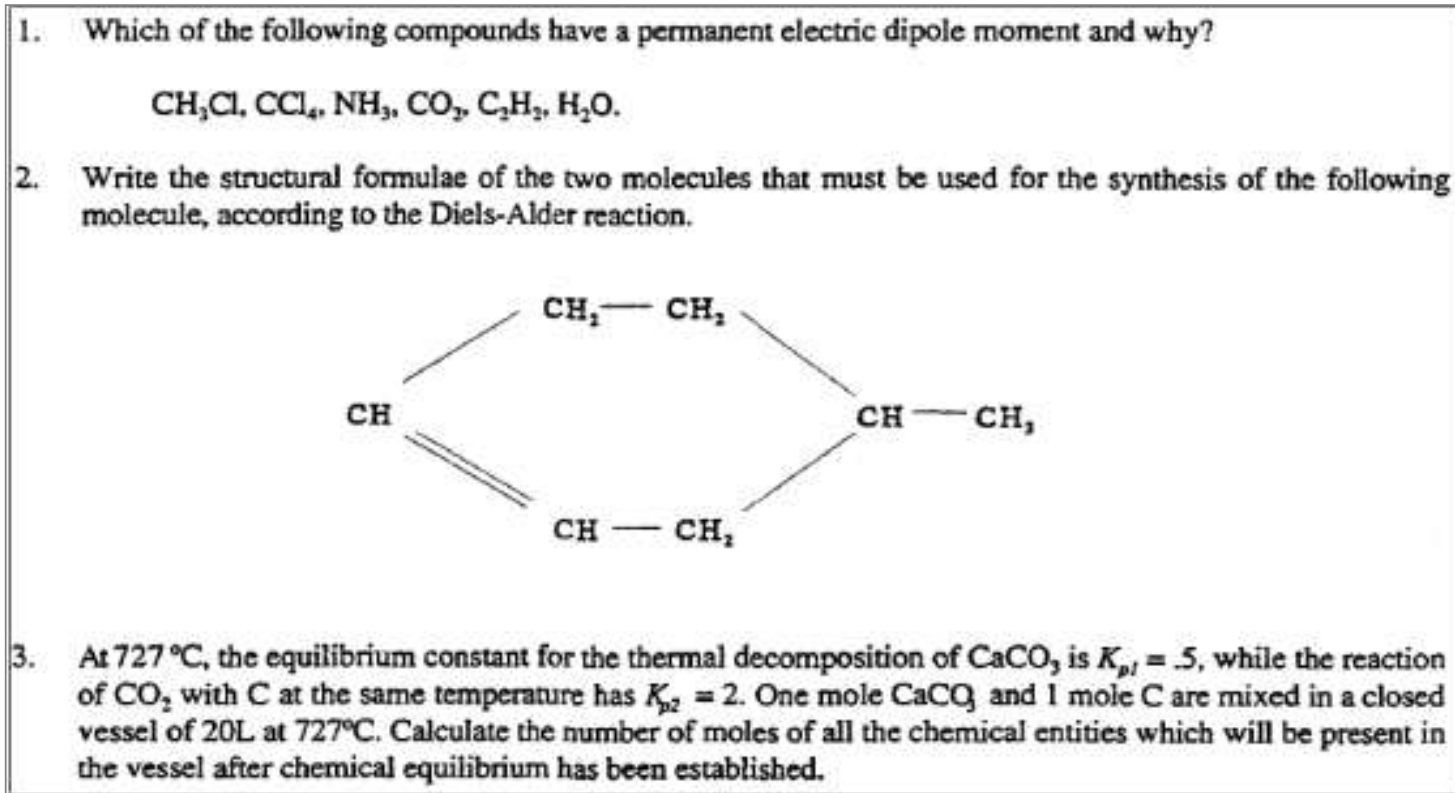

2. Write the structural formulae of the two molecules that must be used for the synthesis of the following molecule, according to the Diels-Alder reaction.

3. At $727^{\circ} \mathrm{C}$, the equilibrium constant for the thermal decomposition of $\mathrm{CaCO}_{3}$ is $K_{p t}=.5$, while the reaction of $\mathrm{CO}_{2}$ with $\mathrm{C}$ at the same temperature has $K_{p 2}=2$. One mole CaCQ and 1 mole $\mathrm{C}$ are mixed in a closed vessel of $20 \mathrm{~L}$ at $727^{\circ} \mathrm{C}$. Calculate the number of moles of all the chemical entities which will be present in the vessel after chemical equilibrium has been established.

As questões que mobilizam habilidades cognitivas de alta ordem são referidas como aquelas que exigem ações tanto quantitativas quanto qualitativas na resolução de problemas não familiares para o aluno, ou requerem para sua resolução, a investigação, análise, tomada de decisões e o desenvolvimento de um pensamento crítico e avaliativo (ZOLLER e TSAPARLIS, 1997; SUART e MARCONDES, 2008). 
No quadro 3 pode-se observar exemplos de questões HOCS retirados do estudo realizado por Zoller e Tsaparlis (1997).

Quadro 3 - Exemplos de questões com habilidade cognitiva de alta ordem (HOCS). (ZOLLER e TSAPARLIS, 1997, p.120).

5. Given that internal-combustion fuels contain sulfur, propose the reactions for the corrosion of marbie monuments by exhaust gases.

6. The ion product of water $\left(K_{\mathrm{w}}\right)$ at $0^{\circ} \mathrm{C}$ is equal to $10^{-13}$, while at $60^{\circ} \mathrm{C}$ it is $10^{-13}$. From these values, find the $p H$ values of pure water at both $0^{\circ} \mathrm{C}$ and $60^{\circ} \mathrm{C}$. Furthermore, infer whether the ionisation of water is an endochermic or an exothermic reaction. Finally, do the same for the neutralisation reaction $\left[\mathrm{H}^{+}(\mathrm{aq})+\mathrm{OH}^{\prime}(\mathrm{aq})\right.$ $\left.-\mathrm{H}_{2} \mathrm{O}(1)\right]$ in aqueous solutions.

Diante dos estudos sobre as potencialidades de questões de habilidades cognitivas de alta e baixa ordem, Zoller et al. (2002) investigaram o desempenho de 97 acadêmicos de duas universidades Israelenses ao responderem questões que demandam HOCS e LOCS. Os resultados revelam que os estudantes tiveram maior desempenho em questões algorítmicas. Os autores acreditam que isto se deve ao fato de que a resolução algorítmica propicia a busca pela resposta correta, e, além disso, consideram que as questões que demandam HOCS são mais difíceis, pois não podem ser resolvidas por mera reprodução, exigindo a elaboração de respostas argumentativas. 


\section{METODOLOGIA}

\subsection{Universo da pesquisa}

Foram analisadas questões de química contendo ilustrações provenientes dos exames vestibulares de cinco grandes Universidades Públicas Paulistas no período de 2007 a 2011.

A partir do ano de 2009 os vestibulares da UFSCAR e da UNIFESP adotaram o Exame Nacional do Ensino Médio (ENEM) como processo de seleção em suas instituições. Assim, as questões do ENEM nos anos de 2010 a 2011 também foram analisadas.

As provas foram obtidas diretamente dos sítios eletrônicos ${ }^{10}$ das respectivas instituições de ensino superior e/ou instituições organizadoras dos exames de ingresso. Em comum com outros exames vestibulares do país, as provas das universidades analisadas são aplicadas por fases (dias de aplicação). Desta forma, a primeira fase é constituída da prova de conhecimentos gerais (CG) e a segunda fase de conhecimentos específicos (ES).

Foram selecionas para a análise somente as questões de química contendo ilustrações nos exames vestibulares de 2007 a 2011, sendo estas imagens e aportes que acompanham os textos das questões, podendo incluir fluxogramas, esquemas, estruturas moleculares, assim como tabelas contendo descrições e dados. Isto foi aplicado para ambas as provas de conhecimentos gerais e conhecimentos específicos.

Encontraram-se 466 questões de química, e destas 252 continham ilustrações, como pode-se observar na tabela 1 , que indica os valores individuais para cada exame analisado.

\footnotetext{
${ }^{10}$ Comissão Permanente de Seleção (COMVEST). Disponível em: <http://www.comvest.unicamp.br/vest anteriores/provas_comentadas.html> Acesso em: dez. 2012 Universidade Estadual Paulista "Júlio de Mesquita filho" (UNESP). Disponível em: <http://vestibular.unesp.br/anteriores> Acesso em: dez. 2012 Universidade Estadual de São Carlos (UFESCAR). Disponível em: $<$ http://www2.ufscar.br/comunidade/proc_selet_anteriores.php> Acesso em: dez. 2012. Vestibular UNIFESP. Disponível em:

$<$ http://vestibular.unifesp.br/index.php?option=com_phocadownload \&view=categories\&Itemid=112>Acesso em: dez. 2012. Fundação Universitária para o Vestibular (FUVEST). Disponível em: < http://www.fuvest.br/provas> Acesso em: dez. 2012.

Instituto Nacional de Estudos e Pesquisas Educacionais Anísio Teixeira (INEP). Disponível em: <http://portal.inep.gov.br/web/enem/edicoes-anteriores/provas-e-gabaritos> Acesso em: dez. 2012.
} 
Tabela 1 - Universo de questões analisadas em cada exame

\begin{tabular}{lcc}
\hline \multicolumn{1}{c}{ Provas } & Questões de Química & Questões de Química com ilustrações \\
\hline FUVEST/USP & 102 & 71 \\
VUNESP/UFSCAR & 35 & 11 \\
VUNESP/UNIFESP & 68 & 51 \\
COMVEST/UNICAMP & 66 & 28 \\
VUNESP/UNESP & 157 & 70 \\
ENEM & 38 & 21 \\
\hline Total & 466 & 252 \\
\hline
\end{tabular}

A seguir é detalhado o universo das questões elencadas para análise nos exames de cada instituição de ensino superior.

\subsubsection{Fundação Universitária para o Vestibular (FUVEST)}

Os exames vestibulares realizados pela FUVEST para a Universidade de São Paulo nos anos de 2007 a 2009 constituíram-se de duas fases, uma prova de conhecimentos gerais na primeira fase, e uma prova de conhecimentos específicos na segunda. Nos anos de 2010 e 2011, a segunda fase do vestibular da USP foi separada em três dias de prova. No primeiro dia, a prova versou sobre português e redação, no segundo dia sobre biologia, química, física, matemática, história, geografia e inglês, e no terceiro dia foram aplicadas questões de conhecimentos gerais.

A tabela 2 apresenta a quantidade de questões de química presente nas provas da FUVEST e as questões que foram analisadas nesta pesquisa. 
Tabela 2 - Questões do exame vestibular da FUVEST/USP que tomaram parte deste trabalho

\begin{tabular}{ccccc}
\hline & Questões de Química & \multicolumn{2}{c}{ Questões de Química com ilustrações } \\
\cline { 2 - 5 } Ano & CG $^{\mathbf{1}}$ & $\mathbf{E S}^{2}$ & CG & ES \\
\hline 2007 & 11 & 10 & 9 & 7 \\
\hline 2008 & 10 & 10 & 8 & 7 \\
\hline 2009 & 10 & 10 & 5 & 9 \\
\hline 2010 & 10 & 10 & 7 & 6 \\
\hline 2011 & 10 & 11 & 5 & 37 \\
\hline Total & 51 & 51 & 34 & \\
\hline $\begin{array}{l}{ }^{1} \text { CG: conhecimentos gerais } \\
{ }^{2} \text { ES: conhecimentos específicos }\end{array}$ & & & \\
\hline
\end{tabular}

No total, 71 questões de química da FUVEST/USP foram analisadas.

\subsubsection{Comissão permanente para os vestibulares (COMVEST)}

A comissão permanente para os vestibulares (COMVEST) da Universidade Estadual de Campinas (UNICAMP) realizou nos anos de 2007 a 2010 provas vestibulares com duas fases de aplicação. Na primeira, uma prova de conhecimentos gerais e na segunda, de conhecimentos específicos.

A partir do ano de 2011, a Universidade adotou um novo formato, estruturando quatro grandes eixos curriculares: 1) língua portuguesa e estrangeira, 2) matemática, 3) ciências humanas, humanidades e artes e 4) ciências da natureza. A tabela 3 indica a relação de questões de química contabilizadas. 
Tabela 3 - Questões do exame vestibular da COMVEST/UNICAMP que tomaram parte deste trabalho

\begin{tabular}{|c|c|c|c|c|}
\hline \multirow[b]{2}{*}{ Ano } & \multicolumn{2}{|c|}{ Questões de Química } & \multicolumn{2}{|c|}{ Questões de Química com ilustrações } \\
\hline & $\mathbf{C G}^{\mathbf{1}}$ & $\mathbf{E S}^{2}$ & CG & ES \\
\hline 2007 & 1 & 12 & 1 & 5 \\
\hline 2008 & 2 & 12 & 2 & 3 \\
\hline 2009 & 2 & 12 & 1 & 5 \\
\hline 2010 & 2 & 12 & 1 & 5 \\
\hline 2011 & 3 & 8 & 0 & 5 \\
\hline Total & 10 & 56 & 5 & 23 \\
\hline $\begin{array}{l}\text { G: conh } \\
\text { s: conhe }\end{array}$ & os gera & & & \\
\hline
\end{tabular}

No total, tomaram parte deste estudo 28 questões de química contendo ilustrações dos exames da COMVEST/UNICAMP.

\subsubsection{Fundação para o Vestibular da Universidade Estadual Paulista (VUNESP)}

A VUNESP nos anos de 2007 a 2011 realizou dois processos de vestibulares ao longo do ano para Universidade Estadual Paulista (UNESP). Cada processo (meio de ano ou final de ano) contêm duas fases. Na primeira fase foi aplicada uma prova de conhecimentos gerais (CG) e, na segunda fase, de conhecimentos específicos (ES). A tabela 4 mostra o número de questões presentes nas provas nos anos de 2007 a 2011, com um total de 157 questões de química, destas, 70 contêm imagens. 
Tabela 4 - Questões do exame vestibular da VUNESP/UNESP que tomaram parte deste trabalho

Questões de Química
Questões de Química com ilustrações

\begin{tabular}{ccccc}
\cline { 2 - 5 } Ano & $\mathbf{C G}^{\mathbf{1}}$ & $\mathbf{E S}^{\mathbf{2}}$ & $\mathbf{C G}$ & $\mathbf{E S}$ \\
\hline 2007 & 24 & 12 & 8 & 5 \\
\hline 2008 & 24 & 12 & 7 & 4 \\
\hline 2009 & 24 & 12 & 12 & 4 \\
\hline 2010 & 20 & 9 & 16 & 3 \\
\hline 2011 & 14 & 6 & 7 & 20 \\
\hline Total & 106 & 51 & 50 & 4 \\
\hline
\end{tabular}

O vestibular da Universidade Federal de São Carlos (UFSCAR) nos anos de 2007 a 2009 apresentou três fases. Na primeira fase, a prova versou sobre os conteúdos de português, inglês e redação, a segunda de matemática, história e química, e a terceira de física, biologia e geografia.

No ano de 2010, o exame vestibular da UFSCAR utilizou a prova do ENEM como primeira fase de seleção. Já a segunda fase do exame consistiu em uma prova de conhecimentos específicos (química, física e matemática) elaborados pela VUNESP.

A partir do ano de 2011, o vestibular UFSCAR adotou somente a prova do ENEM como exame de seleção.

Na tabela 5 pode-se observar o número de questões de química analisados da prova da UFSCAR. 
Tabela 5 - Questões do exame vestibular da VUNESP/UFSCAR que tomaram parte deste trabalho

Questões de Química

Ano

2007

2008

2009

2010

Total

35
Questões de Química com ilustrações

ES

3

4

2

2

11

${ }^{1}$ ES: conhecimentos específicos

O exame vestibular da Universidade Federal de São Paulo (UNIFESP) nos anos de 2007 a 2009 constituiu-se de duas fases. Na primeira fase uma prova de conhecimentos gerais (CG), e na segunda fase uma prova de conhecimentos específicos (ES). Já no ano de 2010 e 2011, o vestibular VUNESP/UNIFESP adotou o sistema misto (ENEM como primeira fase e a segunda fase seria uma prova aplicada pela instituição). A segunda fase realizada pela Universidade foi composta por duas provas em dois dias: a primeira de Língua Portuguesa, Estrangeira e Redação, e a segunda prova de conhecimentos específicos na Área de Ciências Biológicas e Exatas, com 68 questões de química, 51 destas questões continham imagens, como pode-se observar na tabela 6 . 
Tabela 6 - Questões do exame vestibular da VUNESP/UNIFESP que tomaram parte deste trabalho

\begin{tabular}{ccccc}
\hline \multirow{2}{*}{ Ano } & \multicolumn{2}{c}{ Questões de Química } & Questões de Química com ilustrações \\
\cline { 2 - 4 } & CG $^{\mathbf{1}}$ & $\mathbf{E S}^{\mathbf{2}}$ & CG & ES \\
\hline 2007 & 14 & 5 & 9 & 5 \\
\hline 2008 & 14 & 5 & 10 & 5 \\
\hline 2009 & 15 & 5 & 9 & 5 \\
\hline 2010 & - & 5 & - & 4 \\
\hline 2011 & - & 5 & - & 23 \\
\hline Total & 43 & 25 & 28 & \\
\hline${ }^{1}$ EG: conhecimentos gerais & & & \\
\hline
\end{tabular}

\subsubsection{Exame Nacional do Ensino Médio (ENEM)}

O Exame Nacional do Ensino Médio dividiu a sua prova em dois dias. O primeiro continha questões das áreas de ciências da natureza, ciências humanas e suas tecnologias. $\mathrm{O}$ segundo dia de prova englobou as áreas de redação e linguagem, códigos e suas tecnologias, e matemática e suas tecnologias.

A tabela 7 indica o número de questões das provas do ENEM nos anos de $2010 \mathrm{e}$ 2011, sendo 38 questões de química e 21 contendo ilustrações. 
Tabela 7 - Questões do Exame Nacional do Ensino Médio (ENEM) que tomaram parte deste trabalho

\begin{tabular}{ccccc}
\hline & & \multicolumn{2}{c}{ Questões de Química } & \multicolumn{2}{c}{ Questões de Química com ilustrações } \\
\cline { 2 - 5 } Ano & $\mathbf{1}^{\mathbf{a}}$ Prova & $\mathbf{2}^{\text {a }}$ Prova & $\mathbf{1}^{\mathbf{a}}$ Prova & $\mathbf{2}^{\mathbf{a}}$ Prova \\
\hline 2010 & 15 & - & 9 & - \\
\hline 2011 & 23 & - & 12 & - \\
\hline Total & 38 & - & 21 & - \\
\hline
\end{tabular}

\subsection{Critérios de Análise e suas Categorias}

As questões foram classificadas e analisadas segundo as seguintes categorias para cada eixo:

\section{Eixo 1 - A ilustração em si:}

- Tipos de ilustrações

- Funcionalidade das ilustrações

- Grau de iconicidade

- Presença e tipo de etiquetas verbais

Eixo 2 - A Relação entre a representação visual e seu entorno na questão:

- Relação texto-imagem 


\section{Eixo 3: A questão de química como um todo:}

- Assuntos químicos envolvidos nas questões

- Habilidades cognitivas requisitadas

As categorias referentes à relação texto-imagem, funcionalidade das ilustrações, grau de iconicidade e presença e tipo de etiquetas verbais foram construídas a partir da taxonomia proposta por Perales e Jiménes (2002). Os autores analisaram a relação de suportes teóricos (textos) com as imagens contidas em livros didáticos utilizados no processo de ensino-aprendizagem.

\subsection{Descrição das Categorias}

\subsubsection{Eixo 1 - A ilustração em si}

\subsubsection{Tipos de Ilustrações}

Nesta pesquisa, as questões foram classificadas quanto à presença de doze tipos distintos de ilustrações, apresentadas na tabela 8 , juntamente com exemplos retirados do universo analisado. 
Tabela 8 - Exemplos dos tipos de ilustração encontrados nas provas.

(continua)

\section{Tipos de ilustração}

\section{Exemplo}

Gráficos

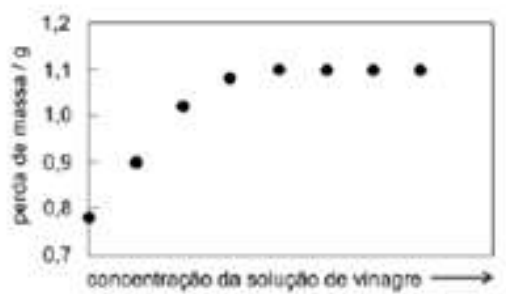

(FUVEST/USP-(CG), 2007, questão 28)

Diagramas

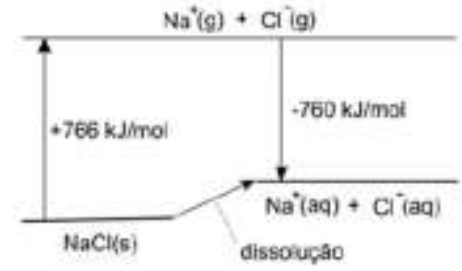

$5=$ achiso

ac $=$ aquoso

$g=g a s a s 0$

(FUVEST/USP-(CG), 2007, questão 20)

Molécula 2D Explícita

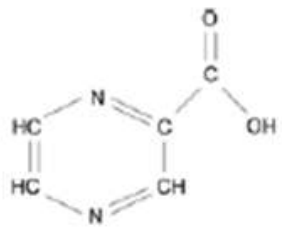

(FUVEST/USP-(CG), 2007, questão 29)

Molécula 2D Implícita<smiles>c1ccc2cc3ccccc3cc2c1</smiles>

(VUNESP/UNESP-(CG), 2007, questão 70)

Molécula 2D Mista

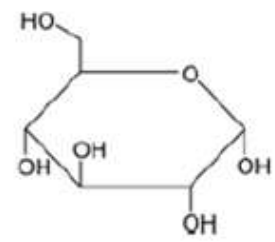

(FUVEST/USP-(CG), 2007, questão 27) 
Tabela 8 - Exemplos dos tipos de ilustração encontrados nas provas.

(continuação)

\section{Tipos de ilustração}

\section{Exemplo}

Molécula 3D

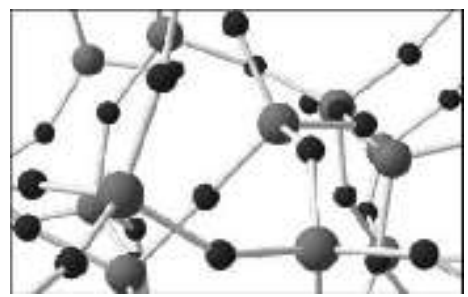

(FUVEST/USP-(CG), 2011, questão 32)

Estrutura Molecular

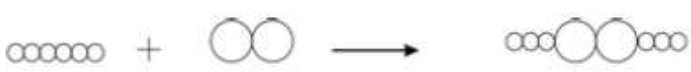

Esquemática
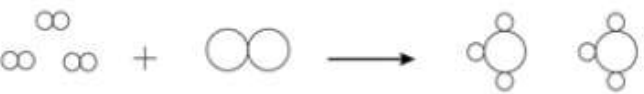

(FUVEST/USP-(CG), 2008, questão 20)

Equação

$$
\mathrm{C}_{2} \mathrm{H}_{5} \mathrm{OH}(g)+\mathrm{H}_{2} \mathrm{O}(v) \rightarrow 4 \mathrm{H}_{2}(g)+2 \mathrm{CO}(g)
$$

(VUNESP/UNESP-(ES), 2007, questão 23)

Tabela

\begin{tabular}{|l|c|}
\hline \multicolumn{1}{|c|}{ Substáncia } & $\begin{array}{c}\text { Concentração } \\
\text { mol } / \mathbf{5 0 0} \mathbf{~ m L} \text { de soluçăo }\end{array}$ \\
\hline Cloreto de sódio & $1,8 \times 10^{-2}$ \\
\hline Citrato de potássio monoidratado & $3,3 \times 10^{-3}$ \\
\hline Citrato de sódio didratado & $1,7 \times 10^{-3}$ \\
\hline Gicose & $6,3 \times 10^{-2}$ \\
\hline
\end{tabular}

(FUVEST/USP-(ES), 2008, questão 9)

Fluxograma

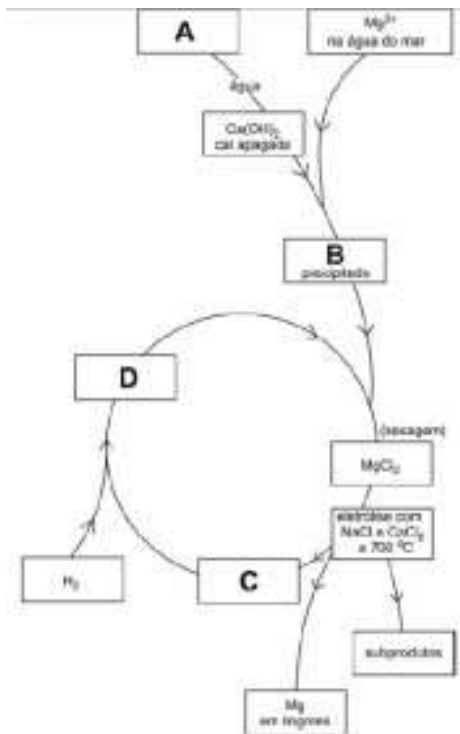

(FUVEST/USP-(ES), 2010, questão 6) 
Tabela 8 - Exemplos dos tipos de ilustração encontrados nas provas.

(conclusão)

Figura

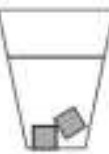

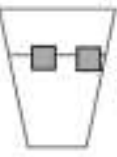

y

$x$

situaçáo inicial
Exemplo

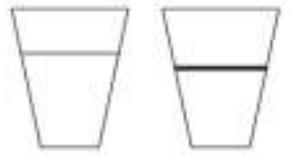

c d

situaçăo final

(COMVEST/UNICAMP-(ES), 2008, questão 06)

Esquemas

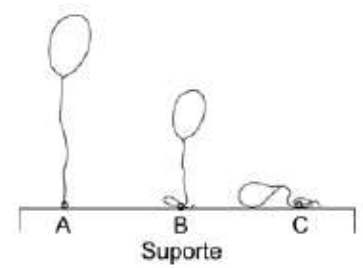

(FUVEST/USP-(CG), 2008, questão 26)

Contabilizou-se as ilustrações conforme ocorrências apresentadas nas questões das provas. As tabelas foram incluídas como tipos de ilustração, por conterem definições e dados que de certa forma orientam e elucidam conceitos e conteúdos abordados nas questões. Ou seja, as tabelas têm como objetivo apresentar informações de maneira organizada e sistematizada. Para isso, utilizam-se linhas e colunas para promover uma visão íntegra de informações que se inter-relacionam (PIRES, RAPOSO e MÓL, 2007).

Já os gráficos são utilizados como instrumentos de apresentações de dados de planilhas e tabelas complexas, garantindo uma forma visual mais eficaz e simples do conteúdo e suas relações entre variáveis e cruzamentos de diferentes grupos de informações, permitindo também comparações e correlações imediatas (PIRES, RAPOSO e MÓL, 2007). 


\subsubsection{Funcionalidade das ilustrações}

A funcionalidade das ilustrações é dividida em três categorias, a inoperante (no qual a ilustração não aponta nenhum elemento utilizável), as operativas elementares (contêm elementos de representações universais) e a sintática (contêm elementos que necessitam de conhecimento científico específico) (PERALES e JIMÉNEZ, 2002). Deste modo, cada ilustração foi analisada conforme o grau de funcionalidade existente. A tabela 9 indica exemplos de questões retirados de alguns exames vestibulares analisados para as categorias de análise de funcionalidade das ilustrações com base na taxonomia proposta por Perales e Jiménez (2002). 
Tabela 9 - Exemplos de questões para as categorias de funcionalidade das ilustrações

(continua)

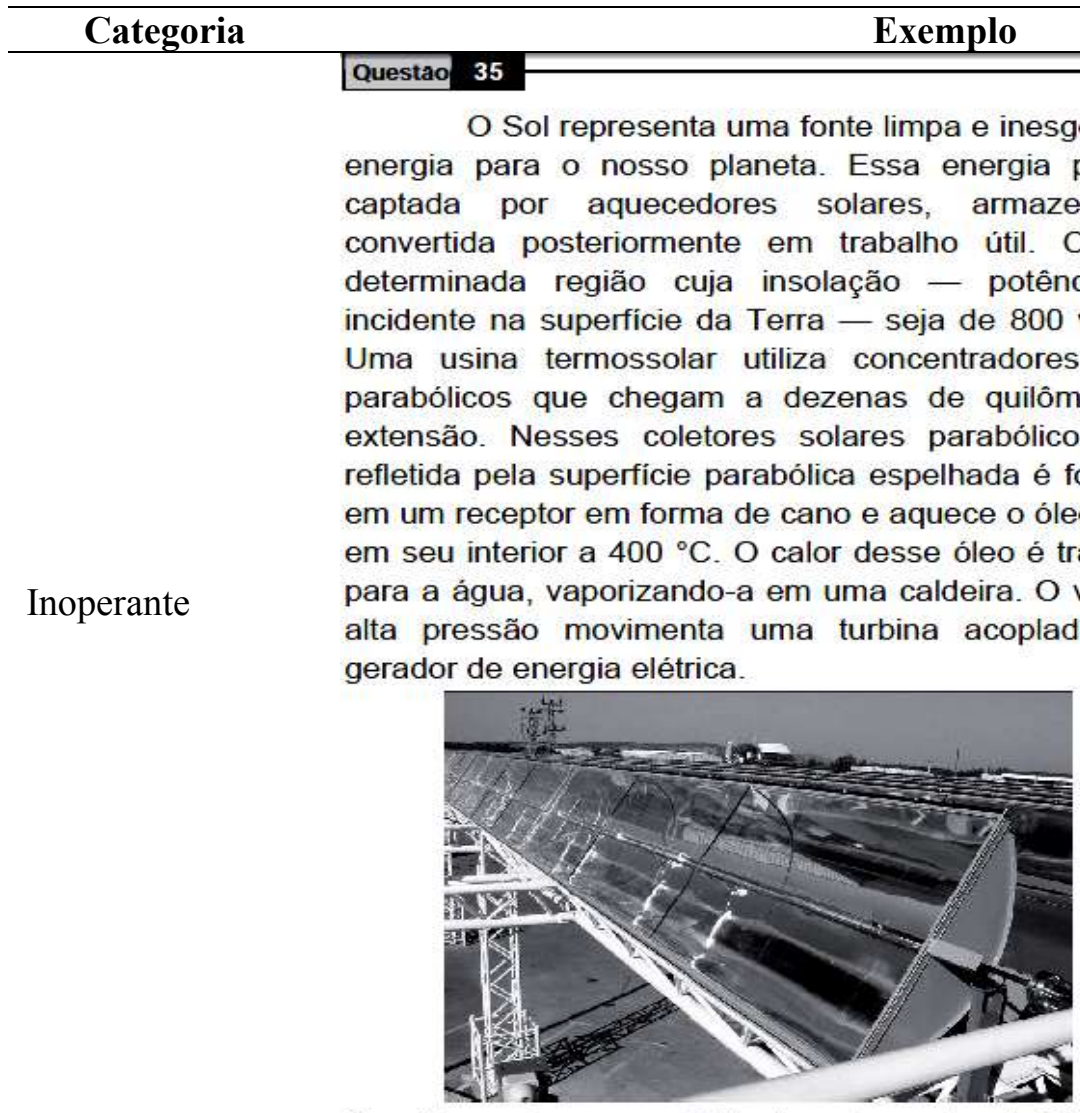

Considerando que a distância entre a borda inferior e a borda superior da superfície refletora tenha $6 \mathrm{~m}$ de largura e que focaliza no receptor os 800 watts $/ \mathrm{m}^{2}$ de radiação provenientes do Sol, e que o calor específico da água é $1 \mathrm{cal} \mathrm{g}^{-1}{ }^{\circ} \mathrm{C}^{-1}=4.200 \mathrm{~J} \mathrm{~kg}^{-1}{ }^{\circ} \mathrm{C}^{-1}$, então o comprimento linear do refletor parabólico necessário para elevar a temperatura de $1 \mathrm{~m}^{3}$ (equivalente a $1 \mathrm{t}$ ) de água de $20^{\circ} \mathrm{C}$ para $100{ }^{\circ} \mathrm{C}$, em uma hora, estará entre
A $15 \mathrm{~m}$ e $21 \mathrm{~m}$.
๑ $22 \mathrm{~m}$ e $30 \mathrm{~m}$.
๑ $105 \mathrm{me} 125 \mathrm{~m}$.
- $680 \mathrm{~m}$ e $710 \mathrm{~m}$.
G $6.700 \mathrm{me} 7.150 \mathrm{~m}$.

(ENEM-(CG), 2010, questão 35)

A ilustração não aponta nenhum elemento utilizável, ou seja, cabe somente observá-la. 
Tabela 9 - Exemplos de questões para as categorias de funcionalidade das ilustrações

(continuação)

\section{Categoria}

Operativas

elementares

\section{Exemplo}

68. Em uma bancada de laboratório encontram-se três tubos de ensaios numerados de I a III, contendo volumes iguais de água. Alguns cristais de acetato de sódio (A), cloreto de sódio (B) e cloreto de amônio (C) são adicionados nos tubos I, II e III, respectivamente.
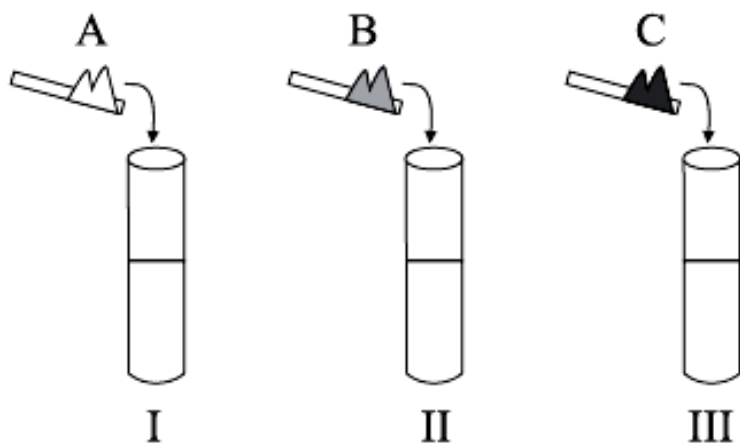

II

Ao medir o $\mathrm{pH}$ das soluções aquosas resultantes nos tubos de ensaio I, II e III, deve-se verificar que:
(A) I $<7$; II $=7$; III $>7$.
(B) I $<7$; II $<7$; III $=7$.
(C) I $>7$; II $=7$; III $<7$.
(D) I $=7$; II $=7$; III $>7$.
(E) I $>7$; II $<7$; III $=7$.

(VUNESP/UNESP-(CG), 2009, questão 68)

Esta categoria representa ilustrações que contém elementos de representações universais, como esboços. No caso desta ilustração, os tubos de ensaio e espátulas não apresentam elementos ou símbolos químicos indicados ou a necessidade do conhecimento científico para identificar substâncias ou concentrações. 
Tabela 9 - Exemplos de questões para as categorias de funcionalidade das ilustrações

(conclusão)

\begin{tabular}{|c|c|}
\hline Categoria & Exemplo \\
\hline & $\begin{array}{l}\text { 2. Os agentes organofosforados tiveram grande desenvolvimento durante a segunda guerra mundial nas pesquisas } \\
\text { que visavam á produçăo de armas quimicas. Mais tarde, constatou-se que alguns desses compostos, em baixas } \\
\text { concentraçóes, poderiam ser usados como pesticidas. Dentre essas substancias destacou-se o glifosato (molécula } \\
\text { abaixo representada), um herbicida que funciona inibindo a via de sintese do ácido chiquimico (ácido } 3,4,5 \text {-tri- } \\
\text { hidroxi-benzoico), um intermediário vital no processo de crescimento e sobrevivéncia de plantas que competem com } \\
\text { a cultura de interesse. Essa via de sintese esta presente em plantas superiores, algas e protozoários, mas è ausente } \\
\text { nos mamiferos, peixes, passaros, répteis e insetos. }\end{array}$ \\
\hline & $\mathrm{OH}$ \\
\hline \multirow[t]{3}{*}{ Sintática } & $\begin{array}{l}\text { a) Ao se dissolver o glifosato em água, a soluçâo final teră um } \mathrm{pH} \text { maior, menor ou igual ao da água antes da } \\
\text { dissoluçâo? Escreva uma equaçăo quimica que justifique a sua resposta. }\end{array}$ \\
\hline & $\begin{array}{l}\text { b) O texto fala do ácido chiquimico. Escreva a sua fórmula estrutural, de acordo com seu nome oficial dado no } \\
\text { texto. }\end{array}$ \\
\hline & $\begin{array}{l}\text { c) Imagine uma propaganda nos seguintestermos: "USE O GLIFOSATO NO COMBATE AMMALÁRIA. MATEO Plasmadium } \\
\text { fakiparum, O PARASITA DO INSETO RESPONSAVEL POR ESSA DOENCA", De acordo com as informaçoes do texto } \\
\text { essa propaganda poderia ser verdadeira? Comece respondendo com SIM ou NĀO e justifique. }\end{array}$ \\
\hline
\end{tabular}

(COMVEST/UNICAMP-(ES), 2007, questão 02)

A ilustração desta questão contém elementos que necessitam do conhecimento científico específico para interpretá-lo, como conhecer a simbologia química dos elementos $(\mathrm{H}=$ hidrogênio, $\mathrm{O}=$ oxigênio, $(\mathrm{N}=$ nitrogênio, $\mathrm{P}=$ fósforo $)$, ter o conhecimento de química orgânica na representação da fórmula estrutural plana, e que os traços simbolizam pares de elétrons que estabelecem uma ligação química.

Requer também a associação de conjunto de átomos e ligação como grupos funcionais na molécula.

\subsubsection{Grau de iconicidade ou nível de complexidade das ilustrações}

Para cada ilustração foi analisado o grau de iconicidade existente, ou seja, o nível de complexidade da imagem. Quando esta possuir um grau de iconicidade menor, exigirá que se obtenha um maior conhecimento do código simbólico utilizado (DIAZ e PANDIELLA, 2007). A tabela 10 indica as descrições de cada categoria de complexidade a partir de exemplos retirados das provas analisadas para o grau de iconicidade de cada ilustração encontrada nas questões, tomando como base o estudo de Perales e Jiménez (2002). 
Tabela 10 - Descrição e exemplos da categoria iconicidade das ilustrações

(continua)

Quando ocorre a interpretação do espaço e da

Fotografia realidade por meio da imagem

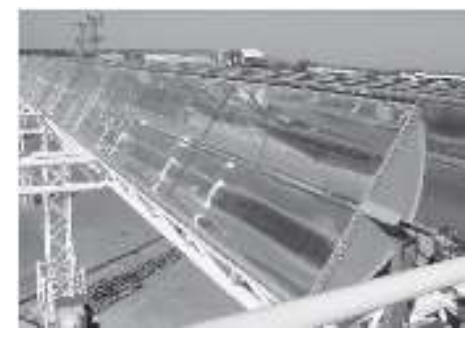

(ENEM-(CG), 2010, q.35)

Aprecia a representação
Desenho figurativo
orgânica,
mostrando objetos mediante
a realidade

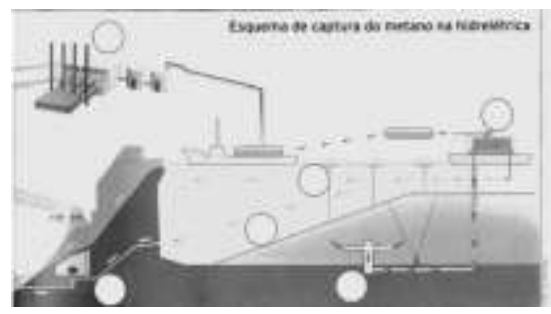

(COMVEST/UNICAMP-(ES), 2010, q.07)

Desenho figurativo magnitudes inobserváveis em com signos um espaço de representação heterogêneo

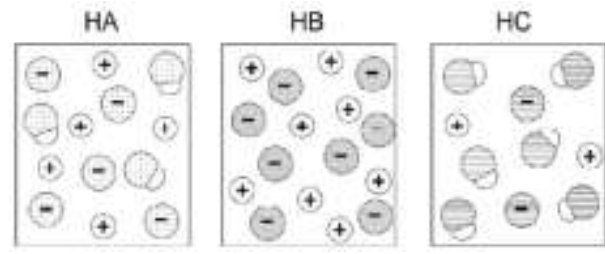

(FUVEST/USP-(CG), 2010, q.63)

Inclui ilustrações em que se representa figurativamente

Desenho figurativo com signos normalizados uma situação e a seu lado se representam alguns aspectos relevantes mediante signos normalizados
Carga de um mol de elétrons $=96500 \mathrm{C}$

Mas5a5 molares $\left(\mathrm{g} \mathrm{mol}^{-1}\right): \mathrm{Zn}=65.4 ; \mathrm{Cu}=63,5$

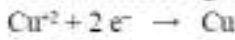

$\mathrm{Zn}^{+2}+2 \mathrm{e}^{-} \rightarrow \mathrm{Zn}$

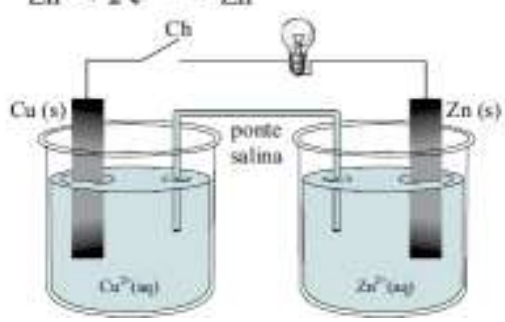

(VUNESP/UNESP-(ES), 2010, q. 76) 
Tabela 10 - Descrição e exemplos da categoria iconicidade das ilustrações

(conclusão)

Categoria

Descrição

Aprecia a representação das

Desenho esquemático

relações independente dos

detalhes
Exemplo

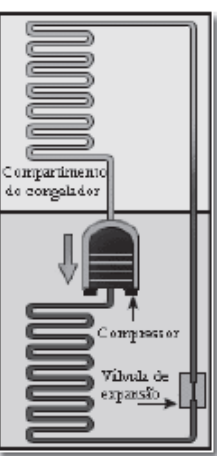

(ENEM-(CG), 2010, q.39)

Representam ações ou magnitudes inobserváveis.

Desenho esquemático Gráficos e tabelas podem ser com signos considerados integrantes desta categoria

\begin{tabular}{|l|c|}
\hline substância & $\Delta \mathrm{H}_{\mathrm{f}}^{\circ}(\mathrm{kJ} / \mathrm{mol})$ \\
\hline $\mathrm{C}_{6} \mathrm{H}_{12} \mathrm{O}_{6}(s)$ & -1268 \\
\hline $\mathrm{H}_{2} \mathrm{O}(\mathrm{l})$ & -286 \\
\hline $\mathrm{CO}_{2}(\mathrm{~g})$ & -394 \\
\hline
\end{tabular}

(VUNESP/UNIFESP-(ES), 2007, q. 89)

Constituem um espaço de Desenho esquemático representação homogêneo e com signos normalizados simbólico que possui regras sintáticas específicas

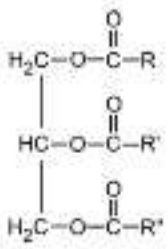

(FUVEST/USP-(ES), 2011, q. 1)

PERALES e JIMÉNEZ, 2002, p. 377; GIBIN, FILL e FERREIRA, 2009, p.705.

\subsubsection{Tipos e presença de etiquetas verbais}

Algumas ilustrações apresentam etiquetas verbais, que são textos que acompanham a imagem, que podem ser divididas em três categorias: as nominativas (letras e palavras que identificam elementos da ilustração), as relacionais (que são textos que descrevem relações entre os elementos da ilustração), e sem etiquetas (ilustrações que não contém texto). As categorias utilizadas para as etiquetas verbais foram construídas a partir da taxonomia utilizada por Perales e Jiménez (2002). A tabela 11 apresenta a descrição com exemplos 
retirados das provas analisadas para as categorias presentes para a análise das etiquetas verbais encontradas nas ilustrações das questões.

Tabela 11 - Descrição e exemplos da categoria etiquetas verbais presente nas ilustrações

(continua)

\section{Etiquetas}

\section{Exemplos}

Verbais

Sem

etiquetas
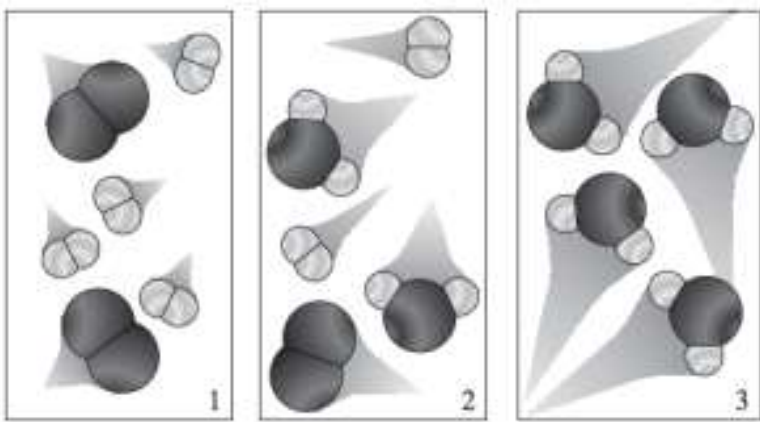

(VUNESP/UNESP-(CG), 2008, questão 61)

Esta ilustração não contém nenhum texto, palavra ou letra que permita algum tipo de identificação.

Nominativas

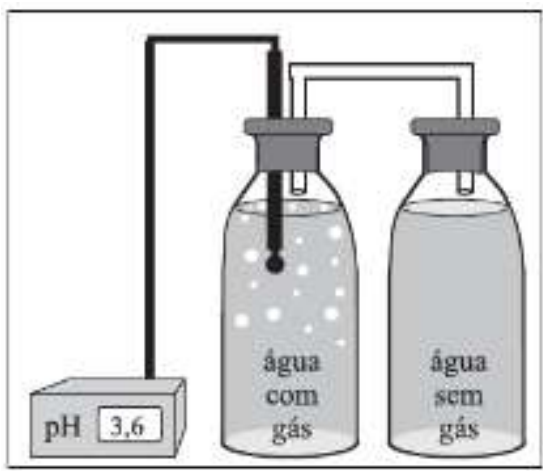

(VUNESP/UNESP-(CG), 2008, questão 70)

Este exemplo mostra a presença de letras e palavras que identificam alguns elementos na ilustração, como a identificação do líquido dentro da garrafa. 
Tabela 11 - Descrição e exemplos da categoria etiquetas verbais presente nas ilustrações

(conclusão)

$\begin{array}{ll}\text { Etiquetas } & \text { Exemplos } \\ \text { Verbais } & \end{array}$

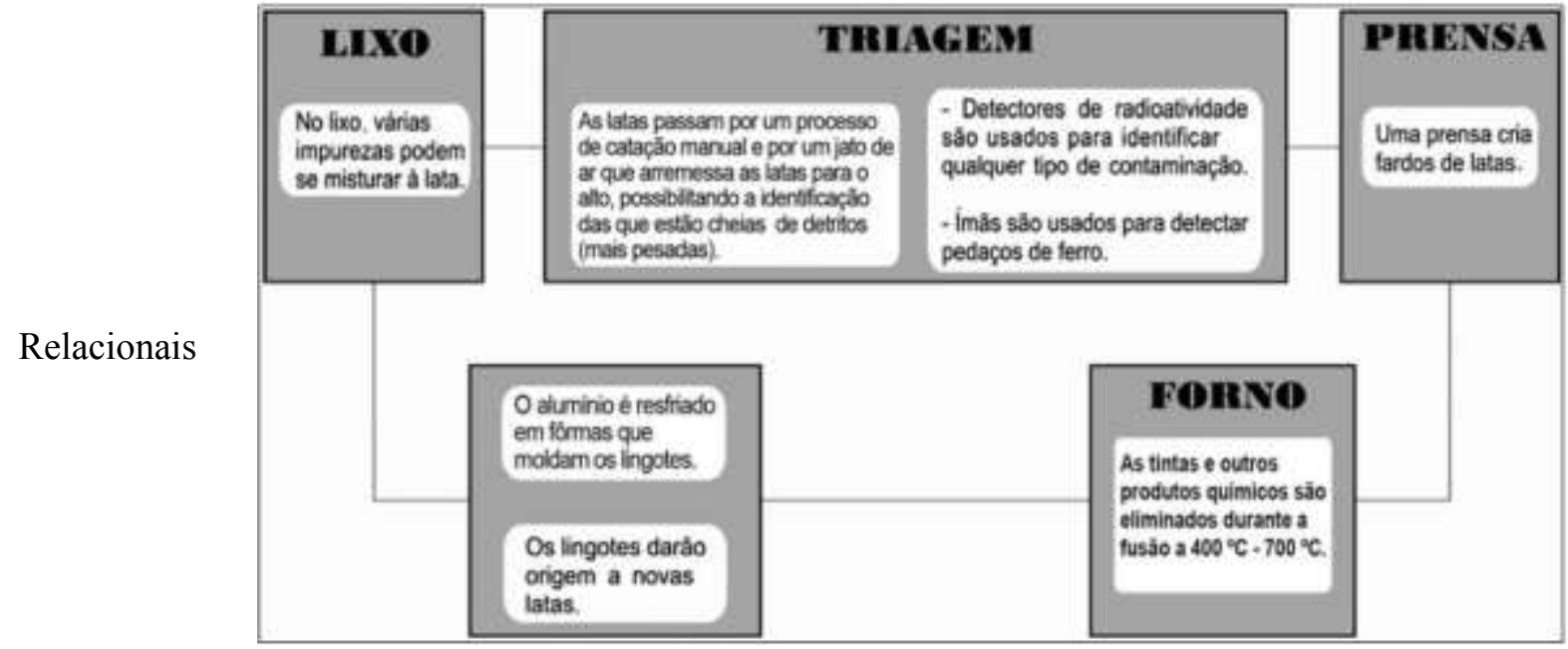

(FUVEST/USP-(CG), 2011, questão 60)

O exemplo mostra os textos que descrevem as relações entre os demais elementos disponíveis nas informações do esquema.

\subsubsection{Eixo 2 - A Relação entre a representação visual e seu entorno na questão}

\subsubsection{Relação texto-imagem}

Esta categoria representa o tipo de relação que se estabelece entre o texto da questão e a imagem apresentada. A análise desta dupla codificação é feita observando-se o texto em relação às ilustrações, podendo estas aparecerem isoladas no texto, ter algum tipo de interação, ou estarem totalmente relacionadas, ou seja, sendo um auxílio para a interpretação.

As categorias estabelecidas são conotativa (quando o texto descreve os conteúdos sem mencionar sua correspondência com os elementos contidos na ilustração, tornando-se óbvias para o leitor), denotativa (o texto estabelece correspondência entre os elementos da 
ilustração e os conteúdos representados), e sinótica (o texto estabelece correspondência entre os elementos da ilustração e os conteúdos representados, tornando a imagem e o texto uma unidade indivisível). Estas categorias foram construídas conforme a taxonomia empregada por Perales e Jiménez (2002). A tabela 12 apresenta exemplos de questões retirados de alguns exames vestibulares analisados. 
Tabela 12 - Exemplos da categoria relação texto-imagem

(continua)

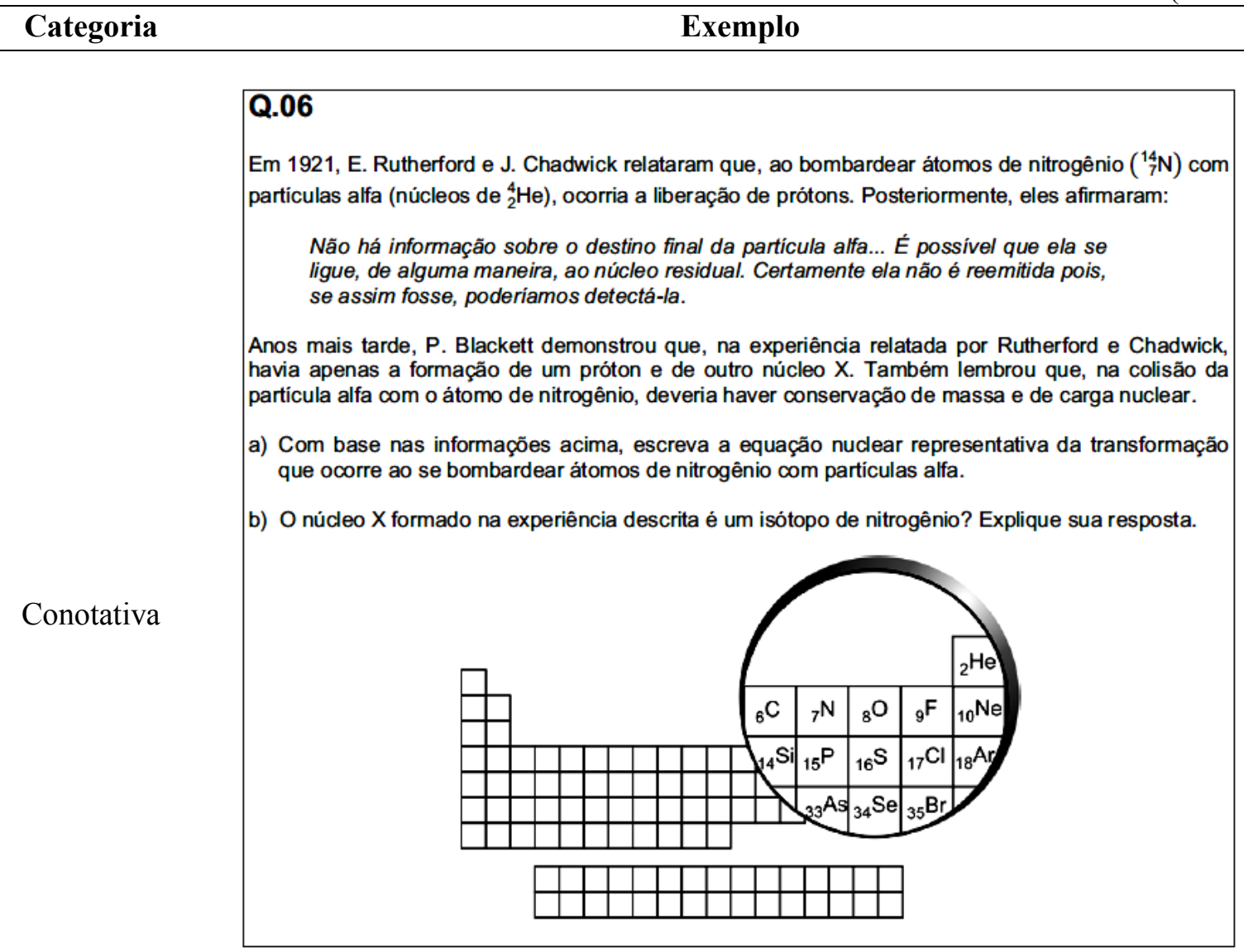

(FUVEST/USP-(ES), 2011, questão 6)

Nesta questão, o texto descreve o assunto relacionado a reações nucleares, e a sua resolução consiste em: (a) escrever a equação nuclear apresentada no texto inicial: ${ }_{7}^{14} N+{ }_{2}^{4} \alpha={ }_{1}^{1} P+{ }_{8}^{17} X$, e a letra (b) observar na própria equação que o número atômico $(Z)$ do elemento $X$ formado é 8 , não sendo isótopo de nitrogênio (que deveria ter números atômicos iguais e diferentes números de massa). Porém, o texto não menciona sua correspondência com os elementos contidos na ilustração (imagem ampliada de elementos químicos da tabela periódica), tornando-se uma relação óbvia para o leitor. 
Tabela 12 - Exemplos da categoria relação texto-imagem

(conclusão)

Categoria $\quad$ Exemplo

4. Os insetos competem com o homem pelas fontes de alimento. Desse modo, o uso de defensivos agricolas é uma arma importante nessa disputa pela sobrevivencia. As plantas tarnbem se defendem do ataque dos insetos e algumas delas desenwolveram eficientes armas quimicas nesse sentido. Um dos exemplos mais ilustrativos dessa capacidade de defesa sâo os piretroides. Abaixo estä representada a formula estrutural de um piretróide sintético utilizado como inseticida:

Denotativa

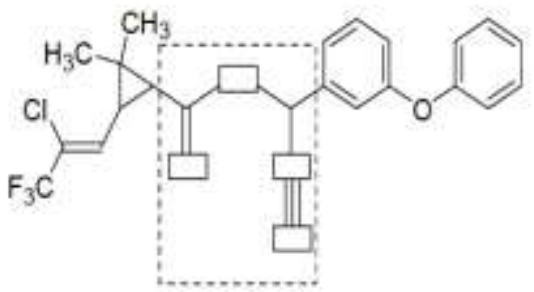

A estrutura dos piretróides é bastante particular, tendo em comum a presença de um anel de trés membros.

a) Reproduza no caderno de respostas a parte da fórmula estrutural delimitada pela linha tracejada. Substitua os retangulos por simbolos de átomos, escolhendo-os dentre os do segundo periodo da tabela periódica.

b) Qual é o valor aproximado dos ångulos internos entre as ligaçōes no anel de trềs membros?

c) Considerando a formula estrutural apresentada, que tipo de isomeria esse composto apresenta? Justifique sua resposta, representando o fragmento da molécula que determina esse tipo de isomeria.

(UNICAMP-(ES), 2007, questão 4)

O texto da questão estabelece correspondência entre os elementos da ilustração com o conteúdo, no sentido de explicitar e identificar na ilustração elementos fundamentais para a resolução da questão.

Sinótica 6. Vários textos da coletânea da prova de redaçăo enfatizam a crescente importáncia das fontes renováveis de energia. No Brasil, o alcool tem sido largamente empregado em substituiç̧ăo à gasolina. Uma das diferenças entre os motores a álicool e a gasolina é o valor da razāo de compressáo da mistura ar-combustivel. 0 diagrama ao lado representa o ciclo de combustāo de um cilindro de motor a alcool. Durante a compressaso (trecho $i \rightarrow f)$, ovolume da misturaè reduzido de $V$, para $V$, A razão de compressão ré definida como $r=\frac{V}{V_{f}}$. Valores tipicos de $r$ para motores a gasolina e a àlcool săo, respectivamente, $r_{g}=9$ e $r_{2}=11$. A eficiència termodinămica $E$ de um motor $E$ a razăo entre o trabalho realizado num óclo completo e o calor produzido na combustāo. A eficiéncia termo-

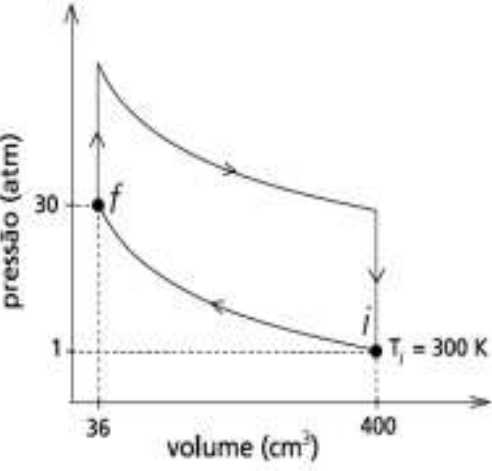
dinámica é funçăo da razāo de compressáo e é dada por: $E \Xi 1-\frac{1}{\sqrt{r}}$

a) Quais são as eficiências termodinâmicas dos motores a álcool e a gasolina?

b) A pressáo $P$, o volume $V$ e a temperatura absoluta $T$ de um gás ideal satisfazem a relaçăo $\frac{P V}{T}=$ constante. Encontre a temperatura da mistura ar-álcool após a compressáo (ponto $f$ do diagrama). Considere a mistura como um gás ideal.

Dados: $\sqrt{7} \cong \frac{8}{3} ; \sqrt{9}=3 ; \sqrt{11} \cong \frac{10}{3} ; \sqrt{13} \cong \frac{18}{5}$

(COMVEST/UNICAMP-(CG), 2007, questão 6)

O texto da questão descreve as propriedades observáveis na ilustração, tornando o entendimento do texto e da imagem uma unidade indivisível. 
As análises das questões ocorreram de acordo com a descrição de cada categoria para cada texto informado/acompanhado na questão juntamente com sua respectiva ilustração, e para isto adotou-se a interpretação que mais se adequava à categoria.

\subsubsection{Eixo 3 - A questão de química no vestibular como um todo}

\subsubsection{Assuntos químicos envolvidos nas questões}

$\mathrm{Na}$ análise das questões que continham ilustrações foram identificados no total cerca de sete grupos de assuntos químicos. A maioria das questões abordou mais de um assunto. Os grupos encontrados para todos os exames vestibulares analisados nos anos de 2007 a 2011 foram: 1) Físico-química, 2) Química orgânica, 3) Química inorgânica, 4) Química geral, 5) Bioquímica, 6) Química nuclear e 7) Meio Ambiente. Este último foi incluído como assunto, pois é tratado no Ensino Básico, nos exames vestibulares e nas provas do ENEM como tema que envolve amplamente conteúdos e assuntos químicos ambientais. O grupo de Química geral inclui questões que podem ser resolvidas apenas com conteúdos e princípios básicos da química.

Cada grupo engloba um conjunto de assuntos químicos, conforme mostrado na tabela 13 . 
Tabela 13 - Assuntos químicos que foram agrupados

\section{Grupos}

Físico-química

Cinética, Eletroquímica, Termodinâmica, Equilíbrio.

Química Orgânica

Funções Orgânicas, Reações Orgânicas, Isomeria.

Química Inorgânica

Funções Inorgânicas, Reações Inorgânicas.

Estequiometria, Ligação Química, Modelos Atômicos,

História da Química, Ácidos e Bases Arrhenius, Ácidos e

Química Geral

Bases Bronsted, Ácidos e Bases Lewis, Separação misturas,

Soluções, Elementos Químicos, Solubilidade, Analítica,

Espectroscopia UV, Forças Intermoleculares, Estrutura química.

Bioquímica

Reações com biomoléculas, Metabolismo, Carboidratos, Lipídios, Proteínas.

Química Nuclear

Reações Nucleares, Radioatividade, Decaimento Radioativo.

Meio Ambiente (temas

Química Ambiental, Reciclagem, Tipos de Energia. ambientais)

No processo de classificação, uma mesma questão pode apresentar mais de um assunto, o que é frequente. Um exemplo de questão que apresenta mais de um assunto químico envolvido é apresentado no quadro 4. 
Quadro 4 - Exemplo de questão que envolve mais de um assunto químico (FUVEST/USP-(ES), 2009, questão 02).

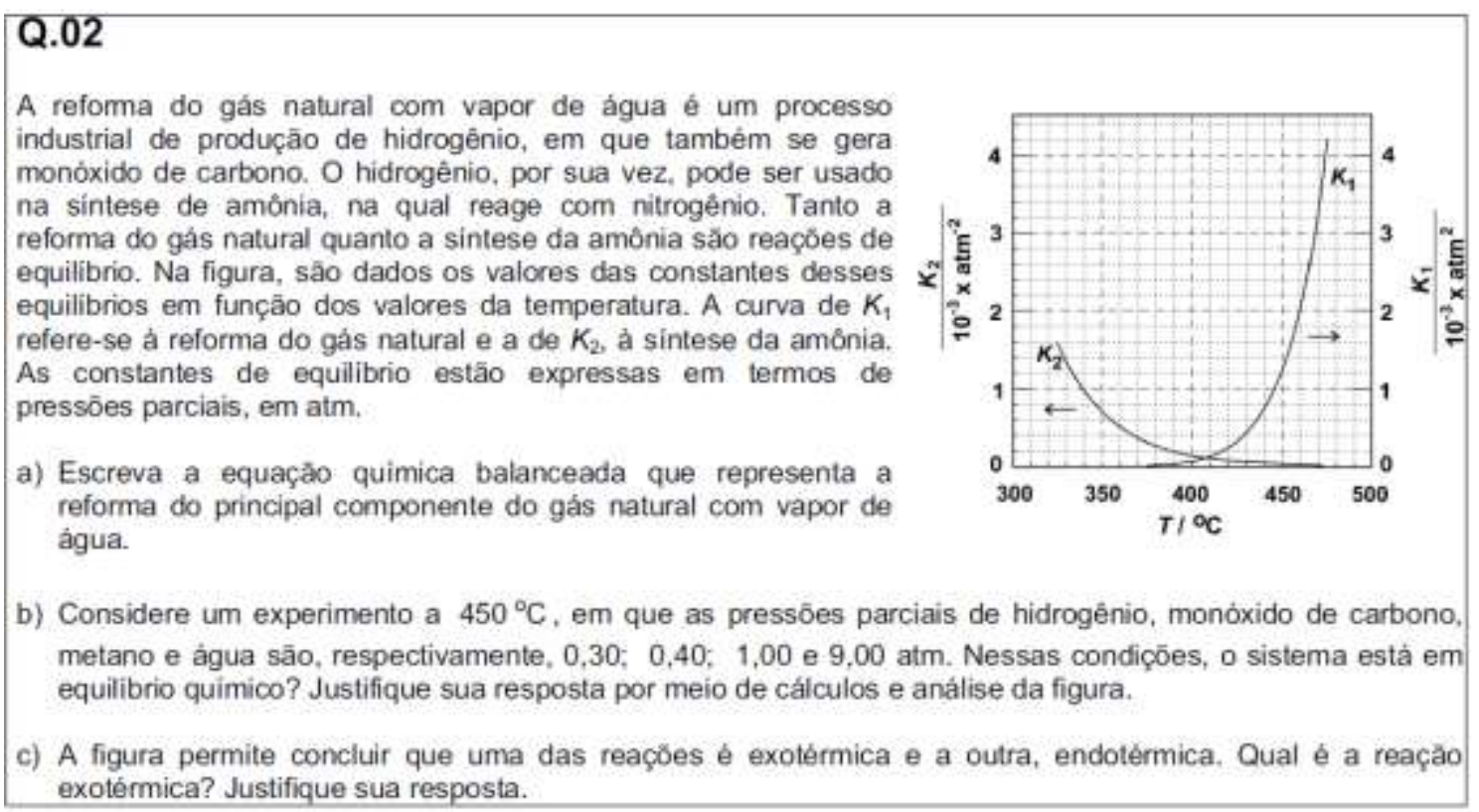

A questão apresenta os assuntos de estequiometria e equilíbrio químico. Este último é abordado do ponto de vista termodinâmico no tocante ao deslocamento de equilíbrio em função da temperatura.

\subsubsection{Habilidades cognitivas requisitadas nas questões segundo Zoller}

As questões selecionadas de cada prova vestibular foram analisadas quanto à ordem das habilidades cognitivas segundo Zoller (HOCS ou LOCS). Para isto, observou-se o assunto tratado na questão e as operações mentais solicitadas para resolvê-la. O quadro 5 exemplifica uma questão que mobiliza LOCS encontrada na prova do ENEM no ano de 2011. 
Quadro 5 - Exemplo de questão que mobiliza habilidades cognitivas de baixa ordem (LOCS) (ENEM, 2011, questão 80).

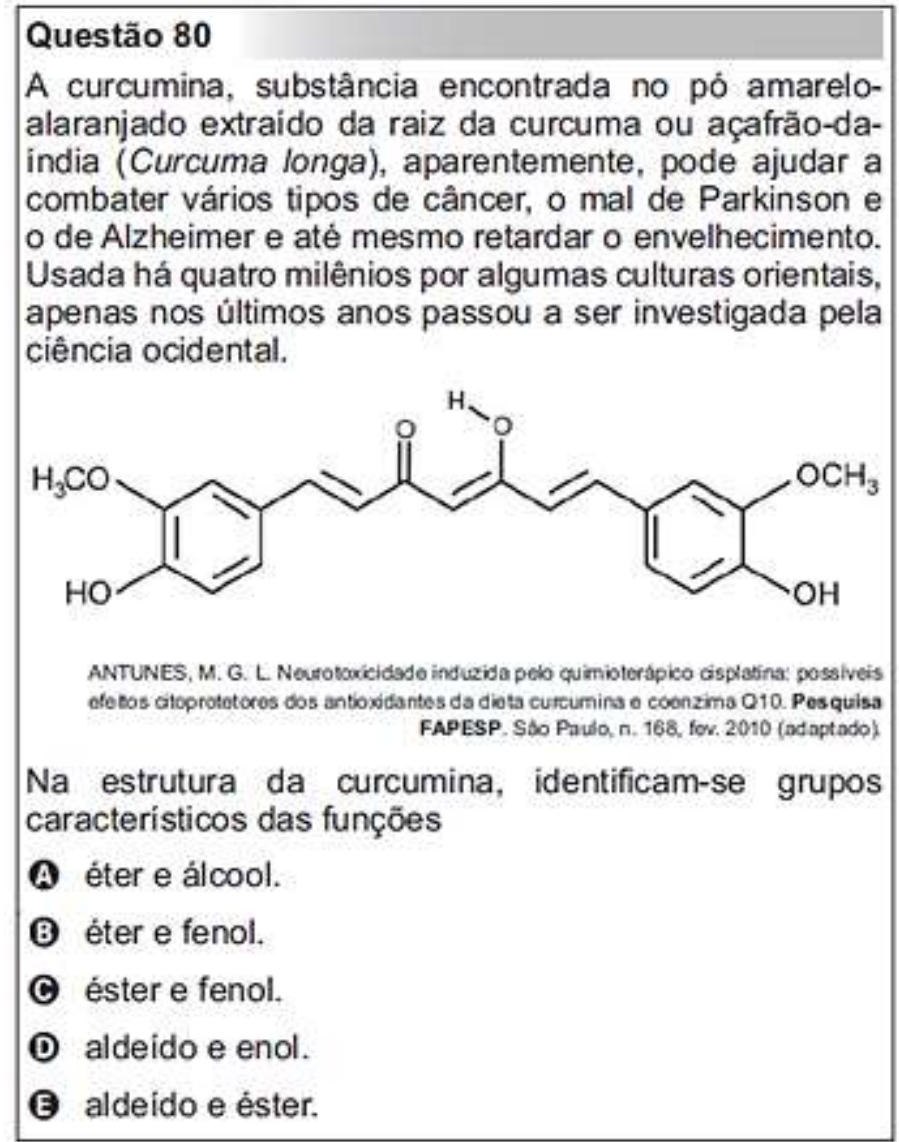

Esta questão assemelha-se ao exemplo de questão que demanda LOCS apresentado no quadro 1 (exercício número 2) analisada por Zoller, em que envolvem conceitos relacionados à química orgânica. A resolução desta questão em específico não implica a utilização de um questionamento ou raciocínio lógico, mas apenas identificar as funções orgânicas da molécula, que pode ser resolvido através da memorização. Esta questão mobiliza a aplicação simples de algoritmos conhecidos para o aluno, sendo necessária apenas a aplicação de teorias familiares ao aluno, exemplificando a categorização realizada para uma questão que requer LOCS.

O quadro 6 indica um exemplo de questão que mobiliza HOCS retirada de uma das provas analisadas. 
Quadro 6 - Exemplo de questão que mobiliza habilidade cognitiva de alta ordem (COMVEST/UNICAMP-(ES), 2007, questão 02).

2. Os agentes organofosforados tiveram grande desenvolvimento durante a segunda guerra mundial nas pesquisas que visavam à produçào de armas quimicas. Mais tarde, constatou-se que alguns desses compostos, em baixas concentraçoes, poderiam ser usados como pesticidas. Dentre essas substancias destacou-se o glifosato (molecula abaixo representada), um herbicida que funciona inibindo a via de sintese do ácido chiquimico (ácido $3,4,5$-trihidroxi-benzoico), um intermediário vital no processo de crescimento e sobrevivencia de plantas que competem com a cultura de interesse. Essa via de sintese está presente em plantas superiores, algas e protozoários, mas é ausente nos mamiferos, peixes, passaros, répteis e insetos.<smiles>O=C(O)CNCP(=O)(O)O</smiles>

a) Ao se dissolver o glifosato em água, a soluça final tera um $\mathrm{pH}$ maior, menor ou igual ao da água antes da dissoluçào? Escreva uma equaçăo química que justifique a sua resposta.

b) O texto fala do ácido chiquimico. Escreva a sua formula estrutural, de acordo com seu nome oficial dado no texto.

c) Imagine uma propaganda nos seguintes termos: "USE O GLIFOSATO NO COMBATEA MALARIA. MATEO Plasmodium falciparum, O PARASITA DO INSETO RESPONSAVEL POR ESSA DOENÇA". De acordo com as informaçoes do texto essa propaganda poderia ser verdadeira? Comece respondendo com SIM ou NĂO e justifique.

Neste quadro pode-se notar que o estudante deve, além de identificar grupos funcionais, relacioná-los com a reatividade do composto. No item (c), há necessidade de argumentação crítica para a resolução com base nas informações contidas no texto. Questões em que o estudante não encontra um formato antes conhecido ou já trabalhado em sala de aula transformam-se em "problemas originais", fazendo com que a teoria já conhecida seja aplicada em situações desconhecidas. Assim categorizaram-se questões como esta em questões que mobilizam habilidades cognitivas de alta ordem, HOCS. 


\section{RESULTADOS E DISCUSSÃO}

A seguir são apresentados os resultados para os três eixos a partir das análises das questões com ilustrações dos exames vestibulares estudados.

\subsection{Eixo 1 - A representação visual em si}

\section{Tipos de ilustrações}

Neste estudo, foram identificados doze tipos de ilustrações, como esquemas, fluxogramas, diagramas, gráficos, dentre outros já citados na tabela 8 .

As imagens que representam as dimensões submicroscópica, macroscópica e simbólica auxiliam na compreensão do assunto químico abordado no texto da questão.

A tabela 14 apresenta a ocorrência dos diferentes tipos de ilustração presentes nas questões da primeira fase e segunda fase para os exames vestibulares, cumulativo para todos os anos. As categorias de tipos de ilustração foram agrupadas segundo a sua relação com as dimensões representacionais propostas por Johnstone (1993). 
Tabela 14 - Ocorrência dos tipos de ilustração encontrados nas questões da primeira e segunda fase dos exames vestibulares das cinco universidades paulistas e ENEM nos anos de 2007 a 2011.

\begin{tabular}{|c|c|c|c|}
\hline \multirow[b]{2}{*}{ Tipo de ilustração } & \multicolumn{3}{|c|}{ Ocorrência nas Questões, \% } \\
\hline & $\begin{array}{c}\mathbf{C G}^{\mathbf{1}} \\
n=172\end{array}$ & $\begin{array}{c}\mathbf{E S}^{\mathbf{2}} \\
n=137\end{array}$ & $\begin{array}{c}\text { Total } \\
n=309\end{array}$ \\
\hline \multicolumn{4}{|c|}{ Representações Visuais variadas } \\
\hline Figura & 17 & 11 & 14 \\
\hline Esquema & 3 & 7 & 5 \\
\hline Fluxograma & 1 & 1 & 1 \\
\hline Sub-total & 21 & 19 & 20 \\
\hline \multicolumn{4}{|c|}{ Representação da dimensão Simbólica } \\
\hline Equação & 20 & 27 & 24 \\
\hline Tabela & 13 & 12 & 13 \\
\hline Gráficos & 12 & 12 & 12 \\
\hline Diagramas & 4 & 0 & 1 \\
\hline Sub-total & 49 & 51 & 50 \\
\hline \multicolumn{4}{|c|}{ Representação da dimensão Submicroscópica } \\
\hline 2D mistos ${ }^{3}$ & 17 & 18 & 17 \\
\hline 2D Explícito ${ }^{4}$ & 9 & 11 & 10 \\
\hline Molécula 3D 5 & 2 & 0 & 1 \\
\hline 2D Implícito ${ }^{6}$ & 1 & 1 & 1 \\
\hline Estrutura Molecular Esquemática & 1 & 0 & 1 \\
\hline Sub-total & 30 & 30 & 30 \\
\hline \multicolumn{4}{|c|}{ 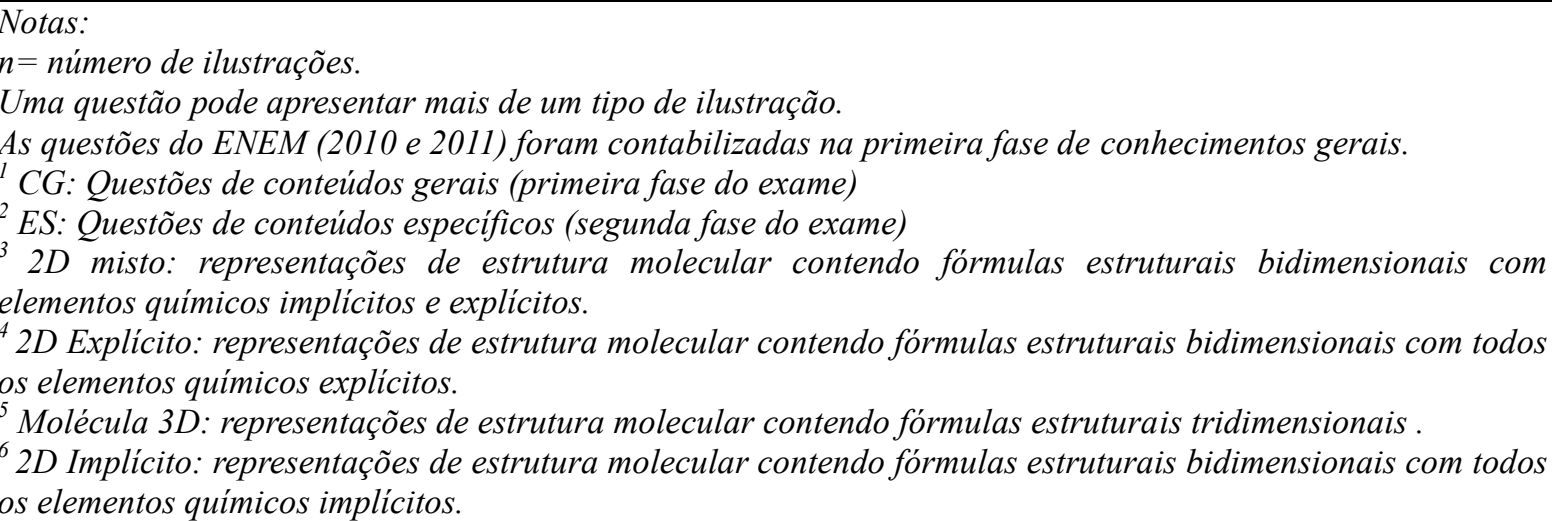 } \\
\hline
\end{tabular}

Os tipos de ilustração mais frequentes na primeira fase de todas as universidades foram "equação" e os modelos "2D mistos", com $20 \%$ e $17 \%$ das ocorrências, respectivamente (tabela 14). O mesmo ocorreu na segunda fase de todos os exames, “equação" com $27 \%$, e os modelos “2D mistos” com 18\% das ocorrências.

A tabela 15 indica os resultados da análise dos tipos de ilustração individuais para cada universidade paulista para a primeira fase de conhecimentos gerais (CG), e a tabela 16 para a segunda fase de conhecimentos específicos (ES). 
Tabela 15 - Ocorrência dos tipos de ilustração encontrados em questões de conhecimentos gerais (primeira fase) dos exames vestibulares de cada universidade e ENEM nos anos de 2007 a 2011.

\begin{tabular}{|c|c|c|c|c|c|c|}
\hline \multirow[b]{2}{*}{ Tipos de ilustração } & \multicolumn{5}{|c|}{ Ocorrência nas Questões, \% } & \multirow[b]{2}{*}{$\begin{array}{c}\text { ENEM } \\
n=22\end{array}$} \\
\hline & $\begin{array}{c}\text { USP } \\
n=44\end{array}$ & $\begin{array}{c}\text { UNICAMP } \\
n=6\end{array}$ & $\begin{array}{c}\text { UNESP } \\
n=60\end{array}$ & $\begin{array}{c}\text { UFSCAR } \\
n=11\end{array}$ & $\begin{array}{c}\text { UNIFESP } \\
n=29\end{array}$ & \\
\hline \multicolumn{7}{|c|}{ Representações Visuais variadas } \\
\hline Figura & 11 & 0 & 22 & 0 & 21 & 27 \\
\hline Esquema & 5 & 0 & 2 & 0 & 3 & 9 \\
\hline Fluxograma & 0 & 0 & 0 & 9 & 3 & 0 \\
\hline Sub-total & 16 & 0 & 24 & 9 & 27 & 36 \\
\hline \multicolumn{7}{|c|}{ Representação da dimensão Simbólica } \\
\hline Equação & 32 & 0 & 22 & 18 & 3 & 18 \\
\hline Gráficos & 7 & 33 & 12 & 9 & 17 & 9 \\
\hline Tabela & 7 & 17 & 15 & 27 & 10 & 14 \\
\hline Diagramas & 7 & 17 & 3 & 0 & 0 & 5 \\
\hline Sub-total & 53 & 67 & 52 & 54 & 30 & 46 \\
\hline \multicolumn{7}{|c|}{ Representação da dimensão Submicroscópica } \\
\hline 2D mistos ${ }^{1}$ & 20 & 17 & 12 & 18 & 24 & 18 \\
\hline 2D Explícito² & 5 & 17 & 10 & 18 & 17 & 0 \\
\hline Molécula 3D³ & 5 & 0 & 2 & 0 & 0 & 0 \\
\hline 2D Implícito & 0 & 0 & 2 & 0 & 0 & 0 \\
\hline Estrutura Molecular Esquemática & 2 & 0 & 0 & 0 & 0 & 0 \\
\hline Sub-total & 32 & 34 & 26 & 36 & 41 & 18 \\
\hline \multicolumn{7}{|c|}{$\begin{array}{l}\text { Notas: } \\
n=\text { número de ilustrações. } \\
\text { Uma questão pode apresentar mais de um tipo de ilustração. } \\
{ }^{2} 2 D \text { misto: representações de estrutura molecular contendo fórmulas estruturais bidimensionais com elementos } \\
\text { químicos implícitos e explicitos. } \\
{ }^{2} 2 D \text { Explícito: representações de estrutura molecular contendo fórmulas estruturais bidimensionais com todos os } \\
\text { elementos quimicos explicitos. } \\
{ }^{3} \text { Molécula } 3 D: \text { representações de estrutura molecular contendo fórmulas estruturais tridimensionais. } \\
{ }^{2} 2 D \text { Implícito: representações de estrutura molecular contendo fórmulas estruturais bidimensionais com todos os } \\
\text { elementos quimicos implicitos. }\end{array}$} \\
\hline
\end{tabular}


Tabela 16 - Ocorrência dos tipos de ilustração encontrados em questões de conhecimentos específicos (segunda fase) dos exames vestibulares de cada universidade nos anos de 2007 a 2011.

\begin{tabular}{|c|c|c|c|c|c|}
\hline \multirow[b]{2}{*}{ Tipos de ilustração } & \multicolumn{5}{|c|}{ Ocorrência nas Questões, \% } \\
\hline & $\begin{array}{c}\text { USP } \\
n=55\end{array}$ & $\begin{array}{c}\text { UNICAMP } \\
n=27\end{array}$ & $\begin{array}{c}\text { UNESP } \\
n=23\end{array}$ & $\begin{array}{c}\text { UFSCAR } \\
n=2\end{array}$ & $\begin{array}{c}\text { UNIFESP } \\
n=30\end{array}$ \\
\hline \multicolumn{6}{|c|}{ Representações Visuais variadas } \\
\hline Esquema & 2 & 15 & 9 & 0 & 3 \\
\hline Figura & 5 & 19 & 4 & 50 & 20 \\
\hline Fluxograma & 2 & 0 & 0 & 0 & 3 \\
\hline Sub-total & 9 & 34 & 13 & 50 & 26 \\
\hline \multicolumn{6}{|c|}{ Representação da dimensão Simbólica } \\
\hline Equação & 29 & 15 & 43 & 0 & 23 \\
\hline Tabela & 15 & 11 & 13 & 0 & 10 \\
\hline Gráficos & 13 & 22 & 0 & 0 & 10 \\
\hline Diagramas & 0 & 0 & 0 & 0 & 0 \\
\hline Sub-total & 57 & 48 & 56 & 0 & 43 \\
\hline \multicolumn{6}{|c|}{ Representação da dimensão Submicroscópica } \\
\hline 2D mistos ${ }^{1}$ & 15 & 15 & 17 & 50 & 27 \\
\hline 2D Implícito ${ }^{2}$ & 20 & 4 & 9 & 0 & 3 \\
\hline 2D Explícito ${ }^{3}$ & 0 & 0 & 4 & 0 & 0 \\
\hline Molécula 3D ${ }^{4}$ & 0 & 0 & 0 & 0 & 0 \\
\hline Estrutura Molecular Esquemática & 0 & 0 & 0 & 0 & 0 \\
\hline Sub-total & 35 & 19 & 30 & 50 & 30 \\
\hline \multicolumn{6}{|c|}{$\begin{array}{l}\text { Notas: } \\
n=\text { número de ilustrações. } \\
\text { Uma questão pode apresentar mais de um tipo de ilustração. } \\
{ }^{12 D} \text { misto: representações de estrutura molecular contendo fórmulas estruturais bidimensionais com elementos } \\
\text { químicos implicitos e explícitos. } \\
22 D \text { Implícito: representações de estrutura molecular contendo fórmulas estruturais bidimensionais com todos } \\
\text { os elementos químicos implícitos. } \\
{ }^{3} 2 D \text { Explicito: representações de estrutura molecular contendo fórmulas estruturais bidimensionais com todos } \\
\text { os elementos químicos explícitos. } \\
{ }^{4} \text { Molécula } 3 D: \text { representaçôes de estrutura molecular contendo fórmulas estruturais tridimensionais. }\end{array}$} \\
\hline
\end{tabular}

Da análise dos dados presentes nas tabelas 15 e 16, salienta-se:

- as questões dos exames apresentam múltiplas formas de representação, com predominância das dimensões simbólica e submicroscópica. Nas provas de conhecimentos gerais o exame do ENEM destaca-se dos demais exames por apresentar ocorrência de $36 \%$ de ilustrações com dimensão variada.

- o vestibular da COMVEST/UNICAMP apresentou 67\% das ocorrências para ilustrações na dimensão simbólica na primeira fase, e a FUVEST/USP 57\% na segunda fase. Para a dimensão submicroscópica, a VUNESP/UNIFESP teve predominância entre os demais exames na fase de conhecimentos gerais, com $41 \%$ das ocorrências.

- à exceção do exame adotado pela UNIFESP (30\% na primeira fase $43 \%$ na segunda) 
e da UFSCAR (sem ocorrências na segunda fase), há predominância de representações referentes à dimensão simbólica, contudo, cada exame é distinto quanto aos tipos de representações predominantes neste grupo.

- em relação à variação nos tipos de representação na dimensão representacional simbólica, nota-se que os exames da FUVESP/USP e VUNESP/UNESP diferem dos demais por haver predomínio de "equação" para representar as reações fornecidas nas questões, tanto nas provas de conhecimentos gerais quanto de conhecimentos específicos.

- o vestibular da COMVEST/UNICAMP destaca-se dos demais exames por ser o único que nas duas fases de conhecimentos das provas não indica a categoria "equação" como categoria mais frequente, havendo uma melhor distribuição dos outros tipos de ilustração.

- é notável que a ocorrência e a distribuição dos tipos de ilustração na dimensão representacional submicroscópica seja similar em todos os exames analisados, com clara predominância de representações bidimensionais da estrutura molecular. Ressalta-se contudo que (nas provas de conhecimentos gerais) no caso do exame da FUVEST/USP há, assim como no caso da dimensão representacional simbólica, predominância de um tipo de representação (representações bidimensionais com elementos químicos implícitos e explícitas).

- outro ponto importante observado nestas tabelas é que a categoria "Molécula 3D" (representando a ilustração de moléculas tridimensionais) é pouco utilizada em provas vestibulares, ocorrendo somente nas provas vestibulares da FUVEST/USP e VUNESP/UNESP em exames de conhecimentos gerais (CG).

- nas provas do ENEM, a categoria "figura" foi mais frequentes $(27 \%)$ no grupo de representações variadas.

As tabelas 17, 18, 19, 20, 21 e 22 indicam os resultados individuais para cada instituição de ensino superior e ENEM, da análise dos tipos de ilustração encontrados nas provas entre os anos 2007 e 2011. 


\section{FUVEST/USP}

Tabela 17 - Resultado dos tipos de ilustração encontrado na primeira fase (CG) e segunda fase (ES) dos exames vestibulares da FUVEST/USP de 2007 a 2011.

\begin{tabular}{|c|c|c|c|c|c|c|c|c|c|c|c|}
\hline \multirow{3}{*}{$\begin{array}{c}\text { Tipos de } \\
\text { ilustração }\end{array}$} & \multicolumn{11}{|c|}{ Ocorrência dos tipos de ilustração para cada ano, para cada prova, \% } \\
\hline & \multicolumn{5}{|c|}{$\mathrm{CG}$} & \multicolumn{5}{|c|}{\begin{tabular}{|l|l} 
ES \\
\end{tabular}} & \multirow{2}{*}{$\begin{array}{l}\text { Total } \\
n=99\end{array}$} \\
\hline & 2007 & 2008 & 2009 & 2010 & 2011 & 2007 & 2008 & 2009 & 2010 & 2011 & \\
\hline \multicolumn{12}{|c|}{ Representações visuais variadas } \\
\hline Figura & 0 & 8 & 17 & 11 & 40 & 0 & 0 & 17 & 0 & 12 & 7 \\
\hline Esquema & 0 & 0 & 0 & 11 & 20 & 0 & 0 & 0 & 0 & 12 & 7 \\
\hline Fluxograma & 0 & 0 & 0 & 0 & 0 & 0 & 0 & 0 & 9 & 0 & 1 \\
\hline Sub-total & 0 & 8 & 17 & 22 & 60 & 0 & 0 & 17 & 9 & 24 & 15 \\
\hline \multicolumn{12}{|c|}{ Representação da dimensão Simbólica } \\
\hline Equação & 42 & 50 & 17 & 22 & 0 & 40 & 29 & 25 & 27 & 25 & 30 \\
\hline Tabela & 0 & 0 & 0 & 33 & 0 & 20 & 21 & 8 & 19 & 0 & 11 \\
\hline Gráficos & 8 & 17 & 0 & 0 & 0 & 20 & 7 & 17 & 9 & 12 & 10 \\
\hline Diagramas & 17 & 0 & 17 & 0 & 0 & 0 & 0 & 0 & 0 & 0 & 3 \\
\hline Sub-total & 67 & 67 & 34 & 55 & 0 & 80 & 57 & 50 & 55 & 37 & 54 \\
\hline \multicolumn{12}{|c|}{ Representação da dimensão Submicroscópica } \\
\hline 2D Misto ${ }^{1}$ & 17 & 17 & 33 & 22 & 20 & 10 & 7 & 8 & 27 & 25 & 17 \\
\hline 2D Explícito² & 8 & 0 & 17 & 0 & 0 & 10 & 36 & 25 & 9 & 12 & 13 \\
\hline Molécula3D 3 & 8 & 0 & 0 & 0 & 20 & 0 & 0 & 0 & 0 & 0 & 2 \\
\hline 2D Implícito & 0 & 0 & 0 & 0 & 0 & 0 & 0 & 0 & 0 & 0 & 0 \\
\hline Estrutura & & & & & & & & & & & \\
\hline $\begin{array}{l}\text { Molecular } \\
\text { Esquemática }\end{array}$ & 0 & 8 & 0 & 0 & 0 & 0 & 0 & 0 & 0 & 0 & 1 \\
\hline Sub-total & 33 & 25 & 50 & 22 & 40 & 20 & 43 & 33 & 36 & 37 & 33 \\
\hline $\begin{array}{l}\text { Notas: } \\
n=\text { número de il } \\
\text { Uma questão po } \\
{ }^{2} 2 \mathrm{D} \text { misto: repre } \\
\text { químicos implic } \\
{ }^{2} \mathrm{D} \text { Explícito: } r \\
\text { os elementos qu} \\
{ }^{3} \text { Molécula } 3 D:{ }^{2} \\
{ }^{4} 2 \mathrm{D} \text { Implícito: } r \\
\text { os elementos qu}\end{array}$ & $\begin{array}{l}\text { atações } \\
\text { e explic } \\
\text { esentaç } \\
\text { cos expl } \\
\text { esentaç } \\
\text { esentaç }\end{array}$ & $\begin{array}{l}\text { ar mais } \\
\text { le estrut } \\
\text { itos. } \\
\text { es de e. } \\
\text { citos. } \\
\text { es de es } \\
\text { es de e. } \\
\text { citos. }\end{array}$ & $\begin{array}{l}\text { de um ti } \\
\text { ira mol } \\
\text { trutura } \\
\text { rutura } \\
\text { trutura }\end{array}$ & $\begin{array}{l}\text { oo de il } \\
\text { cular ce } \\
\text { nolecul } \\
\text { noleculc } \\
\text { nolecul }\end{array}$ & $\begin{array}{l}\text { traçãe } \\
\text { ntendo } \\
\text { conte } \\
\text { conte }\end{array}$ & $\begin{array}{l}\text { fórmulas } \\
\text { do fórm } \\
\text { do fórm } \\
\text { ndo fórm }\end{array}$ & $\begin{array}{l}\text { estrutur } \\
\text { llas est } \\
\text { las estr } \\
\text { ulas est }\end{array}$ & $\begin{array}{l}\text { is bidir } \\
\text { tturais } \\
\text { turais } t \\
\text { tturais }\end{array}$ & $\begin{array}{l}\text { ensiona } \\
\text { idimens } \\
\text { dimens } \\
\text { idimens }\end{array}$ & $\begin{array}{l}\text { s com e } \\
\text { onais c } \\
\text { onais. } \\
\text { onais c }\end{array}$ & $\begin{array}{l}\text { ementos } \\
\text { m todos } \\
\text { m todos }\end{array}$ \\
\hline
\end{tabular}

Os resultados oriundos da tabela 17 indicam que, para os vestibulares da FUVEST/USP:

- no grupo das representações visuais variadas, os anos 2007, 2008 e 2009 não apresentaram ocorrências de "esquema" e "fluxograma". Em ambas as fases, a categoria "figura" foi a mais frequente, principalmente nos anos de 2009 e 2011.

- na dimensão representacional simbólica, a categoria "equação" é a mais frequente nas provas $(30 \%)$. 
- as ilustrações de estruturas moleculares do tipo "2D mistos" foi a única categoria frequente em todas as provas e fases dos exames durante os cinco anos analisados.

- $\quad$ somente no ano 2009, nas provas de conhecimentos gerais, o total de ocorrências da dimensão submicroscópica teve predominância quando comparada com as ocorrências da dimensão simbólica e do grupo das representações variadas, sendo caracterizada pelo predomínio de ilustrações que abordam as representações submicrosópicas da matéria nas questões.

- os resultados mostram ainda que nos anos de 2010 e 2011 houve diminuição do número total de ilustrações presentes nas questões em relação aos anos anteriores analisados. 


\section{COMVEST/UNICAMP}

Tabela 18 - Resultado dos tipos de ilustração encontrado na primeira fase (CG) e segunda fase (ES) dos exames vestibulares da COMVEST/UNICAMP de 2007 a 2011.

\begin{tabular}{|c|c|c|c|c|c|c|c|c|c|c|}
\hline \multirow{4}{*}{$\begin{array}{l}\text { Tipos de } \\
\text { ilustração }\end{array}$} & \multicolumn{10}{|c|}{ Ocorrência dos tipos de ilustração para cada ano, para cada prova, \% } \\
\hline & \multicolumn{4}{|c|}{ CG } & \multicolumn{5}{|c|}{ ES } & \multirow{3}{*}{$\begin{array}{l}\text { Total } \\
n=33\end{array}$} \\
\hline & 2007 & 2008 & 2009 & 2010 & 2007 & 2008 & 2009 & 2010 & 2011 & \\
\hline & $n=1$ & $n=2$ & $n=1$ & $n=2$ & $n=5$ & $n=3$ & $n=8$ & $n=6$ & $n=5$ & \\
\hline \multicolumn{11}{|c|}{ Representações visuais variadas } \\
\hline Figura & 0 & 0 & 0 & 0 & 0 & 67 & 12 & 17 & 20 & 15 \\
\hline Esquema & 0 & 0 & 0 & 0 & 40 & 0 & 12 & 17 & 0 & 12 \\
\hline Fluxograma & 0 & 0 & 0 & 0 & 0 & 0 & 0 & 0 & 0 & 0 \\
\hline Sub-total & 0 & 0 & 0 & 0 & 0 & 67 & 12 & 17 & 20 & 27 \\
\hline \multicolumn{11}{|c|}{ Representação da dimensão Simbólica } \\
\hline Equação & 0 & 0 & 0 & 0 & 20 & 0 & 12 & 17 & 20 & 12 \\
\hline Tabela & 0 & 0 & 100 & 0 & 0 & 0 & 12 & 17 & 20 & 12 \\
\hline Gráficos & 0 & 100 & 0 & 0 & 20 & 0 & 37 & 33 & 0 & 24 \\
\hline Diagramas & 100 & 0 & 0 & 0 & 0 & 0 & 0 & 0 & 0 & 3 \\
\hline Sub-total & 100 & 100 & 100 & 0 & 40 & 0 & 61 & 67 & 40 & 51 \\
\hline \multicolumn{11}{|c|}{ Representação da dimensão Sub-microscópica } \\
\hline 2D Misto ${ }^{1}$ & 0 & 0 & 0 & 50 & 0 & 1 & 12 & 0 & 40 & 15 \\
\hline 2D Explícito² & 0 & 0 & 0 & 50 & 20 & 0 & 0 & 0 & 0 & 6 \\
\hline Molécula3D³ & 0 & 0 & 0 & 0 & 0 & 0 & 0 & 0 & 0 & 0 \\
\hline 2D Implícito ${ }^{4}$ & 0 & 0 & 0 & 0 & 0 & 0 & 0 & 0 & 0 & 0 \\
\hline Estrutura & & & & & & & & & & \\
\hline $\begin{array}{l}\text { Molecular } \\
\text { Esquemática }\end{array}$ & 0 & 0 & 0 & 0 & 0 & 0 & 0 & 0 & 0 & 0 \\
\hline Sub-total & 0 & 0 & 0 & 100 & 20 & 33 & 12 & 0 & 40 & 21 \\
\hline \multicolumn{11}{|c|}{$\begin{array}{l}\text { Notas: } \\
n=\text { número de ilustrações. } \\
\text { Uma questão pode apresentar mais de um tipo de ilustração. } \\
{ }^{2} 2 D \text { misto: representações de estrutura molecular contendo fórmulas estruturais bidimensionais com elementos } \\
\text { químicos implicitos e explícitos. } \\
22 D \text { Explícito: representações de estrutura molecular contendo fórmulas estruturais bidimensionais com todos os } \\
\text { elementos químicos explícitos. } \\
{ }^{3} \text { Molécula } 3 D: \text { representações de estrutura molecular contendo fórmulas estruturais tridimensionais. } \\
{ }^{4} 2 D \text { Implícito: representaçoes de estrutura molecular contendo fórmulas estruturais bidimensionais com todos os } \\
\text { elementos químicos implícitos. }\end{array}$} \\
\hline
\end{tabular}

Para o vestibular da COMVEST/UNICAMP observou-se que:

- o vestibular no ano de 2011 não apresentou questões com ilustrações na prova de conhecimentos gerais.

- diferentemente das demais instituições de ensino superior analisadas, de modo geral, a categoria "equação" não foi a mais frequente, sendo as categorias mais frequentes "gráfico", seguido de "figura" e moléculas "2D mistos".

- no intervalo de tempo analisado, a categoria "tabela" passam a ocorrer nas questões 
dos exames a partir de 2009.

- as provas de conhecimentos gerais não apresentaram ocorrências relativas ao grupo das representações visuais variadas, tais quais as categorias "figura", "fluxograma" e "esquema".

\section{VUNESP/UFSCAR}

Tabela 19 - Resultado dos tipos de ilustração encontrado na primeira fase (CG) e segunda fase (ES) dos exames vestibulares da VUNESP/UFSCAR de 2007 a 2011.

\begin{tabular}{|c|c|c|c|c|c|}
\hline \multirow{4}{*}{ Tipos de ilustração } & \multicolumn{5}{|c|}{$\begin{array}{l}\text { Ocorrência dos tipos de ilustração para cada ano, para cada } \\
\text { prova, \% }\end{array}$} \\
\hline & \multicolumn{3}{|c|}{ CG } & \multirow{3}{*}{$\begin{array}{c}\text { ES } \\
2010 \\
n=2\end{array}$} & \multirow{3}{*}{$\begin{array}{c}\text { Total } \\
n=13\end{array}$} \\
\hline & 2007 & 2008 & 2009 & & \\
\hline & $n=4$ & $n=5$ & $n=2$ & & \\
\hline \multicolumn{6}{|c|}{ Representações visuais variadas } \\
\hline Figura & 0 & 0 & 0 & 0 & 0 \\
\hline Esquema & 0 & 0 & 0 & 50 & 8 \\
\hline Fluxograma & 0 & 20 & 0 & 0 & 8 \\
\hline Sub-total & 0 & 20 & 0 & 50 & 16 \\
\hline \multicolumn{6}{|c|}{ Representação da dimensão Simbólica } \\
\hline Equação & 50 & 0 & 0 & 0 & 15 \\
\hline Tabela & 0 & 40 & 50 & 0 & 23 \\
\hline Gráficos & 0 & 0 & 50 & 0 & 8 \\
\hline Diagramas & 0 & 0 & 0 & 0 & 0 \\
\hline Sub-total & 50 & 40 & 0 & 0 & 46 \\
\hline \multicolumn{6}{|c|}{ Representação da dimensão Submicroscópica } \\
\hline 2D Misto ${ }^{1}$ & 25 & 20 & 0 & 50 & 23 \\
\hline 2D Explícito² & 25 & 20 & 0 & 0 & 15 \\
\hline Molécula3D 3 & 0 & 0 & 0 & 0 & 0 \\
\hline 2D Implícito ${ }^{4}$ & 0 & 0 & 0 & 0 & 0 \\
\hline $\begin{array}{l}\text { Estrutura Molecular } \\
\text { Esquemática }\end{array}$ & 0 & 0 & 0 & 0 & 0 \\
\hline $\begin{array}{l}\text { Esquematica } \\
\text { Sub-total }\end{array}$ & 50 & 40 & 0 & 50 & 38 \\
\hline \multicolumn{6}{|c|}{$\begin{array}{l}\text { Notas: } \\
n=\text { número de ilustrações. } \\
\text { Uma questão pode apresentar mais de um tipo de ilustração. } \\
{ }^{1} 2 D \text { misto: representações de estrutura molecular contendo fórmulas estruturais bidimensionais com } \\
\text { elementos químicos implícitos e explícitos. } \\
{ }^{2} 2 D \text { Explícito: representações de estrutura molecular contendo fórmulas estruturais bidimensionais com todos } \\
\text { os elementos quimicos explícitos. } \\
{ }^{3} \text { Molécula } 3 D: \text { representações de estrutura molecular contendo fórmulas estruturais tridimensionais . } \\
{ }^{4} 2 D \text { Implícito: representações de estrutura molecular contendo fórmulas estruturais bidimensionais com todos } \\
\text { os elementos quimicos implícitos. }\end{array}$} \\
\hline
\end{tabular}


A tabela 19 com os resultados para o vestibular da VUNESP/UFSCAR indicam que:

- dos doze tipos de ilustração categorizados, apenas sete foram identificados, sendo os mais frequentes, de forma geral, as categorias "tabela" e estruturas moleculares "2D Mistos", ambas com 23\% das ocorrências.

\section{VUNESP/UNESP}

Tabela 20 - Resultado dos tipos de ilustração encontrado na primeira fase (CG) e segunda fase (ES) dos exames vestibulares da VUNESP/UNESP de 2007 a 2011.

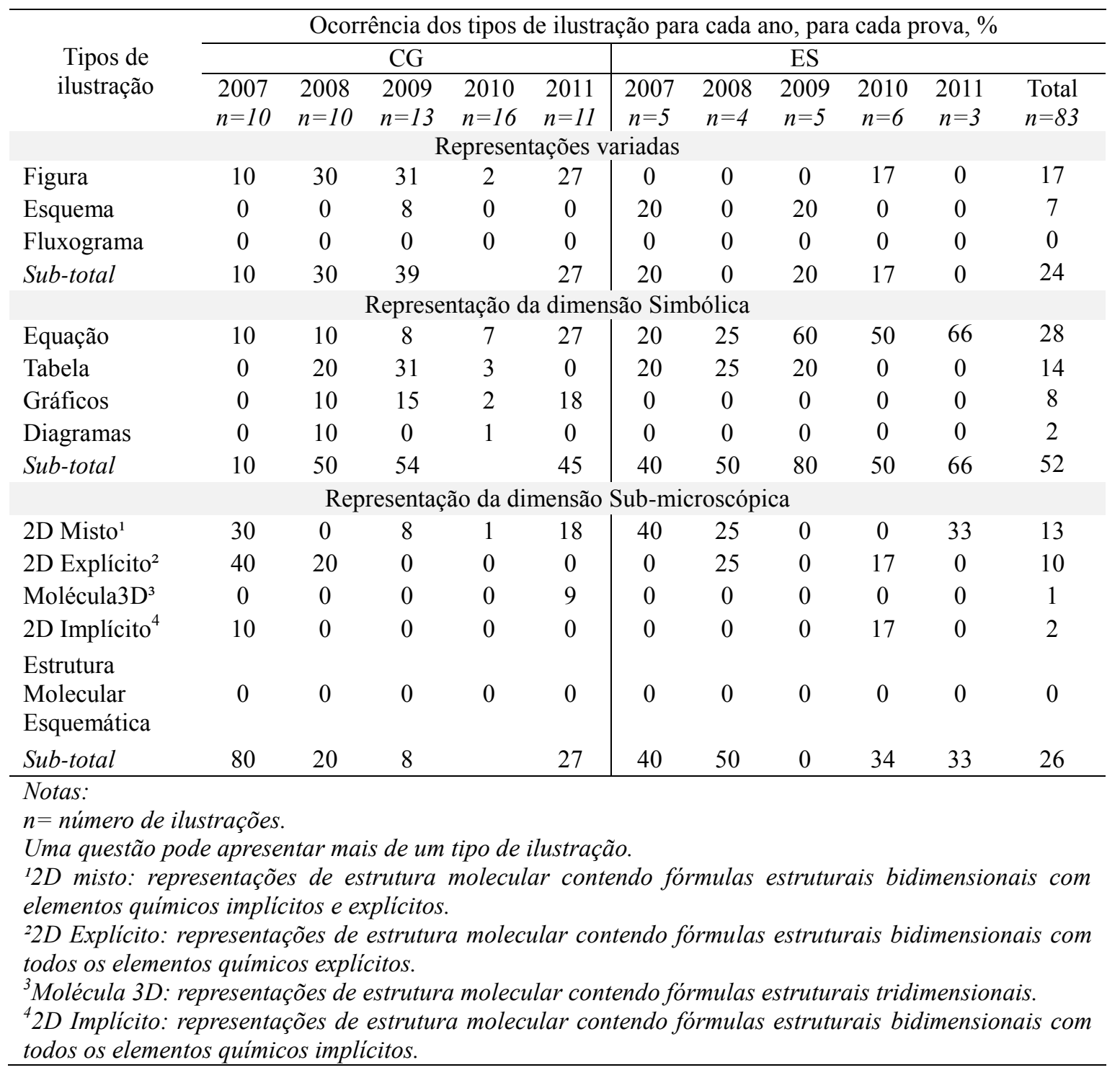


Os resultados apresentados na tabela 20 para o exame vestibular da VUNESP/UNESP indicam que:

- na representação da dimensão simbólica, observa-se que a categoria "equação" aumentou sua frequência com o passar dos anos analisados, sendo a categoria com maior ocorrência entre as demais deste grupo.

- a categoria "figura", que faz parte do grupo das representações visuais variadas, foi evidenciada altas frequências nas provas de conhecimentos gerais (CG), sendo que nas provas de conhecimentos específicos (ES) ocorreu somente no ano de 2010, apresentando $17 \%$ das ocorrências.

- de modo geral, na dimensão da representação submicroscópica, os tipos de ilustração mais frequentes foram as representações das moléculas "2D mistos" e "2D explícitas" (13\% e $10 \%)$. 


\section{VUNESP/UNIFESP}

Tabela 21 - Resultado dos tipos de ilustração encontrado na primeira fase (CG) e segunda fase (ES) dos exames vestibulares da VUNESP/UNIFESP de 2007 a 2011.

\begin{tabular}{|c|c|c|c|c|c|c|c|c|c|}
\hline \multirow{3}{*}{ Tipos de ilustração } & \multicolumn{9}{|c|}{ Ocorrência dos tipos de ilustração para cada ano, para cada prova, \% } \\
\hline & \multicolumn{3}{|c|}{$\mathrm{CG}$} & \multicolumn{5}{|c|}{ ES } & \multirow[b]{2}{*}{$\begin{array}{l}\text { Total } \\
n=59\end{array}$} \\
\hline & $\begin{array}{c}2007 \\
n=9\end{array}$ & $\begin{array}{l}2008 \\
n=11\end{array}$ & $\begin{array}{c}2009 \\
n=9\end{array}$ & $\begin{array}{c}2007 \\
n=5\end{array}$ & $\begin{array}{l}2008 \\
n=7\end{array}$ & $\begin{array}{l}2009 \\
n=5\end{array}$ & $\begin{array}{r}2010 \\
n=6\end{array}$ & $\begin{array}{l}2011 \\
n=7\end{array}$ & \\
\hline \multicolumn{10}{|c|}{ Representações visuais variadas } \\
\hline Figura & 11 & 18 & 33 & 40 & 0 & 40 & 33 & 0 & 20 \\
\hline Esquema & 0 & 0 & 11 & 0 & 14 & 0 & 0 & 0 & 3 \\
\hline Fluxograma & 11 & 0 & 0 & 20 & 0 & 0 & 0 & 0 & 3 \\
\hline Sub-total & 22 & 18 & 44 & 60 & 14 & 40 & 33 & 0 & 26 \\
\hline \multicolumn{10}{|c|}{ Representação da dimensão Simbólica } \\
\hline Equação & 0 & 9 & 0 & 20 & 14 & 20 & 33 & 28 & 14 \\
\hline Tabela & 22 & 9 & 0 & 20 & 14 & 0 & 0 & 14 & 10 \\
\hline Gráficos & 11 & 18 & 22 & 0 & 14 & 0 & 17 & 14 & 14 \\
\hline Diagramas & 0 & 0 & 0 & 0 & 0 & 0 & 0 & 0 & 0 \\
\hline Sub-total & 33 & 36 & 22 & 40 & 42 & 20 & 50 & 56 & 38 \\
\hline \multicolumn{10}{|c|}{ Representação da dimensão Submicroscópica } \\
\hline 2D Misto ${ }^{1}$ & 22 & 27 & 22 & 0 & 29 & 40 & 17 & 43 & 25 \\
\hline 2D Explícito² & 22 & 18 & 11 & 0 & 14 & 0 & 0 & 0 & 10 \\
\hline Molécula3D 3 & 0 & 0 & 0 & 0 & 0 & 0 & 0 & 0 & 0 \\
\hline 2D Implícito ${ }^{4}$ & 0 & 0 & 0 & 0 & 0 & 0 & 0 & 0 & 0 \\
\hline $\begin{array}{l}\text { Estrutura Molecular } \\
\text { Esquemática }\end{array}$ & 0 & 0 & 0 & 0 & 0 & 0 & 0 & 0 & 0 \\
\hline Sub-total & 44 & 45 & 33 & 0 & 43 & 40 & 17 & 43 & 35 \\
\hline \multicolumn{10}{|c|}{$\begin{array}{l}\text { Notas: } \\
n=\text { número de ilustrações. } \\
\text { Uma questão pode apresentar mais de um tipo de ilustração. } \\
{ }^{12 D} \text { misto: representações de estrutura molecular contendo fórmulas estruturais bidimensionais com } \\
\text { elementos químicos implícitos e explícitos. } \\
{ }^{2} 2 D \text { Explícito: representações de estrutura molecular contendo fórmulas estruturais bidimensionais com todos } \\
\text { os elementos quimicos explícitos. } \\
{ }^{3} \text { Molécula } 3 D: \text { representações de estrutura molecular contendo fórmulas estruturais tridimensionais. } \\
{ }^{4} 2 D \text { Implícito: representações de estrutura molecular contendo fórmulas estruturais bidimensionais com todos } \\
\text { os elementos quimicos implícitos. }\end{array}$} \\
\hline
\end{tabular}

Os resultados analisados para o vestibular da VUNESP/UNIFESP mostram que:

- assim como no vestibular da COMVEST/UNICAMP, para a dimensão de representações simbólicas, a categoria "equação" também não foi a mais frequente no vestibular da VUNESP/UNIFESP, mas "equação" e "gráfico", ambos com 14\%. Observa-se, neste grupo de categorias, uma distribuição mais equânime dos tipos de ilustração, durante todo o intervalo e tempo considerado.

- $\quad$ o ano de 2008 foi o que mais envolveu ilustrações em questões de química. No grupo 
de categorias da dimensão submicroscópica, os tipos mais frequentes foram as representações das fórmulas estruturais das moléculas "2D mistos" e "2D explícitas".

\section{ENEM}

Tabela 22 - Resultado dos tipos de ilustração encontrado para o ENEM nos anos 2010 e 2011.

\begin{tabular}{|c|c|c|c|}
\hline \multirow{2}{*}{ Tipos de ilustração } & \multicolumn{3}{|c|}{$\begin{array}{c}\text { Ocorrência dos tipos de ilustração para cada ano, para } \\
\text { cada prova, \% }\end{array}$} \\
\hline & $\begin{array}{l}2010 \\
n=10\end{array}$ & $\begin{array}{l}2011 \\
n=12\end{array}$ & $\begin{array}{l}\text { Total } \\
n=22\end{array}$ \\
\hline \multicolumn{4}{|c|}{ Representações visuais variadas } \\
\hline Figura & 40 & 17 & 27 \\
\hline Esquema & 10 & 8 & 9 \\
\hline Fluxograma & 0 & 0 & 0 \\
\hline Sub-total & 50 & 25 & 36 \\
\hline \multicolumn{4}{|c|}{ Representação da dimensão Simbólica } \\
\hline Equação & 10 & 25 & 18 \\
\hline Tabela & 0 & 25 & 14 \\
\hline Gráficos & 20 & 0 & 9 \\
\hline Diagramas & 0 & 8 & 5 \\
\hline Sub-total & 30 & 58 & 46 \\
\hline \multicolumn{4}{|c|}{ Representação da dimensão Submicroscópica } \\
\hline 2D Misto ${ }^{1}$ & 20 & 17 & 18 \\
\hline 2D Explícito² & 0 & 0 & 0 \\
\hline Molécula3D ${ }^{3}$ & 0 & 0 & 0 \\
\hline 2D Implícito ${ }^{4}$ & 0 & 0 & 0 \\
\hline Estrutura Molecular Esquemática & 0 & 0 & 0 \\
\hline Sub-total & 20 & 17 & 18 \\
\hline \multicolumn{4}{|c|}{$\begin{array}{l}\text { Notas: } \\
n=\text { número de ilustrações. } \\
\text { Uma questão pode apresentar mais de um tipo de ilustração. } \\
{ }^{2} 2 D \text { misto: representações de estrutura molecular contendo fórmulas estruturais bidimensionais com } \\
\text { elementos químicos implícitos e explícitos. } \\
{ }^{2} 2 D \text { Explícito: representações de estrutura molecular contendo fórmulas estruturais bidimensionais com } \\
\text { todos os elementos químicos explícitos. } \\
{ }^{3} \text { Molécula } 3 D: \text { representações de estrutura molecular contendo fórmulas estruturais tridimensionais . } \\
{ }^{4} 2 D \text { Implícito: representações de estrutura molecular contendo fórmulas estruturais bidimensionais com } \\
\text { todos os elementos químicos implícitos. }\end{array}$} \\
\hline
\end{tabular}

Os resultados para o ENEM indicam que:

- as provas dos anos analisados (2010 e 2011) apresentaram 21 questões, totalizando 22 ilustrações que foram classificadas em 7 das 12 categorias de tipos de ilustração.

- no grupo de categorias de representação da dimensão simbólica, a categoria mais frequente em 2010 foi "gráfico" com 20\% das ocorrências. No ano de 2011, as 
categorias "equação" e "tabela" foram as mais frequentes dentro deste grupo, ambas $\operatorname{com} 25 \%$.

- no grupo de representação submicroscópica, houve ocorrência apenas na categoria de representação molecular "2D mistos”, sendo 20\% das ocorrências totais em 2010 e 17\% em 2011, o que corresponde a $18 \%$ do total de ocorrências de todas as categorias identificadas nas ilustrações presentes nas provas do exame ENEM.

As distribuições das categorias de ilustrações nas provas de ensino superior tiveram resultados distintos para cada exame. Como já observado, na maioria dos exames analisados, os tipos de ilustração mais frequentes em ambas as fases foram "equação" e a representação molecular "2D mistos". Contudo, os exames elaborados pela COMVEST (UNICAMP) e pela VUNESP (UNIFESP) tiveram um resultado diferenciado dos demais exames analisados, apresentando maior ocorrência das categorias de ilustrações do tipo "figura" e "gráfico".

Por meio da análise dos resultados gerais, pode-se observar que cada grupo de categorias de imagem teve um tipo de ilustração predominante. Para o grupo da representação da dimensão simbólica foi a categoria "equação", para o grupo da representação da dimensão submicroscópica, a representação molecular "2D mistos" e para a o grupo de representação visual variada a categoria "figura".

Alguns tipos de ilustração mostraram-se menos frequentes, como é o caso das categorias "esquema", "fluxograma”, "diagramas", "estrutura molecular esquemática" e as estruturações tridimensionais na categoria "Molécula3D".

O fato se deve, possivelmente, às finalidades e as possibilidades de representação visual relacionadas a cada categoria. Tomemos como exemplo a baixa ocorrência de representações visuais tridimensionais da estrutura molecular de compostos em relação as representações bidimensionais apresentadas em todos os exames.

As representações visuais em três dimensões são usados comumente para representar as disposições dos átomos e identificar características estruturais dos compostos, como a simetria. Contudo, tais representações são de interpretação mais complexa, seja no tocante às habilidades visuais empregadas seja em relação aos aspectos conceituais envolvidos. Já as representações bidimensionais da estrutura dos compostos, embora não privilegiem a representação de características estruturais detalhadas, explicitam a 
identificação da conexão entre átomos, da identificação dos elementos químicos presentes, aspectos gerais da geometria molecular, bem como a ordem de ligações (duplas, simples etc.) e identificação de grupos funcionais.

Assim, é de se esperar, que o emprego de representações visuais tridimensionais da estrutura molecular ocorram em questões que, de fato, seu uso se faça imprescindível. Este é o caso da questão 23 do exame vestibular da FUVEST/USP no ano de 2007 (Quadro 7), em que a questão solicita os conceitos de polaridade associados à geometria molecular para a identificação de substâncias polares e apolares a partir da análise da estrutura molecular.

Quadro 7 - Exemplo de questão com representação de moléculas 3D (FUVEST/USP-(CG), 2007, questão 23).

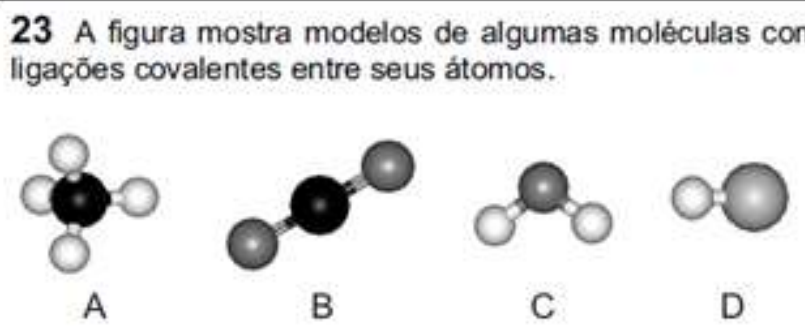

Analise a polaridade dessas moléculas, sabendo que tal propriedade depende da

- diferença de eletronegatividade entre os átomos que estăo diretamente ligados. (Nas moléculas apresentadas, átomos de elementos diferentes têm eletronegatividades diferentes.)

- forma geométrica das moléculas.

Dentre essas moléculas, pode-se afirmar que sāo polares apenas

a) $\mathrm{A}$ e B

b) $\mathrm{A} \in \mathrm{C}$

c) $A, C \in D$

d) $B, C \in D$

e) $\mathrm{C} \in \mathrm{D}$

Observaçăo:

Eletronegatividade é a

capacidade de um átomo para

atrair os elétrons da ligaçăo

covalente.

Os resultados mostram ainda que, dentre as categorias de dimensões representacionais, a mais frequente esta relacionada à dimensão simbólica, correspondendo a aproximadamente $50 \%$ das ocorrências nas provas em ambas as fases de conhecimentos em todos os exames. O grupo relacionado à dimensão submicroscópica apresentou cerca de $30 \%$ das ocorrências, e o grupo de representações variadas, $20 \%$. Ou seja, como seria esperado, a interpretação de símbolos visuais empregados na química é um fator determinante na resolução das questões vestibulares. Contudo, há uma clara predominância deste requisito em relação a interpretação de informações referentes aos aspectos 
submicroscópicos dos conceitos.

\section{Funcionalidade das ilustrações}

Na tabela 23 encontra-se os resultados gerais para a categoria de funcionalidade das ilustrações contidas nas questões das provas das universidades analisadas.

Tabela 23 - Ocorrência para a funcionalidade das ilustrações encontrada nas questões da primeira e segunda fase dos exames vestibulares das cinco universidades paulistas e ENEM nos anos de 2007 a 2011.

\begin{tabular}{|c|c|c|c|}
\hline \multirow[b]{2}{*}{ Funcionalidade } & \multicolumn{3}{|c|}{ Ocorrência nas Questões, \% } \\
\hline & $\begin{array}{c}\mathbf{C G}^{\mathbf{1}} \\
n=172\end{array}$ & $\begin{array}{c}\mathbf{E S}^{\mathbf{2}} \\
n=137\end{array}$ & $\begin{array}{c}\text { Total } \\
n=309\end{array}$ \\
\hline Sintática & 74 & 74 & 74 \\
\hline Operativas Elementares & 24 & 26 & 25 \\
\hline Inoperante & 2 & 0 & 1 \\
\hline \multicolumn{4}{|c|}{$\begin{array}{l}\text { Notas: } \\
n=\text { número de ilustrações. } \\
{ }^{1} \text { CG: Questões de conteúdos gerais (primeira fase do exame) } \\
{ }^{2} \text { ES: Questões de conteúdos especificos (segunda fase do exame) } \\
\text { Uma questão pode apresentar mais de uma ilustração. } \\
\text { As questões do ENEM (2010 e 2011) foram contabilizadas na primeira fase de } \\
\text { conhecimentos gerais. }\end{array}$} \\
\hline
\end{tabular}

Pode-se notar por estes resultados que a categoria "sintática" foi a mais frequente em ambas as fases, apresentando ilustrações que necessitam do conhecimento científico, no caso de conhecimentos químicos, para a sua interpretação. Em seguida, a categoria “operativas elementares" representando questões em que as ilustrações podem ser interpretadas por conterem representações universais do conhecimento. A categoria "inoperante" ficou com menor número de ocorrências, indicando ilustrações que não possuem elementos utilizáveis, sua função é apenas a observação.

As tabelas 24 e 25 indicam os resultados para a categoria funcionalidade das ilustrações para cada exame vestibular estudado para a primeira fase e segunda fase respectivamente. 
Tabela 24 - Ocorrência para a categoria funcionalidade das ilustrações encontrados em questões de conhecimentos gerais (primeira fase) dos exames vestibulares de cada universidade e ENEM nos anos de 2007 a 2011.

\begin{tabular}{|c|c|c|c|c|c|c|}
\hline \multirow[b]{2}{*}{ Funcionalidade } & \multicolumn{6}{|c|}{ Ocorrência nas Questões, \% } \\
\hline & $\begin{array}{c}\text { FUVEST } \\
\text { (USP) } \\
n=44\end{array}$ & $\begin{array}{c}\text { COMVEST } \\
\text { (UNICAMP) } \\
n=6\end{array}$ & $\begin{array}{c}\text { VUNESP } \\
\text { (UNESP) } \\
n=60\end{array}$ & $\begin{array}{c}\text { VUNESP } \\
\text { (UFSCAR) } \\
n=11\end{array}$ & $\begin{array}{c}\text { VUNESP } \\
\text { (UNIFESP) } \\
n=29\end{array}$ & $\begin{array}{c}\text { ENEM } \\
n=22\end{array}$ \\
\hline Sintática & 82 & 50 & 78 & 82 & 66 & 59 \\
\hline $\begin{array}{l}\text { Operativas } \\
\text { elementares }\end{array}$ & 16 & 50 & 20 & 18 & 34 & 36 \\
\hline Inoperante & 2 & 0 & 2 & 0 & 0 & 5 \\
\hline
\end{tabular}

Tabela 25 - Ocorrência para a categoria funcionalidade das ilustrações encontrados em questões de conhecimentos específicos (segunda fase) dos exames vestibulares de cada universidade nos anos de 2007 a 2011.

\begin{tabular}{lccccc}
\hline \multirow{2}{*}{ Funcionalidade } & \multicolumn{5}{c}{ Ocorrência nas Questões, \% } \\
\cline { 2 - 6 } & $\begin{array}{c}\text { FUVEST } \\
\text { (USP) } \\
n=55\end{array}$ & $\begin{array}{c}\text { COMVEST } \\
\text { (UNICAMP) } \\
n=27\end{array}$ & $\begin{array}{c}\text { VUNESP } \\
\text { (UNESP) }\end{array}$ & $\begin{array}{c}\text { VUNESP } \\
\text { (UFSCAR) } \\
n=23\end{array}$ & $\begin{array}{c}\text { VUNESP } \\
\text { (UNIFESP) } \\
n=30\end{array}$ \\
\hline $\begin{array}{l}\text { Sintática } \\
\begin{array}{l}\text { Operativas } \\
\text { elementares }\end{array}\end{array}$ & 76 & 56 & 96 & 50 & 73 \\
Inoperante & 24 & 44 & 4 & 50 & 27 \\
\hline $\begin{array}{l}n=\text { número de ilustrações. } \\
\text { Uma questão pode apresentar mais de uma ilustração. }\end{array}$ & 0 & 0 & 0 & 0 \\
\hline
\end{tabular}

Os resultados contidos nas tabelas 24 e 25 indicam que:

- para o vestibular da FUVEST/USP, em ambas as fases de conhecimentos, a categoria "sintática" foi a mais frequente seguido da categoria "operativas elementares" e com menor frequência a categoria "inoperante".

- já a COMVEST/UNICAMP não apresentou ocorrências na categoria "inoperante", e em ambas as fases de conhecimentos tiveram ocorrências aproximadas, sendo metade das questões descritas "operativas elementares" e a outra "sintática".

- na primeira fase, a VUNESP/UFSCAR apresentou maior frequência na categoria "sintática", seguida da categoria "operativas elementares" e em ambas as fases não tiveram questões sinalizadas como "inoperante". Já na segunda fase, as categorias "sintáticas" e "operativas elementares" apresentaram a mesma ocorrência (50\%). 
- a VUNESP/UNESP obteve uma menor ocorrência (2\%) na categoria "inoperante" na primeira fase e nenhuma ocorrência na segunda fase. A categoria mais frequente foi a "sintática" nas duas fases de conhecimentos.

- os resultados para as provas do ENEM mostram que pouco mais da metade de suas ilustrações são "sintáticas", seguida da categoria "operativas elementares", e com menor frequência para a categoria "inoperante".

As tabelas $26,27,28,29,30$ e 31 indicam os resultados individuais para cada exame vestibular da análise de funcionalidade das ilustrações encontrados nas provas entre os anos 2007 e 2011.

\section{FUVEST/USP}

Tabela 26 - Resultado para a categoria funcionalidade das ilustrações encontrado na primeira fase (CG) e segunda fase (ES) dos exames vestibulares da FUVEST/USP de 2007 a 2011.

\begin{tabular}{|c|c|c|c|c|c|c|c|c|c|c|c|}
\hline \multirow[b]{3}{*}{ Funcionalidade } & \multicolumn{11}{|c|}{ Ocorrência da funcionalidade das ilustrações para cada ano, para cada prova, $\%$} \\
\hline & \multicolumn{5}{|c|}{$\mathrm{CG}^{\mathbf{1}}$} & \multicolumn{5}{|c|}{$\mathbf{E S}^{2}$} & \multirow[b]{2}{*}{$\begin{array}{l}\text { Total } \\
n=99\end{array}$} \\
\hline & $\begin{array}{l}\mathbf{2 0 0 7} \\
n=12\end{array}$ & $\begin{array}{l}\mathbf{2 0 0 8} \\
n=12\end{array}$ & $\begin{array}{c}2009 \\
n=6\end{array}$ & $\begin{array}{c}2010 \\
n=9\end{array}$ & $\begin{array}{l}2011 \\
n=5\end{array}$ & $\begin{array}{l}2007 \\
n=10\end{array}$ & $\begin{array}{l}\mathbf{2 0 0 8} \\
n=14\end{array}$ & $\begin{array}{l}\mathbf{2 0 0 9} \\
n=12\end{array}$ & $\begin{array}{l}2010 \\
n=11\end{array}$ & $\begin{array}{c}2011 \\
n=8\end{array}$ & \\
\hline Sintática & 83 & 92 & 83 & 89 & 40 & 70 & 71 & 92 & 73 & 75 & 78 \\
\hline $\begin{array}{l}\text { Operativas } \\
\text { Elementares }\end{array}$ & 17 & 8 & 17 & 11 & 40 & 30 & 29 & 8 & 27 & 25 & 20 \\
\hline Inoperante & 0 & 0 & 0 & 0 & 20 & 0 & 0 & 0 & 0 & 0 & 2 \\
\hline \multicolumn{12}{|c|}{$\begin{array}{l}\text { Notas: } \\
n=\text { número de ilustrações. } \\
{ }^{1} \text { CG: Questões de conteúdos gerais (primeira fase do exame) } \\
{ }^{2} \text { ES: Questões de conteúdos específicos (segunda fase do exame) } \\
\text { Uma questão pode apresentar mais de uma ilustração. }\end{array}$} \\
\hline
\end{tabular}

Os resultados para o vestibular da FUVEST/USP mostram que:

- a categoria "sintática" foi a mais frequente em relação as outras duas categorias, indicando que todas as provas apresentaram questões que contém ilustrações que necessitam do conhecimento científico para suas interpretações.

- a segunda categoria mais frequente (20\%) foi "operativas elementares".

- $\quad$ somente as provas vestibulares do ano de 2011 tiveram ocorrências de ilustrações com funcionalidade "inoperante", indicando questões com ilustrações que não apresentam função ou informação para a resolução da questão. 
Tabela 27 - Resultado para a categoria funcionalidade das ilustrações encontrado na primeira fase (CG) e segunda fase (ES) dos exames vestibulares da COMVEST/UNICAMP de 2007 a 2011.

\begin{tabular}{|c|c|c|c|c|c|c|c|c|c|c|}
\hline \multirow{3}{*}{ Funcionalidade } & \multicolumn{10}{|c|}{$\begin{array}{l}\text { Ocorrência da funcionalidade das ilustrações para cada ano, para cada } \\
\text { prova, } \%\end{array}$} \\
\hline & \multicolumn{4}{|c|}{$\mathbf{C G}^{1}$} & \multicolumn{5}{|c|}{$\mathbf{E S}^{2}$} & \multirow[b]{2}{*}{$\begin{array}{l}\text { Total } \\
n=33\end{array}$} \\
\hline & $\begin{array}{l}2007 \\
n=1\end{array}$ & $\begin{array}{c}2008 \\
n=2\end{array}$ & $\begin{array}{c}2009 \\
n=1\end{array}$ & $\begin{array}{c}\mathbf{2 0 1 0} \\
n=2\end{array}$ & $\begin{array}{l}2007 \\
n=5\end{array}$ & $\begin{array}{c}2008 \\
n=3\end{array}$ & $\begin{array}{c}2009 \\
n=8\end{array}$ & $\begin{array}{c}2010 \\
n=6\end{array}$ & $\begin{array}{l}2011 \\
n=5\end{array}$ & \\
\hline Sintática & 0 & 0 & 100 & 100 & 60 & 33 & 75 & 33 & 60 & 55 \\
\hline $\begin{array}{l}\text { Operativas } \\
\text { Elementares }\end{array}$ & 100 & 100 & 0 & 0 & 40 & 66 & 25 & 67 & 40 & 45 \\
\hline Inoperante & 0 & 0 & 0 & 0 & 0 & 0 & 0 & 0 & 0 & 0 \\
\hline \multicolumn{11}{|c|}{$\begin{array}{l}\text { Notas: } \\
n=\text { número de ilustrações. } \\
{ }^{1} \text { CG: Questões de conteúdos gerais (primeira fase do exame) } \\
{ }^{2} \text { ES: Questões de conteúdos especificos (segunda fase do exame) } \\
\text { Uma questão pode apresentar mais de uma ilustração. }\end{array}$} \\
\hline
\end{tabular}

Os resultados apresentados na tabela 27 indicam que os vestibulares da COMVEST/UNICAMP:

- não apresentaram durante os cinco anos analisados ocorrência de ilustrações com funcionalidade "inoperante".

- de modo geral, e diferentemente das demais universidades, as categorias "sintática" e "operativas elementares" tiveram ocorrências aproximadas, sendo 55\% e $45 \%$ respectivamente.

- a categoria "sintática" foi mais frequente nas provas de conhecimentos específicos (ES) do que nas provas de conhecimentos gerais (CG).

- ambas as provas no ano de 2008 tiveram predominância por ilustrações com funcionalidade "operativas elementares".

- somente as provas de conhecimentos gerais nos anos de 2009 e 2010 que não apresentaram ilustrações com funcionalidade "operativas elementares". 


\section{VUNESP/UFSCAR}

Tabela 28 - Resultado para a categoria funcionalidade das ilustrações encontrado na primeira fase (CG) e segunda fase (ES) dos exames vestibulares da VUNESP/UFSCAR de 2007 a 2011.

\begin{tabular}{|c|c|c|c|c|c|}
\hline \multirow{3}{*}{ Funcionalidade } & \multicolumn{5}{|c|}{$\begin{array}{l}\text { Ocorrência da funcionalidade das ilustrações para cada ano, para } \\
\text { cada prova, } \%\end{array}$} \\
\hline & \multicolumn{3}{|c|}{$\mathrm{CG}^{1}$} & $\mathbf{E S}^{2}$ & \multirow[b]{2}{*}{$\begin{array}{l}\text { Total } \\
n=13\end{array}$} \\
\hline & $\begin{array}{r}2007 \\
n=4\end{array}$ & $\begin{array}{l}2008 \\
n=5\end{array}$ & $\begin{array}{c}2009 \\
n=2\end{array}$ & $\begin{array}{c}\mathbf{2 0 1 0} \\
n=2\end{array}$ & \\
\hline Sintática & 100 & 60 & 100 & 50 & 77 \\
\hline Operativas Elementares & 0 & 40 & 0 & 50 & 23 \\
\hline Inoperante & 0 & 0 & 0 & 0 & 0 \\
\hline \multicolumn{6}{|c|}{$\begin{array}{l}\text { Notas: } \\
n=\text { número de ilustrações. } \\
{ }^{1} \text { CG: Questões de conteúdos gerais (primeira fase do exame) } \\
{ }^{2} \text { ES: Questões de conteúdos especificos (segunda fase do exame) } \\
\text { Uma questão pode apresentar mais de uma ilustração. }\end{array}$} \\
\hline
\end{tabular}

Os resultados para o vestibular da VUNESP/UFSCAR indicam que:

- assim como no vestibular da COMVEST/UNICAMP o exame da VUNESP/UFSCAR não apresentou resultados para a categoria "inoperante”.

- a categoria "sintática" foi a mais frequente. Porém, com o passar dos anos as provas de conhecimentos gerais (CG) diminuíram o uso de ilustrações com funcionalidade "sintática", ou seja, houve uma diminuição de questões com ilustrações que necessitam de conhecimento científico específico (no caso conhecimentos químicos) para a sua resolução.

- em 2010 a VUNESP/UFSCAR realizou uma prova de conhecimentos específicos como segunda fase de exame. Esta apresentou duas questões com ilustrações, apresentando ocorrência de 50\% na categoria "sintática" e 50\% na categoria "operativas elementares". 


\section{VUNESP/UNESP}

Tabela 29 - Resultado para a categoria funcionalidade das ilustrações encontrado na primeira fase (CG) e segunda fase (ES) dos exames vestibulares da VUNESP/UNESP de 2007 a 2011.

\begin{tabular}{|c|c|c|c|c|c|c|c|c|c|c|c|}
\hline \multirow{3}{*}{ Funcionalidade } & \multicolumn{11}{|c|}{ Ocorrência da funcionalidade das ilustrações para cada ano, para cada prova, $\%$} \\
\hline & \multicolumn{5}{|c|}{$\mathbf{C G}^{\mathbf{1}}$} & \multicolumn{5}{|c|}{$\mathbf{E S}^{2}$} & \multirow[b]{2}{*}{$\begin{array}{l}\text { Total } \\
n=83\end{array}$} \\
\hline & $\begin{array}{l}\mathbf{2 0 0 7} \\
n=10\end{array}$ & $\begin{array}{l}\mathbf{2 0 0 8} \\
n=10\end{array}$ & $\begin{array}{l}\mathbf{2 0 0 9} \\
n=13\end{array}$ & $\begin{array}{l}2010 \\
n=16\end{array}$ & $\begin{array}{l}2011 \\
n=11\end{array}$ & $\begin{array}{l}\mathbf{2 0 0 7} \\
n=5\end{array}$ & $\begin{array}{c}2008 \\
n=4\end{array}$ & $\begin{array}{c}2009 \\
n=5\end{array}$ & $\begin{array}{r}2010 \\
n=6\end{array}$ & $\begin{array}{l}2011 \\
n=3\end{array}$ & \\
\hline Sintática & 90 & 70 & 54 & 95 & 82 & 100 & 100 & 80 & 100 & 100 & 83 \\
\hline $\begin{array}{l}\text { Operativas } \\
\text { Elementares }\end{array}$ & 10 & 30 & 46 & 6 & 9 & 0 & 0 & 20 & 0 & 0 & 16 \\
\hline Inoperante & 0 & 0 & 0 & 0 & 9 & 0 & 0 & 0 & 0 & 0 & 1 \\
\hline \multicolumn{12}{|c|}{$\begin{array}{l}\text { Notas: } \\
n=\text { número de ilustrações. } \\
{ }^{1} \text { CG: Questões de conteúdos gerais (primeira fase do exame) } \\
{ }^{2} \text { ES: Questões de conteúdos especificos (segunda fase do exame) } \\
\text { Uma questão pode apresentar mais de uma ilustração. }\end{array}$} \\
\hline
\end{tabular}

Diante dos resultados para o vestibular do VUNESP/UNESP:

- $\quad$ percebe-se que em todas as provas e anos, a categoria mais frequente entre as demais foi a "sintática".

- a categoria com menor frequência foi a "inoperante" apresentando $9 \%$ das ocorrências somente no ano de 2011 na prova de conhecimentos gerais.

- as ilustrações com funcionalidade "operativas elementares" foram mais frequentes em provas de conhecimentos gerais do que nas provas de conhecimentos específicos. 


\section{VUNESP/UNIFESP}

Tabela 30 - Resultado para a categoria funcionalidade das ilustrações encontrado na primeira fase (CG) e segunda fase (ES) dos exames vestibulares da VUNESP/UNIFESP de 2007 a 2011.

Ocorrência da funcionalidade das ilustrações para cada ano, para cada

\begin{tabular}{|c|c|c|c|c|c|c|c|c|c|}
\hline \multirow{3}{*}{ Funcionalidade } & \multicolumn{9}{|c|}{ prova, $\%$} \\
\hline & \multicolumn{3}{|c|}{$\mathbf{C G}^{\mathbf{1}}$} & \multicolumn{5}{|c|}{$\mathbf{E S}^{2}$} & \multirow[b]{2}{*}{$\begin{array}{l}\text { Total } \\
n=59\end{array}$} \\
\hline & $\begin{array}{c}\mathbf{2 0 0 7} \\
n=9\end{array}$ & $\begin{array}{l}\mathbf{2 0 0 8} \\
n=11\end{array}$ & $\begin{array}{c}2009 \\
n=9\end{array}$ & $\begin{array}{c}2007 \\
n=5\end{array}$ & $\begin{array}{c}2008 \\
n=7\end{array}$ & $\begin{array}{l}\mathbf{2 0 0 9} \\
N=5\end{array}$ & $\begin{array}{c}2010 \\
n=6\end{array}$ & $\begin{array}{l}2011 \\
n=7\end{array}$ & \\
\hline Sintática & 78 & 73 & 44 & 80 & 71 & 80 & 67 & 71 & 69 \\
\hline $\begin{array}{l}\text { Operativas } \\
\text { Elementares }\end{array}$ & 22 & 27 & 55 & 20 & 29 & 20 & 33 & 29 & 31 \\
\hline Inoperante & 0 & 0 & 0 & 0 & 0 & 0 & 0 & 0 & 0 \\
\hline \multicolumn{10}{|c|}{$\begin{array}{l}\text { Notas: } \\
n=\text { número de ilustrações. } \\
{ }^{1} \text { CG: Questões de conteúdos gerais (primeira fase do exame) } \\
{ }^{2} \text { ES: Questões de conteúdos especificos (segunda fase do exame) } \\
\text { Uma questão pode apresentar mais de uma ilustração. }\end{array}$} \\
\hline
\end{tabular}

O resultado das provas vestibulares da VUNESP/UNIFESP salientam que:

- ilustrações "sintáticas" foram as mais frequentes em relação as demais categorias, apresentando altas ocorrências nos anos analisados.

- nas provas de conhecimentos gerais, observa-se que a categoria "operativas elementares" teve um aumento no número de ocorrências no decorrer dos anos 2007 a 2009.

- a categoria de funcionalidade de ilustrações "inoperante" não apresentou ocorrências. 
Tabela 31 - Resultado para a categoria funcionalidade das ilustrações encontrado no exame do ENEM nos anos 2010 e 2011.

\begin{tabular}{lccc}
\hline \multirow{2}{*}{ Funcionalidade } & \multicolumn{3}{c}{$\begin{array}{c}\text { Ocorrência da funcionalidade das ilustrações } \\
\text { para cada ano, para cada prova, \% }\end{array}$} \\
\cline { 2 - 4 } & $\mathbf{2 0 1 0}$ & $\mathbf{2 0 1 1}$ & $\begin{array}{c}\text { Total } \\
n=12\end{array}$ \\
& $n=10$ & $n=22$ \\
\hline Sintática & 50 & 67 & 55 \\
Operativas & 40 & 33 & 36 \\
Elementares & 10 & 0 & 5 \\
Inoperante & & & \\
\hline Notas: & & \\
$n=$ número de ilustrações. \\
Uma questão pode apresentar mais de uma ilustração.
\end{tabular}

Os resultados encontrados para as provas do ENEM indicam que:

- no ano de 2010 as categorias "sintática" e "operativas elementares" tiveram ocorrências aproximadas.

- em 2011 a categoria "sintática" foi a mais frequente com 67\% das ocorrências.

- as provas do ENEM não apresentaram ilustrações com funcionalidade "inoperante" em 2011.

- comparando os anos, 2011 teve um aumento do número de ilustrações "sintáticas" em relação ao ano anterior.

De uma forma geral, os resultados indicam que as provas dos exames vestibulares estudados trazem ilustrações coesas e que necessitam de ações interpretativas na tentativa de melhorar a compreensão do conhecimento científico abordado no texto da questão.

Portanto, as provas analisadas contém questões com ilustrações que necessitam de conhecimentos químicos para a sua resolução, como pode ser observado a partir dos resultados para as categorias "sintática" e "operativas elementares". 


\section{Grau de Iconicidade}

Para a análise do grau de iconicidade das ilustrações optou-se por utilizar a adaptação realizada por Perales e Jiménez (2002) em seu trabalho, em que se estabelece um grau crescente da simbolização usada. As imagens (ou ilustrações) que possuem um menor grau de iconicidade são interpretadas como menos realistas, resultando em uma maior exigência de conhecimento do código simbolizado.

A tabela 32 apresenta os resultados gerais da análise do grau de iconicidade das ilustrações.

Tabela 32 - Ocorrência para o grau de iconicidade encontrados nas questões da primeira e segunda fase dos exames vestibulares das cinco universidades paulistas e ENEM nos anos de 2007 a 2011.

\begin{tabular}{lcc|c}
\hline & \multicolumn{3}{c}{ Ocorrência nas Questões, \% } \\
\cline { 2 - 4 } Grau de iconicidade & $\mathbf{C G}^{\mathbf{1}}$ & $\mathbf{E S}^{\mathbf{2}}$ & Total \\
& $n=172$ & $n=137$ & $n=309$ \\
\hline Fotografia & 2 & 0 & 1 \\
\hline Desenho figurativo & 7 & 4 & 6 \\
\hline Desenho figurativo com signos & 2 & 2 & 2 \\
\hline Desenho figurativo com signos normalizados & 3 & 7 & 2 \\
\hline Desenho esquemático & 8 & 55 & 56 \\
\hline Desenho esquemático com signos & 56 & 30 & 25 \\
\hline Desenho esquemático com signos normalizados & 22 & \\
\hline Notas: & & & \\
$n=$ número de ilustrações. & & \\
I CG: Questóes de conteúdos gerais (primeira fase do exame) \\
${ }^{2}$ ES: Questões de conteúdos específicos (segunda fase do exame) \\
Uma questão pode apresentar mais de uma ilustração. \\
As questões do ENEM (2010 e 2011) foram contabilizadas na primeira fase de conhecimentos \\
gerais.
\end{tabular}

Por meio da análise dos resultados observa-se que a categoria mais frequente em ambas as fases é a "desenho esquemático com signos", seguida da categoria "desenho esquemático com signos normalizados".

As tabelas 33 e 34 salientam os resultados para a fase de conhecimentos gerais (CG) e conhecimentos específicos (ES) respectivamente. 
Tabela 33 - Ocorrência para a categoria grau de iconicidade das ilustrações encontrados em questões de conhecimentos gerais (primeira fase) dos exames vestibulares de cada universidade e ENEM nos anos de 2007 a 2011.

\begin{tabular}{lcccccc}
\hline \multirow{2}{*}{$\begin{array}{l}\text { Grau de } \\
\text { Iconicidade }\end{array}$} & $\begin{array}{c}\text { FUVEST } \\
\text { (USP) } \\
n=44\end{array}$ & $\begin{array}{c}\text { COMVEST } \\
\text { (UNICAMP) } \\
n=6\end{array}$ & $\begin{array}{c}\text { Ocorrência nas Questões, } \\
\text { (UNESP) } \\
n=60\end{array}$ & $\begin{array}{c}\text { VUNESP } \\
\text { (UFSCAR) } \\
n=11\end{array}$ & $\begin{array}{c}\text { VUNESP } \\
\text { (UNIFESP) } \\
n=29\end{array}$ & $\begin{array}{c}\text { ENEM } \\
n=22\end{array}$ \\
\hline Fotografia & 0 & 0 & 2 & 0 & 0 & 9 \\
\hline $\begin{array}{l}\text { Desenho } \\
\text { figurativo }\end{array}$ & 7 & 0 & 7 & 0 & 7 & 14 \\
\hline $\begin{array}{l}\text { Desenho } \\
\text { figurativo com } \\
\text { signos }\end{array}$ & 2 & 0 & 0 & 0 & 10 & 0 \\
\hline $\begin{array}{l}\text { Desenho } \\
\text { figurativo com } \\
\text { signos } \\
\text { normalizados }\end{array}$ & 0 & 0 & 8 & 0 & 0 & 0 \\
\hline $\begin{array}{l}\text { Desenho } \\
\text { esquemático }\end{array}$ & 14 & 33 & 0 & 0 & 10 & 14 \\
\hline $\begin{array}{l}\text { Desenho } \\
\text { esquemático } \\
\text { com signos }\end{array}$ & 43 & 67 & 57 & 82 & 69 & 45 \\
\hline $\begin{array}{l}\text { Desenho } \\
\text { esquemático } \\
\text { com signos } \\
\text { normalizados }\end{array}$ & 34 & 0 & 27 & 18 & 3 & 18 \\
\hline $\begin{array}{l}n=\text { número de ilustrações. } \\
\text { Uma questão pode apresentar mais de uma ilustração. }\end{array}$ & & & & & \\
\hline
\end{tabular}


Tabela 34 - Ocorrência para a categoria grau de iconicidade das ilustrações encontrados em questões de conhecimentos específico (segunda fase) dos exames vestibulares de cada universidade nos anos de 2007 a 2011.

\begin{tabular}{lccccc}
\hline \multirow{2}{*}{$\begin{array}{l}\text { Grau de } \\
\text { Iconicidade }\end{array}$} & $\begin{array}{c}\text { FUVEST } \\
\text { (USP) } \\
n=55\end{array}$ & $\begin{array}{c}\text { COMVEST } \\
\text { (UNICAMP) } \\
n=27\end{array}$ & $\begin{array}{c}\text { VUNESP } \\
\text { (UNESP) } \\
n=23\end{array}$ & $\begin{array}{c}\text { VUNESP } \\
\text { (UFSCAR) } \\
n=2\end{array}$ & $\begin{array}{c}\text { VUNESP } \\
\text { (UNIFESP) } \\
n=30\end{array}$ \\
\hline Fotografia & 0 & 12 & 0 & 0 & 0 \\
\hline $\begin{array}{l}\text { Desenho } \\
\text { figurativo }\end{array}$ & 0 & 12 & 0 & 0 & 10 \\
\hline $\begin{array}{l}\text { Desenho } \\
\text { figurativo com } \\
\text { signos }\end{array}$ & 2 & 12 & 0 & 0 & 0 \\
\hline $\begin{array}{l}\text { Desenho } \\
\text { figurativo com } \\
\text { signos } \\
\text { normalizados }\end{array}$ & 2 & 12 & 0 & 0 & 0 \\
\hline $\begin{array}{l}\text { Desenho } \\
\text { esquemático }\end{array}$ & 5 & 15 & 9 & 50 & 3 \\
\hline $\begin{array}{l}\text { Desenho } \\
\text { esquemático } \\
\text { com signos }\end{array}$ & 60 & 24 & 43 & 50 & 30 \\
\hline $\begin{array}{l}\text { Desenho } \\
\text { esquemático } \\
\text { com signos } \\
\text { normalizados }\end{array}$ & 31 & 12 & 48 & 0 & \\
\hline $\begin{array}{l}n=\text { número de ilustrações. } \\
\text { Uma questão pode apresentar mais de uma ilustração. }\end{array}$ & & & & \\
\hline
\end{tabular}

Da análise dos dados presentes nas tabelas 33 e 34, salienta-se:

- a categoria "fotografia" ocorre apenas na primeira fase de prova no vestibular VUNESP/UNESP, e na segunda fase no vestibular COMVEST/UNICAMP, sendo as categorias de destaque em ambas as fases a de "desenho esquemático com signos" e "desenho esquemático com signos normalizados".

As tabelas 35, 36, 37, 38, 39 e 40 indicam os resultados individuais para cada instituição de ensino superior e ENEM, da análise para o grau de iconicidade das ilustrações encontrados nas provas entre os anos 2007 e 2011. 


\section{FUVEST/USP}

Tabela 35 - Resultado para a categoria grau de iconicidade das ilustrações encontrado na primeira fase (CG) e segunda fase (ES) dos exames vestibulares da FUVEST/USP de 2007 a 2011.

\begin{tabular}{|c|c|c|c|c|c|c|c|c|c|c|c|}
\hline \multirow{3}{*}{$\begin{array}{c}\text { Grau de } \\
\text { iconicidade }\end{array}$} & \multicolumn{11}{|c|}{ Ocorrência do grau de iconicidade nas ilustrações para cada ano, para cada prova, $\%$} \\
\hline & \multicolumn{5}{|c|}{$\mathrm{CG}^{\mathbf{1}}$} & \multicolumn{5}{|c|}{$\mathbf{E S}^{2}$} & \multirow[b]{2}{*}{$\begin{array}{l}\text { Total } \\
n=99\end{array}$} \\
\hline & $\begin{array}{l}\mathbf{2 0 0 7} \\
n=12\end{array}$ & $\begin{array}{l}\mathbf{2 0 0 8} \\
n=12\end{array}$ & $\begin{array}{c}2009 \\
n=6\end{array}$ & $\begin{array}{l}2010 \\
n=9\end{array}$ & $\begin{array}{l}2011 \\
n=5\end{array}$ & $\begin{array}{l}\mathbf{2 0 0 7} \\
n=10\end{array}$ & $\begin{array}{l}\mathbf{2 0 0 8} \\
n=14\end{array}$ & $\begin{array}{l}2009 \\
n=12\end{array}$ & $\begin{array}{c}\mathbf{2 0 1 0} \\
n=11\end{array}$ & $\begin{array}{l}2011 \\
n=8\end{array}$ & \\
\hline Fotografia & 0 & 0 & 0 & 0 & 0 & 0 & 0 & 0 & 0 & 0 & 0 \\
\hline $\begin{array}{l}\text { Desenho } \\
\text { figurativo }\end{array}$ & 0 & 8 & 0 & 0 & 40 & 0 & 0 & 0 & 0 & 0 & 3 \\
\hline $\begin{array}{l}\text { Desenho } \\
\text { figurativo com } \\
\text { signos }\end{array}$ & 0 & 0 & 0 & 11 & 0 & 0 & 0 & 0 & 0 & 13 & 2 \\
\hline $\begin{array}{l}\text { Desenho } \\
\text { figurativo com } \\
\text { signos } \\
\text { normalizados }\end{array}$ & 0 & 0 & 0 & 0 & 0 & 0 & 0 & 0 & 0 & 13 & 1 \\
\hline $\begin{array}{l}\text { Desenho } \\
\text { esquemático }\end{array}$ & 17 & 8 & 17 & 11 & 20 & 0 & 0 & 17 & 9 & 0 & 9 \\
\hline $\begin{array}{l}\text { Desenho } \\
\text { esquemático } \\
\text { com signos }\end{array}$ & 42 & 33 & 67 & 55 & 20 & 60 & 71 & 58 & 64 & 37 & 52 \\
\hline $\begin{array}{l}\text { Desenho } \\
\text { esquemático } \\
\text { com signos } \\
\text { normalizados }\end{array}$ & 42 & 50 & 17 & 22 & 20 & 40 & 29 & 25 & 27 & 37 & 32 \\
\hline $\begin{array}{l}\text { Notas: } \\
n=\text { número de ilu } \\
{ }^{1} \text { CG: Questões } d \\
{ }^{2} \text { ES: Questões de } \\
\text { Uma questão pod }\end{array}$ & $\begin{array}{l}\text { ucões. } \\
\text { onteúdo } \\
\text { iteúdo } \\
\text { present }\end{array}$ & $\begin{array}{l}\text { erais }(p \\
\text { pecificc } \\
\text { mais de }\end{array}$ & $\begin{array}{l}\text { neira. } \\
\text { (segur } \\
\text { na ilu. }\end{array}$ & $\begin{array}{l}\text { e do ex } \\
\text { fased } \\
\text { ç̧ão. }\end{array}$ & $\begin{array}{l}\text { ne) } \\
\text { xame) }\end{array}$ & & & & & & \\
\hline
\end{tabular}

Os resultados para os exames vestibulares da FUVEST/USP indicam que:

- as categorias predominantes foram "desenho esquemático com signos" e "desenho esquemático com signos normalizados" em ambas as fases de prova. Isto mostra que as provas da USP contém ilustrações com menor grau de iconicidade.

- a categoria "fotografia" não obteve nenhuma ocorrência durante os cinco anos analisados.

- a categoria "desenho figurativo com signos normalizados" apresentou ocorrência somente na prova de conhecimentos específicos no ano de 2011.

- o número de ocorrências oscilou com o passar dos anos, e em 2011 houve uma diminuição do número de ilustrações em relação anos anteriores. 


\section{COMVEST/UNICAMP}

Tabela 36 - Resultado para a categoria grau de iconicidade das ilustrações encontrado na primeira fase (CG) e segunda fase (ES) dos exames vestibulares da COMVES/UNICAMP de 2007 a 2011.

\begin{tabular}{|c|c|c|c|c|c|c|c|c|c|c|}
\hline \multirow{3}{*}{$\begin{array}{c}\text { Grau de } \\
\text { iconicidade }\end{array}$} & \multicolumn{10}{|c|}{ Ocorrência do grau de iconicidade nas ilustrações para cada ano, para cada prova, \% } \\
\hline & \multicolumn{4}{|c|}{$\mathrm{CG}^{1}$} & \multirow[b]{2}{*}{$\begin{array}{l}\mathbf{2 0 0 7} \\
n=2\end{array}$} & \multicolumn{4}{|c|}{$\mathbf{E S}^{2}$} & \multirow[b]{2}{*}{$\begin{array}{l}\text { Total } \\
n=33\end{array}$} \\
\hline & $\begin{array}{c}\mathbf{2 0 0 7} \\
n=1\end{array}$ & $\begin{array}{l}\mathbf{2 0 0 8} \\
N=5\end{array}$ & $\begin{array}{l}2009 \\
n=1\end{array}$ & $\begin{array}{c}\mathbf{2 0 1 0} \\
n=2\end{array}$ & & $\begin{array}{c}\mathbf{2 0 0 8} \\
n=3\end{array}$ & $\begin{array}{l}2009 \\
n=8\end{array}$ & $\begin{array}{l}2010 \\
n=6\end{array}$ & $\begin{array}{c}2011 \\
n=5\end{array}$ & \\
\hline Fotografia & 0 & 0 & 0 & 0 & 0 & 0 & 0 & 0 & 0 & 0 \\
\hline $\begin{array}{l}\text { Desenho } \\
\text { figurativo }\end{array}$ & 0 & 0 & 0 & 0 & 0 & 2 & 0 & 1 & 0 & 9 \\
\hline $\begin{array}{l}\text { Desenho } \\
\text { figurativo com } \\
\text { signos }\end{array}$ & 0 & 0 & 0 & 0 & 0 & 0 & 1 & 0 & 1 & 6 \\
\hline $\begin{array}{l}\text { Desenho } \\
\text { figurativo com } \\
\text { signos } \\
\text { normalizados }\end{array}$ & 0 & 0 & 0 & 0 & 0 & 0 & 0 & 0 & 0 & 0 \\
\hline $\begin{array}{l}\text { Desenho } \\
\text { esquemático }\end{array}$ & 0 & 0 & 0 & 2 & 2 & 0 & 1 & 0 & 0 & 15 \\
\hline $\begin{array}{l}\text { Desenho } \\
\text { esquemático } \\
\text { com signos }\end{array}$ & 1 & 2 & 1 & 0 & 2 & 1 & 6 & 3 & 3 & 58 \\
\hline $\begin{array}{l}\text { Desenho } \\
\text { esquemático } \\
\text { com signos } \\
\text { normalizados }\end{array}$ & 0 & 0 & 0 & 0 & 1 & 0 & 0 & 2 & 1 & 12 \\
\hline $\begin{array}{l}\text { Notas: } \\
n=\text { número de ilu } \\
{ }^{l} \text { CG: Questões } d \\
{ }^{2} \text { ES: Questões de } \\
\text { Uma questão pod }\end{array}$ & $\begin{array}{l}\text { ações. } \\
\text { conteúdo } \\
\text { onteúdo } \\
\text { apresent }\end{array}$ & $\begin{array}{l}\text { gerais (p } \\
\text { specifico } \\
\text { mais de }\end{array}$ & $\begin{array}{l}\text { imeiraf } \\
\text { isegun } \\
\text { ina ilus }\end{array}$ & $\begin{array}{l}\text { e do ex } \\
\text { fase d } \\
\text { lção. }\end{array}$ & $\begin{array}{l}\text { xame) } \\
\text { xam }\end{array}$ & & & & & \\
\hline
\end{tabular}

Os resultados para o vestibular da COMVEST/UNICAMP mostram que:

- $\quad$ as provas apresentam poucas representações visuais, dando ênfase nas questões para informações textuais.

- a categoria mais frequente foi "desenho esquemático com signos", com ocorrência predominante na prova de conhecimentos gerais no ano de 2009.

- as categorias "fotografia" e "desenho figurativo com signos normalizados" não apresentaram ocorrência em suas provas durante os cinco anos analisados. 


\section{VUNESP/UFSCAR}

Tabela 37 - Resultado para a categoria grau de iconicidade das ilustrações encontrado na primeira fase (CG) e segunda fase (ES) dos exames vestibulares da VUNESP/UFSCAR de 2007 a 2011.

Ocorrência do grau de iconicidade nas ilustrações para cada ano, para cada prova, $\%$

\begin{tabular}{|c|c|c|c|c|c|}
\hline \multirow{2}{*}{ Grau de iconicidade } & \multicolumn{3}{|c|}{$\mathbf{C G}^{\mathbf{1}}$} & \multirow{2}{*}{$\begin{array}{c}\mathbf{E S}^{\mathbf{2}} \\
2010 \\
n=2\end{array}$} & \multirow[b]{2}{*}{$\begin{array}{l}\text { Total } \\
n=13\end{array}$} \\
\hline & $\begin{array}{l}2007 \\
n=4\end{array}$ & $\begin{array}{l}2008 \\
n=5\end{array}$ & $\begin{array}{c}2009 \\
n=2\end{array}$ & & \\
\hline Fotografia & 0 & 0 & 0 & 0 & 0 \\
\hline Desenho figurativo & 0 & 0 & 0 & 0 & 0 \\
\hline Desenho figurativo com signos & 0 & 0 & 0 & 0 & 0 \\
\hline $\begin{array}{l}\text { Desenho figurativo com signos } \\
\text { normalizados }\end{array}$ & 0 & 0 & 0 & 0 & 0 \\
\hline Desenho esquemático & 0 & 0 & 0 & 50 & 8 \\
\hline Desenho esquemático com signos & 50 & 100 & 100 & 50 & 77 \\
\hline $\begin{array}{l}\text { Desenho esquemático com signos } \\
\text { normalizados }\end{array}$ & 50 & 0 & 0 & 0 & 15 \\
\hline $\begin{array}{l}\text { Notas: } \\
n=\text { número de ilustrações. } \\
{ }^{1} \text { CG: Questões de conteúdos gerais }(p \\
{ }^{2} \text { ES: Questões de conteúdos especifica } \\
\text { Uma questão pode apresentar mais de }\end{array}$ & $\begin{array}{l}\text { ira fas } \\
\text { gunda } \\
\text { ilustr }\end{array}$ & $\begin{array}{l}\text { me) } \\
\text { exame, }\end{array}$ & & & \\
\hline
\end{tabular}

Os resultados encontrados na tabela 37 indicam que:

- mesmo apresentando menor quantidade de ilustrações em relação aos demais exames analisados, o vestibular da VUNESP/UFSCAR obteve altas ocorrências nas categorias designadas desenhos esquemáticos, sendo que dentre estas a com maior frequência foi "desenho esquemático com signos". Este perfil se diferencia dos demais exames vestibulares analisados. 


\section{VUNESP/UNESP}

Tabela 38 - Resultado para a categoria grau de iconicidade das ilustrações encontrado na primeira fase (CG) e segunda fase (ES) dos exames vestibulares da VUNESP/UNESP de 2007 a 2011.

\begin{tabular}{|c|c|c|c|c|c|c|c|c|c|c|c|}
\hline \multirow{3}{*}{$\begin{array}{l}\text { Grau de } \\
\text { iconicidade }\end{array}$} & \multicolumn{11}{|c|}{ Ocorrência do grau de iconicidade nas ilustrações para cada ano, para cada prova, $\%$} \\
\hline & \multicolumn{5}{|c|}{ CG $^{\mathbf{1}}$} & \multicolumn{5}{|c|}{$\mathbf{E S}^{2}$} & \multirow[b]{2}{*}{$\begin{array}{l}\text { Total } \\
n=83\end{array}$} \\
\hline & $\begin{array}{l}\mathbf{2 0 0 7} \\
n=10\end{array}$ & $\begin{array}{l}\mathbf{2 0 0 8} \\
n=10\end{array}$ & $\begin{array}{l}\mathbf{2 0 0 9} \\
n=13\end{array}$ & $\begin{array}{l}\mathbf{2 0 1 0} \\
n=16\end{array}$ & $\begin{array}{l}2011 \\
n=11\end{array}$ & $\begin{array}{l}2007 \\
n=5\end{array}$ & $\begin{array}{c}2008 \\
n=4\end{array}$ & $\begin{array}{l}2009 \\
n=5\end{array}$ & $\begin{array}{c}2010 \\
n=6\end{array}$ & $\begin{array}{l}2011 \\
n=3\end{array}$ & \\
\hline Fotografia & 0 & 0 & 0 & 0 & 9 & 0 & 0 & 0 & 0 & 0 & 1 \\
\hline $\begin{array}{l}\text { Desenho } \\
\text { figurativo }\end{array}$ & 10 & 10 & 8 & 6 & 0 & 0 & 0 & 0 & 0 & 0 & 5 \\
\hline $\begin{array}{l}\text { Desenho } \\
\text { figurativo } \\
\text { com signos }\end{array}$ & 0 & 0 & 0 & 0 & 0 & 0 & 0 & 0 & 0 & 0 & 0 \\
\hline $\begin{array}{l}\text { Desenho } \\
\text { figurativo } \\
\text { com signos } \\
\text { normalizados }\end{array}$ & 0 & 20 & 15 & 0 & 9 & 0 & 0 & 0 & 0 & 0 & 6 \\
\hline $\begin{array}{l}\text { Desenho } \\
\text { esquemático }\end{array}$ & 0 & 0 & 0 & 0 & 0 & 0 & 0 & 20 & 17 & 0 & 2 \\
\hline $\begin{array}{l}\text { Desenho } \\
\text { esquemático } \\
\text { com signos }\end{array}$ & 80 & 60 & 62 & 44 & 45 & 60 & 75 & 20 & 33 & 33 & 53 \\
\hline $\begin{array}{l}\text { Desenho } \\
\text { esquemático } \\
\text { com signos } \\
\text { normalizados }\end{array}$ & 10 & 10 & 15 & 50 & 36 & 40 & 25 & 60 & 50 & 66 & 32 \\
\hline $\begin{array}{l}\text { Notas: } \\
n=\text { número de } \\
{ }^{1} \text { CG: Questões } \\
{ }^{2} \text { ES: Questões } \\
\text { Uma questão p }\end{array}$ & $\begin{array}{l}\text { rações. } \\
\text { conteúdo } \\
\text { onteúdos } \\
\text { apresent }\end{array}$ & $\begin{array}{l}\text { gerais (p } \\
\text { specifice } \\
\text { mais de }\end{array}$ & $\begin{array}{l}\text { imeiraf } \\
\text { (segun } \\
\text { ima ilus }\end{array}$ & $\begin{array}{l}\text { se do exa } \\
\text { a fase do } \\
\text { ação. }\end{array}$ & $\begin{array}{l}\text { e) } \\
\text { came) }\end{array}$ & & & & & & \\
\hline
\end{tabular}

Nas provas vestibulares da VUNESP/UNESP os resultados apontam que:

- a categoria "desenho esquemático com signos" em ambas as fases teve uma diminuição do número de ocorrências com o passar dos anos.

- a categoria "desenho esquemático com signos normalizados" apresentou um aumento nas ocorrências de ilustrações com o passar dos anos até o ano de 2010.

- as provas da VUNESP/UNESP não apresentaram ocorrências de ilustrações na categoria "desenho figurativo com signos".

- $\quad$ somente a prova de conhecimentos gerais do ano de 2011 apresentou ocorrência para a categoria "figura".

- a categoria "desenho figurativo" foi frequente somente em provas de conhecimentos 
gerais.

\section{VUNESP/UNIFESP}

Tabela 39 - Resultado para a categoria grau de iconicidade das ilustrações encontrado na primeira fase (CG) e segunda fase (ES) dos exames vestibulares da VUNESP/UNIFESP de 2007 a 2011.

\begin{tabular}{|c|c|c|c|c|c|c|c|c|c|}
\hline \multirow{3}{*}{$\begin{array}{l}\text { Grau de } \\
\text { iconicidade }\end{array}$} & \multicolumn{9}{|c|}{$\begin{array}{l}\text { Ocorrência do grau de iconicidade nas ilustrações para cada ano, para cada } \\
\text { prova, } \%\end{array}$} \\
\hline & \multicolumn{3}{|c|}{$\mathrm{CG}^{1}$} & \multicolumn{5}{|c|}{$\mathbf{E S}^{2}$} & \multirow[b]{2}{*}{$\begin{array}{l}\text { Total } \\
n=59\end{array}$} \\
\hline & $\begin{array}{c}\mathbf{2 0 0 7} \\
n=9\end{array}$ & $\begin{array}{l}2008 \\
n=11\end{array}$ & $\begin{array}{c}2009 \\
n=9\end{array}$ & $\begin{array}{l}2007 \\
n=5\end{array}$ & $\begin{array}{l}2008 \\
n=7\end{array}$ & $\begin{array}{c}2009 \\
n=5\end{array}$ & $\begin{array}{c}2010 \\
n=6\end{array}$ & $\begin{array}{l}2011 \\
n=7\end{array}$ & \\
\hline Fotografia & 0 & 0 & 0 & 0 & 0 & 0 & 0 & 0 & 0 \\
\hline $\begin{array}{l}\text { Desenho } \\
\text { figurativo }\end{array}$ & 11 & 0 & 11 & 20 & 0 & 0 & 33 & 0 & 8 \\
\hline $\begin{array}{l}\text { Desenho } \\
\text { figurativo com } \\
\text { signos }\end{array}$ & 0 & 18 & 11 & 0 & 0 & 0 & 0 & 0 & 5 \\
\hline $\begin{array}{l}\text { Desenho } \\
\text { figurativo com } \\
\text { signos } \\
\text { normalizados }\end{array}$ & 0 & 0 & 0 & 0 & 0 & 0 & 0 & 0 & 0 \\
\hline $\begin{array}{l}\text { Desenho } \\
\text { esquemático }\end{array}$ & 11 & 0 & 22 & 0 & 0 & 20 & 0 & 0 & 7 \\
\hline $\begin{array}{l}\text { Desenho } \\
\text { esquemático } \\
\text { com signos }\end{array}$ & 78 & 73 & 55 & 60 & 86 & 20 & 33 & 71 & 63 \\
\hline $\begin{array}{l}\text { Desenho } \\
\text { esquemático } \\
\text { com signos } \\
\text { normalizados }\end{array}$ & 0 & 9 & 0 & 20 & 14 & 60 & 33 & 28 & 17 \\
\hline $\begin{array}{l}\text { Notas: } \\
n=\text { número de il } \\
{ }^{l} \text { CG: Questões } \\
{ }^{2} \text { ES: Questões d } \\
\text { Uma questão po }\end{array}$ & $\begin{array}{l}\text { ações. } \\
\text { onteú } \\
\text { onteúd } \\
\text { aprese }\end{array}$ & $\begin{array}{l}\text { gerai } \\
\text { especi } \\
\text { mais }\end{array}$ & $\begin{array}{l}\text { imeirc } \\
\text { (segl } \\
\text { ma il }\end{array}$ & $\begin{array}{l}\text { do e. } \\
\text { fase d } \\
\text { cão. }\end{array}$ & ame) & & & & \\
\hline
\end{tabular}

Os resultados para as provas vestibulares da VUNESP/UNIFESP mostram que:

- assim como as demais instituições, a categoria mais frequente para o exame da VUNESP/UNIFESP foi “desenho esquemático mais signos", que com o passar dos anos teve uma diminuição no número de ocorrências devido a inclusão da prova do ENEM como processo de seleção.

- as categorias "figura" e "desenho figurativo com signos normalizados" não 
apresentaram ocorrências durante os cinco anos de exames analisados.

- $\quad$ somente as provas de conhecimentos gerais nos anos 2008 e 2009 apresentaram ocorrências para a categoria "desenho figurativo com signos".

\section{ENEM}

Tabela 40 - Resultado para a categoria grau de iconicidade das ilustrações encontrado para as provas do ENEM nos anos de 2010 e 2011.

\begin{tabular}{lcc|c}
\hline & \multicolumn{3}{c}{$\begin{array}{l}\text { Ocorrência do grau de iconicidade } \\
\text { nas ilustrações para cada ano, para } \\
\text { cada prova, \% }\end{array}$} \\
\cline { 2 - 4 } Grau de Iconicidade & $\begin{array}{r}\mathbf{2 0 1 0} \\
n=10\end{array}$ & $\begin{array}{c}\mathbf{2 0 1 1} \\
n=12\end{array}$ & $\begin{array}{c}\text { Total } \\
n=22\end{array}$ \\
\hline Fotografia & 20 & 0 & 9 \\
\hline Desenho figurativo & 20 & 8 & 14 \\
\hline Desenho figurativo com signos & 0 & 0 & 0 \\
\hline $\begin{array}{l}\text { Desenho figurativo com signos } \\
\text { normalizados }\end{array}$ & 0 & 0 & 0 \\
\hline Desenho esquemático & 10 & 17 & 14 \\
\hline Desenho esquemático com signos & 40 & 50 & 45 \\
\hline $\begin{array}{l}\text { Desenho esquemático com signos } \\
\text { normalizados }\end{array}$ & 10 & 25 & 18 \\
\hline $\begin{array}{l}\text { Notas: } \\
\begin{array}{l}n=\text { número de ilustrações. } \\
\text { Uma questão pode apresentar mais de uma ilustração. }\end{array}\end{array}$ \\
\hline
\end{tabular}

Os resultados oriundos da tabela 40 indicam que:

- a prova do ENEM se diferencia dos demais exames vestibulares por distribuir o uso de ilustrações com diferentes graus de iconicidade, sendo evidenciado pela ocorrência em categorias como "figura" e "desenho figurativo", que foi pouco evidenciado nos outros exames vestibulares.

- houve uma diminuição no ano 2011 para a categoria "desenho figurativo" e a categoria "figura" não obteve ocorrências.

- as provas do ENEM nos dois anos analisados apresentaram maior ocorrência na categoria "desenho esquemático com signos". De modo geral, o exame no ano de 2011 obteve maior número de ocorrências nesta categoria em comparação com a prova do ano anterior. 
Questões de exames vestibulares com textos científicos que contém ilustrações de diferentes tipos (contendo variadas tarefas ou graus de iconicidade) frequentemente corroboram com a compreensão e interpretação do conteúdo desse texto (DIAZ e PANDIELLA, 2007).

Com base no grau de iconicidade das ilustrações, o candidato deve sincronizar o entendimento e a potencialidade da ilustração no ato da leitura para consequente resolução da questão vestibular. Assim, para obter sucesso na compreensão do processamento da informação gráfica apresentada, necessita-se a compreensão do significado dos signos e também das regras sintáticas que os relacionam (DIAZ e PANDIELA, 2007).

As ilustrações com menor grau de iconicidade são menos realistas, e exigem maior conhecimento do código simbólico utilizado. De acordo com os resultados obtidos, as categorias do grau de iconicidade mais frequentes, de modo geral em todos os exames vestibulares e na prova do ENEM, foram "desenho esquemático com signos" e "desenho esquemático com signos normalizados". Isto mostra coerência com a ideia de que ilustrações com menor grau de iconicidade requerem maiores explicações para sua compreensão.

As "fotografias", "desenhos figurativos" e "desenhos esquemáticos" foram pouco frequentes nos resultados, mostrando certo controle por parte das instituições e equipes organizadoras e responsáveis pelas provas sobre o uso de ilustrações de forma massiva e desconexa. Isto indica que as provas dos exames vestibulares, em geral, são bem elaboradas quanto a isto. 


\section{Presença e Tipo de Etiquetas Verbais}

$\mathrm{Na}$ tabela 41 encontram-se os resultados gerais para a classificação das etiquetas verbais das ilustrações presentes nas provas de todos os exames estudados.

Tabela 41 - Ocorrência para as etiquetas verbais encontradas nas questões da primeira e segunda fase dos exames vestibulares das cinco universidades paulistas e ENEM nos anos de 2007 a 2011.

\begin{tabular}{|c|c|c|c|}
\hline & \multicolumn{3}{|c|}{ Ocorrência nas Questões, \% } \\
\hline Etiquetas Verbais & $\begin{array}{c}\mathbf{C G}^{\mathbf{1}} \\
n=172\end{array}$ & $\begin{array}{c}\mathbf{E S}^{\mathbf{2}} \\
n=137\end{array}$ & $\begin{array}{c}\text { Total } \\
n=309\end{array}$ \\
\hline Sem etiquetas & 31 & 34 & 32 \\
\hline Nominativas & 64 & 64 & 64 \\
\hline Relacionais & 5 & 2 & 4 \\
\hline \multicolumn{4}{|c|}{$\begin{array}{l}\text { Notas: } \\
n=\text { número de ilustrações. } \\
{ }^{2} \text { CG: Questôes de conteúdos gerais (primeira fase do exame) } \\
{ }^{2} \text { ES: Questões de conteúdos especificos (segunda fase do exame) } \\
\text { Uma questão pode apresentar mais de uma ilustração. } \\
\text { As questões do ENEM (2010 e 2011) foram contabilizadas na primeira fase de } \\
\text { conhecimentos gerais. }\end{array}$} \\
\hline
\end{tabular}

Os resultados mostram que na maior parte das ilustrações prevalece a categoria "nominativa" com 64\% das ocorrências em ambas as fases de conhecimento. A categoria "sem etiqueta" apresentou $31 \%$ nos conhecimentos gerais e $34 \%$ conhecimentos específicos, ou seja, as ilustrações não estavam acompanhadas de palavras ou letras que ajudassem na sua interpretação e/ou identificassem elementos gráficos. A categoria "relacional" é pouco frequente em ambas as fases de conhecimentos (5\% na primeira e $2 \%$ na segunda).

As tabelas 42 e 43 indicam os resultados para as questões com etiquetas verbais de cada exame vestibular analisado. 
Tabela 42 - Ocorrência para as etiquetas verbais das ilustrações encontradas em questões de conhecimentos gerais (primeira fase) dos exames vestibulares de cada universidade e ENEM nos anos de 2007 a 2011.

\begin{tabular}{lcccccc}
\hline \multirow{2}{*}{$\begin{array}{l}\text { Etiquetas } \\
\text { Verbais }\end{array}$} & $\begin{array}{c}\text { FUVEST } \\
\text { (USP) } \\
n=44\end{array}$ & $\begin{array}{c}\text { COMVEST } \\
\text { (UNICAMP) } \\
n=6\end{array}$ & $\begin{array}{c}\text { Ocorrência nas Questões, \% } \\
\text { (UNESP) } \\
n=60\end{array}$ & $\begin{array}{c}\text { VUNESP } \\
\text { (UFSCAR) } \\
n=11\end{array}$ & $\begin{array}{c}\text { VUNESP } \\
\text { (UNIFESP) } \\
n=29\end{array}$ & $\begin{array}{c}\text { ENEM } \\
n=22\end{array}$ \\
\hline Sem etiquetas & 32 & 67 & 32 & 45 & 17 & 32 \\
Nominativas & 64 & 33 & 58 & 55 & 83 & 64 \\
Relacionais & 5 & 0 & 10 & 0 & 0 & 5 \\
\hline$n=$ número de ilustrações. \\
Uma questão pode apresentar mais de uma ilustração.
\end{tabular}

Tabela 43 - Ocorrência para as etiquetas verbais das ilustrações encontradas em questões de conhecimentos específicos (segunda fase) dos exames vestibulares de cada universidade nos anos de 2007 a 2011.

\begin{tabular}{lccccc}
\hline \multirow{2}{*}{ Etiquetas Verbais } & \multicolumn{5}{c}{ Ocorrência nas Questões, \% } \\
\cline { 2 - 6 } & $\begin{array}{c}\text { FUVEST } \\
\text { (USP) } \\
n=55\end{array}$ & $\begin{array}{c}\text { COMVEST } \\
\text { (UNICAMP) } \\
n=27\end{array}$ & $\begin{array}{c}\text { VUNESP } \\
\text { (UNESP) }\end{array}$ & $\begin{array}{c}\text { VUNESP } \\
\text { (UFSCAR) }\end{array}$ & $\begin{array}{c}\text { VUNESP } \\
\text { (UNIFESP) } \\
n=30\end{array}$ \\
\hline Sem etiquetas & 31 & 37 & 39 & 50 & 30 \\
Nominativas & 67 & 63 & 57 & 50 & 67 \\
Relacionais & 2 & 0 & 4 & 0 & 3 \\
\hline$n=$ número de ilustrações. & \multicolumn{7}{c}{ Uma questão pode apresentar mais de uma ilustração. }
\end{tabular}

Da análise dos dados presentes nas tabelas 42 e 43, salienta-se que:

- de modo geral, a categoria "nominativa" apresentou maior predominância, em seguida a categoria "sem etiquetas" com ocorrências significativas e com menor frequência a categoria "relacionais".

- apenas o vestibular da COMVEST/UNICAMP apresentou como categoria predominante "sem etiquetas", sendo $67 \%$ nas provas de conhecimentos gerais.

As tabelas 44, 45, 46, 47, 48 e 49 indicam os resultados para a análise de etiquetas verbais encontrados nos exames vestibulares entre os anos 2007 e 2011. 


\section{FUVEST/USP}

Tabela 44 - Resultado para as etiquetas verbais encontradas na primeira fase (CG) e segunda fase (ES) dos exames vestibulares da FUVEST/USP de 2007 a 2011.

\begin{tabular}{|c|c|c|c|c|c|c|c|c|c|c|c|}
\hline \multirow{3}{*}{$\begin{array}{l}\text { Etiquetas } \\
\text { Verbais }\end{array}$} & \multicolumn{11}{|c|}{ Ocorrência das etiquetas verbais nas ilustrações para cada ano, para cada prova, \% } \\
\hline & \multicolumn{5}{|c|}{$\mathbf{C G}^{\mathbf{1}}$} & \multicolumn{5}{|c|}{$\mathbf{E S}^{2}$} & \multirow[b]{2}{*}{$\begin{array}{l}\text { Total } \\
n=99\end{array}$} \\
\hline & $\begin{array}{l}\mathbf{2 0 0 7} \\
n=12\end{array}$ & $\begin{array}{l}\mathbf{2 0 0 8} \\
n=12\end{array}$ & $\begin{array}{c}2009 \\
n=6\end{array}$ & $\begin{array}{c}2010 \\
n=9\end{array}$ & $\begin{array}{c}2011 \\
n=5\end{array}$ & $\begin{array}{l}\mathbf{2 0 0 7} \\
n=10\end{array}$ & $\begin{array}{l}\mathbf{2 0 0 8} \\
n=14\end{array}$ & $\begin{array}{l}\mathbf{2 0 0 9} \\
n=12\end{array}$ & $\begin{array}{l}2010 \\
n=11\end{array}$ & $\begin{array}{c}2011 \\
n=8\end{array}$ & \\
\hline Sem etiquetas & 42 & 33 & 17 & 33 & 20 & 40 & 28 & 33 & 18 & 37 & 31 \\
\hline Nominativas & 58 & 67 & 83 & 44 & 60 & 60 & 71 & 67 & 73 & 62 & 66 \\
\hline Relacionais & 0 & 0 & 0 & 22 & 0 & 0 & 0 & 0 & 9 & 0 & 3 \\
\hline \multicolumn{12}{|c|}{$\begin{array}{l}\text { Notas: } \\
n=\text { número de ilustrações. } \\
{ }^{1} \text { CG: Questões de conteúdos gerais (primeira fase do exame) } \\
{ }^{2} \text { ES: Questões de conteúdos especificos (segunda fase do exame) } \\
\text { Uma questão pode apresentar mais de uma ilustração. }\end{array}$} \\
\hline
\end{tabular}

Os resultados para o vestibular da FUVEST/USP mostram que:

- a categoria "sem etiquetas" teve uma diminuição de suas ocorrências com o passar dos anos.

- a categoria "nominativa" apresentou a maior frequência dos resultados entre as três categorias.

- ilustrações com etiquetas verbais "relacionais" tiveram ocorrências somente no ano de 2010.

- os resultados permaneceram praticamente homogêneos com o passar dos anos. 
Tabela 45 - Resultado para as etiquetas verbais encontradas na primeira fase (CG) e segunda fase (ES) dos exames vestibulares da COMVEST/UNICAMP de 2007 a 2011.

\begin{tabular}{|c|c|c|c|c|c|c|c|c|c|c|}
\hline \multirow{3}{*}{$\begin{array}{l}\text { Etiquetas } \\
\text { Verbais }\end{array}$} & \multicolumn{10}{|c|}{ Ocorrência das etiquetas verbais nas ilustrações para cada ano, para cada prova, \% } \\
\hline & \multicolumn{4}{|c|}{$\mathrm{CG}^{1}$} & \multicolumn{5}{|c|}{$\mathbf{E S}^{2}$} & \multirow[b]{2}{*}{$\begin{array}{l}\text { Total } \\
n=33\end{array}$} \\
\hline & $\begin{array}{c}\mathbf{2 0 0 7} \\
n=1\end{array}$ & $\begin{array}{c}2008 \\
n=2\end{array}$ & $\begin{array}{c}2009 \\
n=1\end{array}$ & $\begin{array}{c}\mathbf{2 0 1 0} \\
n=2\end{array}$ & $\begin{array}{l}\mathbf{2 0 0 7} \\
N=5\end{array}$ & $\begin{array}{c}2008 \\
n=3\end{array}$ & $\begin{array}{c}2009 \\
n=8\end{array}$ & $\begin{array}{c}\mathbf{2 0 1 0} \\
n=6\end{array}$ & $\begin{array}{l}2011 \\
n=5\end{array}$ & \\
\hline $\begin{array}{l}\text { Sem } \\
\text { etiquetas }\end{array}$ & 0 & 100 & 0 & 100 & 80 & 0 & 25 & 33 & 40 & 42 \\
\hline Nominativas & 100 & 0 & 100 & 0 & 20 & 100 & 75 & 67 & 60 & 58 \\
\hline Relacionais & 0 & 0 & 0 & 0 & 0 & 0 & 0 & 0 & 0 & 0 \\
\hline \multicolumn{11}{|c|}{$\begin{array}{l}\text { Notas: } \\
n=\text { número de ilustrações. } \\
{ }^{1} \text { CG: Questões de conteúdos gerais (primeira fase do exame) } \\
{ }^{2} E S: \text { Questões de conteúdos específicos (segunda fase do exame) } \\
\text { Uma questão pode apresentar mais de uma ilustração. }\end{array}$} \\
\hline
\end{tabular}

Os resultados presentes na tabela 45 para os exames vestibulares da COMVEST/UNICAMP indicam que:

- houve variação das ocorrências ao longo dos anos analisados.

- a categoria "nominativa" apresentou a maior frequência entre as demais categorias nas provas de conhecimentos específicos.

- nas provas de conhecimentos gerais nos anos 2007 e 2009 prevaleceu a categoria "nominativa" e nos anos 2008 e 2010 a categoria "sem etiquetas".

- os exames não apresentaram provas com questões que contém ilustrações com etiquetas verbais "relacionais".

- nota-se que as ilustrações "sem etiquetas" foram mais frequentes nas provas de conhecimentos específicos do que nas provas de conhecimentos gerais. 


\section{VUNESP/UFSCAR}

Tabela 46 - Resultado para as etiquetas verbais encontradas na primeira fase (CG) e segunda fase (ES) dos exames vestibulares da VUNESP/UFSCAR de 2007 a 2011.

\begin{tabular}{|c|c|c|c|c|c|}
\hline \multirow{3}{*}{ Etiquetas Verbais } & \multicolumn{5}{|c|}{$\begin{array}{l}\text { Ocorrência das etiquetas verbais nas ilustrações para cada ano, para } \\
\text { cada prova, } \%\end{array}$} \\
\hline & \multicolumn{3}{|c|}{$C^{1}$} & \multirow{2}{*}{$\begin{array}{c}\mathbf{E S}^{\mathbf{2}} \\
\mathbf{2 0 1 0} \\
n=2\end{array}$} & \multirow[b]{2}{*}{$\begin{array}{l}\text { Total } \\
n=13\end{array}$} \\
\hline & $\begin{array}{l}2007 \\
n=4\end{array}$ & $\begin{array}{l}2008 \\
N=5\end{array}$ & $\begin{array}{c}2009 \\
n=2\end{array}$ & & \\
\hline Sem etiquetas & 100 & 20 & 0 & 50 & 46 \\
\hline Nominativas & 0 & 80 & 100 & 50 & 54 \\
\hline Relacionais & 0 & 0 & 0 & 0 & 0 \\
\hline \multicolumn{6}{|c|}{$\begin{array}{l}\text { Notas: } \\
n=\text { número de ilustrações. } \\
{ }^{1} \text { CG: Questões de conteúdos gerais (primeira fase do exame) } \\
{ }^{2} \text { ES: Questões de conteúdos específicos (segunda fase do exame) } \\
\text { Uma questão pode apresentar mais de uma ilustração. }\end{array}$} \\
\hline
\end{tabular}

Os resultados para a VUNESP/UFSCAR indicam que:

- somente as categorias de etiquetas verbais "nominativas" e "sem etiquetas" apresentaram ocorrências.

- o ano de 2007 obteve somente ilustrações "sem etiquetas" e em 2009 somente "nominativas". 


\section{VUNESP/UNESP}

Tabela 47 - Resultado para as etiquetas verbais encontradas na primeira fase (CG) e segunda fase (ES) dos exames vestibulares da VUNESP/UNESP de 2007 a 2011.

\begin{tabular}{|c|c|c|c|c|c|c|c|c|c|c|c|}
\hline \multirow{3}{*}{$\begin{array}{c}\text { Etiquetas } \\
\text { Verbais }\end{array}$} & \multicolumn{11}{|c|}{ Ocorrência das etiquetas verbais nas ilustrações para cada ano, para cada prova, \% } \\
\hline & \multicolumn{5}{|c|}{ CG $^{\mathbf{1}}$} & \multicolumn{5}{|c|}{$\mathbf{E S}^{2}$} & \multirow[b]{2}{*}{$\begin{array}{l}\text { Total } \\
n=83\end{array}$} \\
\hline & $\begin{array}{l}\mathbf{2 0 0 7} \\
n=10\end{array}$ & $\begin{array}{l}\mathbf{2 0 0 8} \\
n=10\end{array}$ & $\begin{array}{l}\mathbf{2 0 0 9} \\
n=13\end{array}$ & $\begin{array}{l}2010 \\
n=16\end{array}$ & $\begin{array}{l}2011 \\
n=11\end{array}$ & $\begin{array}{l}2007 \\
n=5\end{array}$ & $\begin{array}{c}2008 \\
n=4\end{array}$ & $\begin{array}{c}2009 \\
n=5\end{array}$ & $\begin{array}{l}2010 \\
n=6\end{array}$ & $\begin{array}{l}2011 \\
n=3\end{array}$ & \\
\hline Sem etiquetas & 40 & 30 & 15 & 44 & 27 & 40 & 25 & 40 & 33 & 66 & 34 \\
\hline Nominativas & 60 & 60 & 77 & 50 & 45 & 60 & 50 & 60 & 67 & 33 & 58 \\
\hline Relacionais & 0 & 10 & 8 & 6 & 27 & 0 & 25 & 0 & 0 & 0 & 8 \\
\hline \multicolumn{12}{|c|}{$\begin{array}{l}\text { Notas: } \\
n=\text { número de ilustrações. } \\
{ }^{1} \text { CG: Questões de conteúdos gerais (primeira fase do exame) } \\
{ }^{2} \text { ES: Questões de conteúdos especificos (segunda fase do exame) } \\
\text { Uma questão pode apresentar mais de uma ilustração. }\end{array}$} \\
\hline
\end{tabular}

O exame vestibular da VUNESP/UNESP apresentou:

- a categoria mais frequente foi a "nominativa", sendo que a maior ocorrência dos resultados sobreveio entre os anos de 2009 e 2010.

- a maior ocorrência de resultados para a categoria de etiquetas verbais "relacionais" dentre todos os exames vestibulares analisados.

- a categoria "sem etiquetas" foi mais frequente nas provas de conhecimentos específicos do que nas provas de conhecimentos gerais. 
Tabela 48 - Resultado para as etiquetas verbais encontradas na primeira fase (CG) e segunda fase (ES) dos exames vestibulares da VUNESP/UNIFESP de 2007 a 2011.

\begin{tabular}{|c|c|c|c|c|c|c|c|c|c|}
\hline \multirow{3}{*}{$\begin{array}{l}\text { Etiquetas } \\
\text { Verbais }\end{array}$} & \multicolumn{9}{|c|}{$\begin{array}{l}\text { Ocorrência das etiquetas verbais nas ilustrações para cada ano, para cada } \\
\text { prova, } \%\end{array}$} \\
\hline & \multicolumn{3}{|c|}{$\mathrm{CG}^{1}$} & \multicolumn{5}{|c|}{$\mathbf{E S}^{2}$} & \multirow[b]{2}{*}{$\begin{array}{l}\text { Total } \\
n=59\end{array}$} \\
\hline & $\begin{array}{c}2007 \\
n=9\end{array}$ & $\begin{array}{l}2008 \\
n=11\end{array}$ & $\begin{array}{c}2009 \\
n=9\end{array}$ & $\begin{array}{c}2007 \\
n=5\end{array}$ & $\begin{array}{c}2008 \\
n=7\end{array}$ & $\begin{array}{c}2009 \\
n=5\end{array}$ & $\begin{array}{c}2010 \\
n=6\end{array}$ & $\begin{array}{c}2011 \\
n=7\end{array}$ & \\
\hline Sem etiquetas & 11 & 18 & 22 & 40 & 14 & 20 & 67 & 14 & 24 \\
\hline Nominativas & 89 & 82 & 78 & 40 & 86 & 80 & 33 & 86 & 74 \\
\hline Relacionais & 0 & 0 & 0 & 20 & 0 & 0 & 0 & 0 & 2 \\
\hline $\begin{array}{l}\text { Notas: } \\
n=\text { número de ilus } \\
{ }^{1} \text { CG: Questões de } \\
{ }^{2} \text { ES: Questões de } \\
\text { Uma questão pode }\end{array}$ & sent & is de & ilustr & $\mathrm{ram}$ & & & & & \\
\hline
\end{tabular}

Os resultados oriundos da tabela 48 salientam que:

- a categoria "nominativa" apresentou a maior ocorrência dos resultados obtidos para as etiquetas verbais dos exames da VUNESP/UNIFESP.

- a categoria "sem etiquetas" manteve altas frequências nos anos 2007 e 2010 nas provas de conhecimentos específicos. Nos anos 2010 e 2011 as ocorrências foram somente para as provas de conhecimentos específicos, pois as provas de conhecimentos gerais foram substituídas pela prova do ENEM. 
Tabela 49 - Resultado para as etiquetas verbais encontradas no exame do ENEM nos anos 2010 e 2011.

\begin{tabular}{|c|c|c|c|}
\hline \multirow{2}{*}{ Etiquetas Verbais } & \multicolumn{3}{|c|}{$\begin{array}{c}\text { Ocorrência das etiquetas verbais nas } \\
\text { ilustrações para cada ano, para cada } \\
\text { prova, } \%\end{array}$} \\
\hline & $\begin{array}{l}\mathbf{2 0 1 0} \\
n=10\end{array}$ & $\begin{array}{l}\mathbf{2 0 1 1} \\
n=12\end{array}$ & $\begin{array}{l}\text { Total } \\
n=22\end{array}$ \\
\hline Sem etiquetas & 40 & 25 & 32 \\
\hline Nominativas & 60 & 67 & 64 \\
\hline Relacionais & 0 & 8 & 4 \\
\hline \multicolumn{4}{|c|}{$\begin{array}{l}\text { Notas: } \\
n=\text { número de ilustrações. } \\
\text { Uma questão pode apresentar mais de uma ilustração. }\end{array}$} \\
\hline
\end{tabular}

Os resultados apresentados na tabela 49 indicam que:

- as ilustrações com etiquetas verbais "nominativas" foram as mais frequentes nas provas do ENEM.

- apenas uma ilustração presente na prova de 2011 foi classificada na categoria de etiquetas verbais "relacionais".

No processo de exploração das ilustrações no ensino de ciências, o uso de etiquetas verbais ou tarefas que obriguem o leitor a extrair informações delas mesmas são muito importantes e essenciais.

Os resultados, de forma geral e individual, mostraram que a maior parte das provas dos vestibulares das instituições paulistas e ENEM envolvem etiquetas verbais em ilustrações de química, evidenciando altas frequências na categoria "nominativa". 


\subsection{Eixo 2 - A Relação entre a representação visual e seu entorno na questão}

\section{Relação texto-imagem}

Foram analisados os tipos de relações existentes entre o texto e a imagem, fazendo referência explícita à ilustração (ou ilustrações) presente no texto da questão como um todo, excluindo o que se incorpora na própria ilustração.

Na tabela 50 encontram-se os resultados para a categoria relação texto-imagem para as questões das provas de primeira e segunda fase dos exames vestibulares nos anos de 2007 a 2011.

Tabela 50 - Ocorrência para a relação texto-imagem encontrada nas questões da primeira e segunda fase dos exames vestibulares das cinco universidades paulistas e ENEM nos anos de 2007 a 2011.

\begin{tabular}{|c|c|c|c|}
\hline \multirow[b]{2}{*}{ Texto-imagem } & \multicolumn{3}{|c|}{ Ocorrência nas Questões, $\%$} \\
\hline & $\begin{array}{c}\mathbf{C G}^{\mathbf{1}} \\
n=172\end{array}$ & $\begin{array}{c}\mathbf{E S}^{\mathbf{2}} \\
n=137\end{array}$ & $\begin{array}{c}\text { Total } \\
n=309\end{array}$ \\
\hline Sinótica & 74 & 76 & 75 \\
\hline Denotativa & 24 & 15 & 20 \\
\hline Conotativa & 2 & 9 & 5 \\
\hline \multicolumn{4}{|c|}{$\begin{array}{l}\text { Notas: } \\
\text { n= número de ilustrações. } \\
\text { I CG: Questões de conteúdos gerais (primeira fase do exame) } \\
2 \text { ES: Questões de conteúdos específicos (segunda fase do exame) } \\
\text { Uma questão pode apresentar mais de uma ilustração. } \\
\text { As questões do ENEM (2010 e 2011) foram contabilizadas na primeira fase de } \\
\text { conhecimentos gerais. }\end{array}$} \\
\hline
\end{tabular}

Em ambas as fases, a categoria mais frequente é a "sinótica" apresentando maior ocorrência em relação às demais categorias (74\% na primeira fase e $76 \%$ na segunda fase), ou seja, a maior parte das ilustrações encontradas apresenta uma forte relação com o texto da questão, existindo a linguagem combinada entre ambos e estabelecendo uma dupla codificação (texto e imagem) que deve ser corretamente interpretada no momento da leitura.

As tabelas 51 e 52 apresentam os resultados da análise individual da relação textoimagem para cada exame analisado. 
Tabela 51 - Ocorrência para a relação texto-imagem encontrada em questões de conhecimentos gerais (primeira fase) dos exames vestibulares de cada universidade e ENEM nos anos de 2007 a 2011.

\begin{tabular}{|c|c|c|c|c|c|c|}
\hline \multirow[b]{2}{*}{$\begin{array}{l}\text { Texto- } \\
\text { imagem }\end{array}$} & \multicolumn{6}{|c|}{ Ocorrência nas Questões, \% } \\
\hline & $\begin{array}{c}\text { FUVEST } \\
\text { (USP) } \\
n=44\end{array}$ & $\begin{array}{c}\text { COMVEST } \\
\text { (UNICAMP) } \\
n=6\end{array}$ & $\begin{array}{c}\text { VUNESP } \\
\text { (UNESP) } \\
n=60\end{array}$ & $\begin{array}{c}\text { VUNESP } \\
\text { (UFSCAR) } \\
n=11\end{array}$ & $\begin{array}{c}\text { VUNESP } \\
\text { (UNIFESP) } \\
n=29\end{array}$ & $\begin{array}{c}\text { ENEM } \\
n=22\end{array}$ \\
\hline Sinótica & 80 & 100 & 72 & 100 & 72 & 52 \\
\hline Denotativa & 20 & 0 & 27 & 0 & 24 & 38 \\
\hline Conotativa & 0 & 0 & 2 & 0 & 3 & 10 \\
\hline
\end{tabular}

Tabela 52 - Ocorrência para a relação texto-imagem encontrada em questões de conhecimentos específicos (segunda fase) dos exames vestibulares de cada universidade nos anos de 2007 a 2011.

\begin{tabular}{lccccc}
\hline \multirow{2}{*}{$\begin{array}{l}\text { Texto- } \\
\text { imagem }\end{array}$} & $\begin{array}{c}\text { FUVEST } \\
\text { (USP) } \\
n=44\end{array}$ & $\begin{array}{c}\text { COMVEST } \\
\text { (UNICAMP) } \\
n=6\end{array}$ & $\begin{array}{c}\text { VUNESP } \\
\text { (UNESP) } \\
n=60\end{array}$ & $\begin{array}{c}\text { VUNESP } \\
\text { (UFSCAR) } \\
n=11\end{array}$ & $\begin{array}{c}\text { VUNESP } \\
\text { (UNIFESP) } \\
n=29\end{array}$ \\
\hline Sinótica & 64 & 81 & 91 & 50 & 83 \\
Denotativa & 18 & 19 & 9 & 50 & 7 \\
Conotativa & 18 & 0 & 0 & 0 & 10 \\
\hline
\end{tabular}

$n=$ número de ilustrações.

Uma questão pode apresentar mais de uma ilustração.

As tabelas 51 e 52 indicam que:

- de uma forma geral, a categoria "sinótica" foi a mais frequente dos resultados em relação as demais categorias. Isto sugere a ideia de complementação do texto com a imagem como forma indivisível, mostrando que existe certa preocupação com as imagens constatadas nas questões na função de auxiliar o candidato na sua total compreensão do tema abordado, tornando mais "adequado" o uso da visualização no ensino da química.

- outro ponto notável na tabela 51 da primeira fase é que as provas da COMVEST/UNICAMP e da VUNESP/UFSCAR totalizaram 100\% na categoria "sinótica", ou seja, as provas de conhecimentos gerais destas universidades utilizam imagens totalmente relacionadas com o texto da questão.

- as questões contabilizadas na categoria "denotativa" também são importantes, pois 
demonstram a existência da relação texto-imagem, porém não de uma forma indivisível.

- os resultados para o ENEM revelam que pouco mais da metade de suas questões (52\%) corresponde à categoria "sinótica", e 38\% para "denotativa". Assim, as imagens presentes estão interligadas ao texto das questões, mostrando-se importantes para a interpretação do conhecimento envolvido. A categoria "conotativa" apresentou ocorrência de $10 \%$, ou seja, questões que não relacionam a ilustração com o texto que contém as informações para sua resolução.

As tabelas 53, 54, 55, 56, 57 e 58 indicam os resultados individuais para cada exame das instituições de ensino superior e ENEM para a análise da relação texto-imagem entre os anos de 2007 e 2011.

\section{FUVEST/USP}

Tabela 53 - Resultado para a relação texto-imagem das ilustrações encontrado na primeira fase (CG) e segunda fase (ES) dos exames vestibulares da FUVEST/USP de 2007 a 2011.

\begin{tabular}{|c|c|c|c|c|c|c|c|c|c|c|c|}
\hline \multirow{3}{*}{$\begin{array}{c}\text { Texto- } \\
\text { imagem }\end{array}$} & \multicolumn{11}{|c|}{ Ocorrência para a relação texto-imagem para cada ano, para cada prova, $\%$} \\
\hline & \multicolumn{5}{|c|}{$\mathbf{C G}^{\mathbf{1}}$} & \multicolumn{5}{|c|}{$\mathbf{E S}^{2}$} & \multirow[b]{2}{*}{$\begin{array}{l}\text { Total } \\
n=99\end{array}$} \\
\hline & $\begin{array}{l}\mathbf{2 0 0 7} \\
n=12\end{array}$ & $\begin{array}{l}\mathbf{2 0 0 8} \\
n=12\end{array}$ & $\begin{array}{c}2009 \\
n=6\end{array}$ & $\begin{array}{c}2010 \\
n=9\end{array}$ & $\begin{array}{l}2011 \\
n=5\end{array}$ & $\begin{array}{l}\mathbf{2 0 0 7} \\
n=10\end{array}$ & $\begin{array}{l}\mathbf{2 0 0 8} \\
n=14\end{array}$ & $\begin{array}{l}\mathbf{2 0 0 9} \\
n=12\end{array}$ & $\begin{array}{l}2010 \\
n=11\end{array}$ & $\begin{array}{c}2011 \\
n=8\end{array}$ & \\
\hline Sinótica & 75 & 83 & 83 & 89 & 60 & 30 & 79 & 42 & 91 & 75 & 70 \\
\hline Denotativa & 25 & 17 & 17 & 11 & 40 & 30 & 21 & 17 & 9 & 12 & 19 \\
\hline Conotativa & 0 & 0 & 0 & 0 & 0 & 40 & 0 & 42 & 0 & 12 & 10 \\
\hline \multicolumn{12}{|c|}{$\begin{array}{l}\text { Notas: } \\
n=\text { número de ilustrações. } \\
{ }^{1} \text { CG: Questões de conteúdos gerais (primeira fase do exame) } \\
{ }^{2} \text { ES: Questões de conteúdos especificos (segunda fase do exame) } \\
\text { Uma questão pode apresentar mais de uma ilustração. }\end{array}$} \\
\hline
\end{tabular}

Os resultados apresentados para o vestibular da FUVEST/USP indicam que:

- nas provas de conhecimentos gerais, para cada categoria, as ocorrências apresentamse de forma homogênea com o passar dos anos, diferentemente das provas de conhecimentos específicos.

- a categoria mais frequente foi a "sinótica", apresentando altas ocorrências em relação 
as demais categorias.

- houve uma diminuição do número de ocorrência para a categoria "denotativa" com o passar dos anos, com exceção da prova de conhecimentos gerais do ano de 2011.

- a categoria "conotativa" não obteve ocorrências nas provas de conhecimentos gerais durante os cinco anos analisados, apenas em provas de conhecimentos específicos nos anos de 2007, 2009 e 2011.

\section{COMVEST/UNICAMP}

Tabela 54 - Resultado para a categoria relação texto-imagem das ilustrações encontrado na primeira fase (CG) e segunda fase (ES) dos exames vestibulares da COMVEST/UNICAMP de 2007 a 2011.

\begin{tabular}{|c|c|c|c|c|c|c|c|c|c|c|}
\hline \multirow[b]{3}{*}{$\begin{array}{l}\text { Texto- } \\
\text { imagem }\end{array}$} & \multicolumn{10}{|c|}{ Ocorrência para a relação texto-imagem para cada ano, para cada prova, $\%$} \\
\hline & \multicolumn{4}{|c|}{$\mathrm{CG}^{1}$} & \multicolumn{5}{|c|}{$\mathbf{E S}^{2}$} & \multirow[b]{2}{*}{$\begin{array}{l}\text { Total } \\
n=33\end{array}$} \\
\hline & $\begin{array}{c}2007 \\
n=1\end{array}$ & $\begin{array}{c}\mathbf{2 0 0 8} \\
n=2\end{array}$ & $\begin{array}{c}2009 \\
n=1\end{array}$ & $\begin{array}{l}2010 \\
n=2\end{array}$ & $\begin{array}{c}2007 \\
n=5\end{array}$ & $\begin{array}{c}2008 \\
n=3\end{array}$ & $\begin{array}{c}\mathbf{2 0 0 9} \\
n=8\end{array}$ & $\begin{array}{c}2010 \\
n=6\end{array}$ & $\begin{array}{c}2011 \\
n=5\end{array}$ & \\
\hline Sinótica & 100 & 100 & 100 & 100 & 60 & 66 & 100 & 83 & 80 & 85 \\
\hline Denotativa & 0 & 0 & 0 & 0 & 40 & 33 & 0 & 17 & 20 & 15 \\
\hline Conotativa & 0 & 0 & 0 & 0 & 0 & 0 & 0 & 0 & 0 & 0 \\
\hline \multicolumn{11}{|c|}{$\begin{array}{l}\text { Notas: } \\
n=\text { número de ilustrações. } \\
{ }^{1} \text { CG: Questões de conteúdos gerais (primeira fase do exame) } \\
{ }^{2} \text { ES: Questões de conteúdos específicos (segunda fase do exame) } \\
\text { Uma questão pode apresentar mais de uma ilustração. }\end{array}$} \\
\hline
\end{tabular}

Os resultados para o vestibular da COMVEST/UNICAMP mostram que:

- nas provas de primeira fase, todas as questões são "sinóticas", ou seja, todas as questões de conhecimentos gerais se relacionam fortemente com a imagem.

- a categoria "conotativa" não apresentou ocorrências durante os anos analisados.

- a categoria "denotativa" apresentou ocorrências somente em provas de conhecimentos específicos.

- com o passar dos anos as questões que relacionam o texto com a imagem representados pela categoria "sinótica" tiveram um aumento de ocorrências em 2009 e 2010, porém diminuíram em 2011. 


\section{VUNESP/UFSCAR}

Tabela 55 - Resultado para a categoria relação texto-imagem das ilustrações encontrado na primeira fase (CG) e segunda fase (ES) dos exames vestibulares da VUNESP/UFSCAR de 2007 a 2011.

\begin{tabular}{|c|c|c|c|c|c|}
\hline \multirow{3}{*}{ Texto-imagem } & \multicolumn{5}{|c|}{$\begin{array}{l}\text { Ocorrência para a relação texto-imagem para cada ano, para cada } \\
\text { prova, } \%\end{array}$} \\
\hline & \multicolumn{3}{|c|}{$\mathbf{C G}^{1}$} & \multirow{2}{*}{$\begin{array}{c}\mathbf{E S}^{\mathbf{2}} \\
\mathbf{2 0 1 0} \\
n=2\end{array}$} & \multirow[b]{2}{*}{$\begin{array}{l}\text { Tota } \\
n=13\end{array}$} \\
\hline & $\begin{array}{l}2007 \\
n=4\end{array}$ & $\begin{array}{l}2008 \\
N=5\end{array}$ & $\begin{array}{l}2009 \\
n=2\end{array}$ & & \\
\hline Sinótica & 100 & 100 & 100 & 50 & 92 \\
\hline Denotativa & 0 & 0 & 0 & 50 & 8 \\
\hline Conotativa & 0 & 0 & 0 & 0 & 0 \\
\hline \multicolumn{6}{|c|}{$\begin{array}{l}\text { Notas: } \\
n=\text { número de ilustrações. } \\
{ }^{1} \text { CG: Questões de conteúdos gerais (primeira fase do exame) } \\
{ }^{2} \text { ES: Questões de conteúdos especificos (segunda fase do exame) } \\
\text { Uma questão pode apresentar mais de uma ilustração. }\end{array}$} \\
\hline
\end{tabular}

Os resultados para os exames vestibulares da VUNESP/UFSCAR indicam que:

- $\quad$ somente a prova de conhecimentos específicos em 2010 apresentou ocorrência para a categoria "denotativa".

- a categoria "conotativa" não apresentou ocorrências durante os anos analisados.

- as altas ocorrências para a categoria "sinótica" refletem a existência da relação textoimagem das questões de química contendo ilustrações. 


\section{VUNESP/UNESP}

Tabela 56 - Resultado para a relação texto-imagem das ilustrações encontrado na primeira fase (CG) e segunda fase (ES) dos exames vestibulares da VUNESP/UNESP de 2007 a 2011.

\begin{tabular}{|c|c|c|c|c|c|c|c|c|c|c|c|}
\hline \multirow{3}{*}{$\begin{array}{c}\text { Texto- } \\
\text { imagem }\end{array}$} & \multicolumn{11}{|c|}{ Ocorrência para a relação texto-imagem para cada ano, para cada prova, $\%$} \\
\hline & \multicolumn{5}{|c|}{$\mathbf{C G}^{\mathbf{1}}$} & \multicolumn{5}{|c|}{$\mathbf{E S}^{2}$} & \multirow[b]{2}{*}{$\begin{array}{l}\text { Total } \\
n=83\end{array}$} \\
\hline & $\begin{array}{l}2007 \\
n=10\end{array}$ & $\begin{array}{l}\mathbf{2 0 0 8} \\
n=10\end{array}$ & $\begin{array}{l}\mathbf{2 0 0 9} \\
n=13\end{array}$ & $\begin{array}{l}2010 \\
n=16\end{array}$ & $\begin{array}{l}2011 \\
n=11\end{array}$ & $\begin{array}{c}2007 \\
n=5\end{array}$ & $\begin{array}{c}2008 \\
n=4\end{array}$ & $\begin{array}{c}2009 \\
n=5\end{array}$ & $\begin{array}{c}2010 \\
n=6\end{array}$ & $\begin{array}{c}2011 \\
n=3\end{array}$ & \\
\hline Sinótica & 80 & 70 & 69 & 62 & 82 & 80 & 100 & 100 & 100 & 66 & 77 \\
\hline Denotativa & 20 & 20 & 31 & 38 & 18 & 20 & 0 & 0 & 0 & 33 & 22 \\
\hline Conotativa & 0 & 10 & 0 & 0 & 0 & 0 & 0 & 0 & 0 & 0 & 1 \\
\hline \multicolumn{12}{|c|}{$\begin{array}{l}\text { Notas: } \\
n=\text { número de ilustrações. } \\
{ }^{1} \text { CG: Questões de conteúdos gerais (primeira fase do exame) } \\
{ }^{2} \text { ES: Questões de conteúdos especificos (segunda fase do exame) } \\
\text { Uma questão pode apresentar mais de uma ilustração. }\end{array}$} \\
\hline
\end{tabular}

Os resultados encontrados para a relação texto-imagem indicam que:

- diferente dos demais exames, os resultados para as provas de conhecimentos específicos foram mais homogêneos durante os anos analisados.

- a categoria "sinótica" foi a mais frequente dentre as três categorias, apresentando maiores ocorrências nas provas de conhecimentos específicos.

- apenas a prova de conhecimentos gerais de 2008 apresentou ocorrência (10\%) na categoria "conotativa".

- as provas de conhecimentos específicos nos anos de 2008, 2009 e 2010 apresentaram ocorrências somente na categoria "sinótica" salientando que $100 \%$ das questões que contém ilustrações mantém a relação texto-imagem. 


\section{VUNESP/UNIFESP}

Tabela 57 - Resultado para a relação texto-imagem das ilustrações encontrado na primeira fase (CG) e segunda fase (ES) dos exames vestibulares da VUNESP/UNIFESP de 2007 a 2011.

\begin{tabular}{|c|c|c|c|c|c|c|c|c|c|}
\hline \multirow{3}{*}{ Texto-imagem } & \multicolumn{9}{|c|}{ Ocorrência para a relação texto-imagem para cada ano, para cada prova, \% } \\
\hline & \multicolumn{3}{|c|}{$\mathbf{C G}^{\mathbf{1}}$} & \multicolumn{5}{|c|}{$\mathbf{E S}^{2}$} & \multirow[b]{2}{*}{$\begin{array}{l}\text { Total } \\
n=59\end{array}$} \\
\hline & $\begin{array}{c}2007 \\
n=9\end{array}$ & $\begin{array}{l}\mathbf{2 0 0 8} \\
n=11\end{array}$ & $\begin{array}{c}2009 \\
n=9\end{array}$ & $\begin{array}{c}2007 \\
n=5\end{array}$ & $\begin{array}{c}2008 \\
n=7\end{array}$ & $\begin{array}{c}2009 \\
n=5\end{array}$ & $\begin{array}{c}2010 \\
n=6\end{array}$ & $\begin{array}{c}2011 \\
n=7\end{array}$ & \\
\hline Sinótica & 89 & 73 & 55 & 100 & 57 & 80 & 83 & 100 & 78 \\
\hline Denotativa & 11 & 18 & 44 & 0 & 0 & 20 & 17 & 0 & 15 \\
\hline Conotativa & 0 & 9 & 0 & 0 & 43 & 0 & 0 & 0 & 7 \\
\hline \multicolumn{10}{|c|}{$\begin{array}{l}\text { Notas: } \\
n=\text { número de ilustrações. } \\
{ }^{2} \text { CG: Questões de conteúdos gerais (primeira fase do exame) } \\
2 \text { ES: Questôes de conteúdos especificos (segunda fase do exame) } \\
\text { Uma questão pode apresentar mais de uma ilustração. }\end{array}$} \\
\hline
\end{tabular}

Os resultados para os vestibulares da VUNESP/UNIFESP mostram que:

- de modo geral, a categoria mais frequente nas provas foi a "sinótica". Com o passar dos anos houve uma diminuição do número de ocorrências nas provas de conhecimentos gerais.

- já a categoria "denotativa" teve um aumento de ocorrências nas provas de conhecimentos gerais do ano 2007 a 2009.

- a categoria "conotativa" apresentou ocorrências somente nas provas do ano de 2008, sendo $43 \%$ das ocorrências nas provas de conhecimentos específicos (ES) e 9\% em conhecimentos gerais (CG). 
Tabela 58 - Resultado para a relação texto-imagem das ilustrações encontrado no exame do ENEM nos anos 2010 e 2011.

\begin{tabular}{lcc|c}
\hline \multirow{2}{*}{ Texto-imagem } & \multicolumn{3}{c}{$\begin{array}{c}\text { Ocorrência para a relação texto-imagem para } \\
\text { cada ano, para cada prova, \% }\end{array}$} \\
\cline { 2 - 4 } & $\begin{array}{c}\mathbf{2 0 1 0} \\
n=10\end{array}$ & $\begin{array}{c}\mathbf{2 0 1 1} \\
n=12\end{array}$ & $\begin{array}{c}\text { Total } \\
n=22\end{array}$ \\
\hline Sinótica & 20 & 75 & 50 \\
Denotativa & 60 & 25 & 41 \\
Conotativa & 20 & 0 & 9 \\
\hline $\begin{array}{l}\text { Notas: } \\
n=\text { número de ilustrações. } \\
\text { Uma questão pode apresentar mais de uma ilustração. }\end{array}$ \\
\hline
\end{tabular}

Os resultados para as provas do ENEM mostram que:

- diferente dos resultados gerais encontrados para todos os exames, a categoria mais frequente para a prova do ENEM no ano de 2010 foi a "denotativa". As categorias "sinótica" e "conotativa" tiveram o mesmo número de ocorrências (20\%)

- já nas provas de 2011, a categoria mais frequente foi a "sinótica" com $75 \%$ das ocorrências, seguida da categoria "denotativa" com 25\%. A categoria "conotativa" não apresentou ocorrências para este ano.

Os exames vestibulares como um todo envolvem conceitos e fenômenos que podem ser compreendidos além da sua representação teórica, potencializando o seu uso associado às imagens. Diante dos resultados, de modo geral, algumas ocorrências apareceram em ambas as fases do conhecimento (geral e específico) para questões que não envolveram a relação texto-imagem, podendo ser observado nos resultados obtidos para a categoria “conotativa". Somente a presença da representação gráfica não fará a garantia de que os candidatos que prestam o exame vestibular resolvam as questões e estabeleçam por si próprios os vínculos necessários entre os conteúdos e conceitos apresentados nestas provas de seleção.

Os resultados para os vestibulares da USP e UFSCAR mostram que suas questões relacionam fortemente a imagem com o texto informativo, apresentando altas ocorrências na 
categoria "sinótica" e nenhuma ocorrência na "conotativa". A categoria "denotativa" apresentou ocorrências significativas nas provas da USP, porém, identificou-se que estas foram diminuindo com o passar dos anos, ou seja, aumentando a relação texto-imagem das questões. O contrário ocorreu com os vestibulares da UNIFESP, as quais apresentaram altas ocorrências para a categoria "sinótica", porém houve uma diminuição com o passar dos anos, aumentando assim as ocorrências para as categorias "denotativa" e "conotativa".

Já nas provas de conhecimentos específicos do vestibular da UNICAMP e do exame do ENEM (2010), a categoria predominante foi a "denotativa", em que o texto estabelece a correspondência entre os elementos da ilustração e os conteúdos nela representados, mas não de uma forma indivisível ou que se tenha uma dependência entre ambos, como para a categoria "sinótica".

No que diz respeito a taxonomia empregada a partir do trabalho de Perales e Jiménez (2002), percebe-se que esta se torna um útil instrumento de análise e investigação, pois possibilitou fazer identificações e classificações das representações visuais assim como a função que podem desempenhar nos textos das questões. Portanto, este estudo pode servir para selecionar materiais didáticos que apresentam ilustrações, podendo identificar fracas conexões entre as imagens e os textos, assim como a carência de etiquetas verbais que podem contribuir na compreensão da ilustração. Além disso, a taxonomia elaborada por Perales e Jiménez (2002) aborda a compreensão das ilustrações e o seu processamento pelos leitores, assim, pode auxiliar em investigações do processo de compreensão de conteúdos. 


\subsection{Eixo 3 - A questão de química no vestibular como um todo}

\section{Assuntos químicos envolvidos nas questões}

Nesta análise totalizou-se sete assuntos químicos envolvidos nas questões que continham ilustrações. Na tabela 59 encontram-se os resultados gerais dos seis exames estudados durante os anos de 2007 a 2011, divididos em primeira fase (CG) e segunda fase (ES).

Tabela 59 - Ocorrência para os assuntos químicos das questões da primeira e segunda fase dos exames vestibulares das cinco universidades paulistas e ENEM nos anos de 2007 a 2011.

\begin{tabular}{|c|c|c|c|}
\hline \multirow[b]{2}{*}{ Assuntos Químicos } & \multicolumn{3}{|c|}{ Ocorrência nas Questões, \% } \\
\hline & $\begin{array}{c}\mathbf{C G}^{\mathbf{1}} \\
n=176\end{array}$ & $\begin{array}{c}\mathbf{E S}^{\mathbf{2}} \\
n=146\end{array}$ & $\begin{array}{c}\text { Total } \\
n=322\end{array}$ \\
\hline Físico-química & 34 & 26 & 33 \\
\hline Química Orgânica & 26 & 25 & 28 \\
\hline Química Inorgânica & 14 & 9 & 12 \\
\hline Química Geral & 11 & 15 & 14 \\
\hline Bioquímica & 6 & 5 & 6 \\
\hline Meio Ambiente & 6 & 2 & 4 \\
\hline Química Nuclear & 4 & 2 & 3 \\
\hline \multicolumn{4}{|c|}{$\begin{array}{l}\text { Notas: } \\
n=\text { número total de assuntos quimicos abordados nas questões. } \\
{ }^{1} \text { CG: Questões de conteúdos gerais (primeira fase do exame) } \\
2 \text { ES: Questões de conteúdos especificos (segunda fase do exame) } \\
\text { Uma questão pode apresentar mais de um assunto quimico. } \\
\text { As questões do ENEM (2010 e 2011) foram contabilizadas na primeira fase de } \\
\text { conhecimentos gerais. }\end{array}$} \\
\hline
\end{tabular}

Diante dos resultados, percebe-se que na primeira fase (CG) o assunto químico mais frequente é "físico-química" com 34\% das ocorrências. Na segunda fase (ES) "físicoquímica" e "química orgânica" tiveram ocorrências aproximadas, $26 \%$ e $25 \%$ respectivamente. As tabelas 60 e 61 indicam os assuntos químicos mais frequentes em cada exame na primeira e segunda fase respectivamente. 
Tabela 60 - Ocorrência para os assuntos químicos encontrados nas questões de conhecimentos gerais (primeira fase) dos exames vestibulares de cada universidade e ENEM nos anos de 2007 a 2011.

\begin{tabular}{|c|c|c|c|c|c|c|}
\hline \multirow[b]{2}{*}{$\begin{array}{l}\text { Assuntos } \\
\text { Químicos }\end{array}$} & \multicolumn{6}{|c|}{ Ocorrência nas Questões, \% } \\
\hline & $\begin{array}{c}\text { FUVEST } \\
\text { (USP) } \\
n=37\end{array}$ & $\begin{array}{c}\text { COMVEST } \\
\text { (UNICAMP) } \\
n=6\end{array}$ & $\begin{array}{c}\text { VUNESP } \\
\text { (UNESP) } \\
n=62\end{array}$ & $\begin{array}{c}\text { VUNESP } \\
\text { (UFSCAR) } \\
n=10\end{array}$ & $\begin{array}{c}\text { VUNESP } \\
\text { (UNIFESP) } \\
n=33\end{array}$ & $\begin{array}{c}\text { ENEM } \\
n=28\end{array}$ \\
\hline Físico-química & 30 & 33 & 42 & 30 & 24 & 36 \\
\hline Química Orgânica & 35 & 33 & 19 & 50 & 27 & 14 \\
\hline $\begin{array}{l}\text { Química } \\
\text { Inorgânica }\end{array}$ & 16 & 17 & 10 & 0 & 24 & 11 \\
\hline Química Geral & 8 & 17 & 10 & 10 & 15 & 11 \\
\hline Bioquímica & 3 & 0 & 11 & 0 & 6 & 4 \\
\hline Meio Ambiente & 3 & 0 & 5 & 10 & 0 & 18 \\
\hline Química Nuclear & 5 & 0 & 3 & 0 & 3 & 7 \\
\hline
\end{tabular}

Tabela 61 - Ocorrência para os assuntos químicos encontrados nas questões de conhecimentos específicos (segunda fase) dos exames vestibulares de cada universidade nos anos de 2007 a 2011.

\begin{tabular}{|c|c|c|c|c|c|}
\hline \multirow[b]{2}{*}{ Assuntos Químicos } & \multirow[b]{2}{*}{$\begin{array}{c}\text { FUVEST } \\
\text { (USP) } \\
n=49\end{array}$} & \multicolumn{4}{|c|}{ Ocorrência nas Questões, $\%$} \\
\hline & & $\begin{array}{c}\text { COMVEST } \\
\text { (UNICAMP) } \\
n=37\end{array}$ & $\begin{array}{c}\text { VUNESP } \\
\text { (UNESP) } \\
n=22\end{array}$ & $\begin{array}{c}\text { VUNESP } \\
\text { (UFSCAR) } \\
n=3\end{array}$ & $\begin{array}{c}\text { VUNESP } \\
\text { (UNIFESP) } \\
n=35\end{array}$ \\
\hline Físico-química & 29 & 19 & 41 & 0 & 43 \\
\hline Química Orgânica & 39 & 22 & 32 & 33 & 26 \\
\hline Química Inorgânica & 10 & 14 & 9 & 0 & 9 \\
\hline Química Geral & 8 & 27 & 18 & 33 & 20 \\
\hline Bioquímica & 10 & 11 & 0 & 0 & 0 \\
\hline Meio Ambiente & 0 & 5 & 0 & 33 & 0 \\
\hline Química Nuclear & 4 & 3 & 0 & 0 & 3 \\
\hline
\end{tabular}

Os resultados das tabelas 60 e 61 indicam que:

- em geral, os assuntos químicos mais frequentes foram "físico-química" e "química orgânica”. Os exames apresentam um grande número de estruturas orgânicas em suas ilustrações quando abordam reações orgânicas e identificação de funções orgânicas.

- na prova do ENEM, os assuntos químicos predominantes foram "físico-química", "química orgânica" e "meio ambiente". Acredita-se que o tema "meio ambiente" foi mais frequente nas provas do ENEM por relacionar assuntos interdisciplinares, sendo esta uma característica do perfil do exame. A questão ambiental se relaciona facilmente com várias áreas do conhecimento, tornando a prova com características de conhecimentos gerais, sem especificação de uma determinada área como a 
química, mas sim como ciências naturais.

- $\quad$ os exames da USP, da UNICAMP e do ENEM foram os que abrangeram todos os assuntos químicos em suas questões, apresentando a melhor distribuição.

As tabelas 62, 63, 64, 65, 66 e 67 indicam os resultados individuais para cada exame das instituições de ensino superior e ENEM para a análise da ocorrência de assuntos químicos encontrado nas provas entre os anos de 2007 e 2011.

\section{FUVEST/USP}

Tabela 62 - Resultado para os assuntos químicos encontrados na primeira fase (CG) e segunda fase (ES) dos exames vestibulares da FUVEST/USP de 2007 a 2011.

\begin{tabular}{|c|c|c|c|c|c|c|c|c|c|c|c|}
\hline \multirow{3}{*}{$\begin{array}{l}\text { Assuntos } \\
\text { Químicos }\end{array}$} & \multicolumn{11}{|c|}{ Ocorrência dos assuntos químicos para cada ano, para cada prova, $\%$} \\
\hline & \multicolumn{5}{|c|}{$\mathbf{C G}^{\mathbf{1}}$} & \multicolumn{5}{|c|}{$\mathbf{E S}^{2}$} & \multirow[b]{2}{*}{$\begin{array}{l}\text { Total } \\
n=86\end{array}$} \\
\hline & $\begin{array}{l}\mathbf{2 0 0 7} \\
n=10\end{array}$ & $\begin{array}{c}2008 \\
n=8\end{array}$ & $\begin{array}{l}2009 \\
n=5\end{array}$ & $\begin{array}{c}2010 \\
n=9\end{array}$ & $\begin{array}{l}2011 \\
n=5\end{array}$ & $\begin{array}{l}\mathbf{2 0 0 7} \\
n=10\end{array}$ & $\begin{array}{c}2008 \\
n=9\end{array}$ & $\begin{array}{l}2009 \\
n=10\end{array}$ & $\begin{array}{l}\mathbf{2 0 1 0} \\
n=14\end{array}$ & $\begin{array}{l}2011 \\
n=6\end{array}$ & \\
\hline Físico-química & 20 & 50 & 20 & 22 & 40 & 30 & 33 & 40 & 29 & 0 & 29 \\
\hline $\begin{array}{l}\text { Química } \\
\text { Orgânica }\end{array}$ & 30 & 37 & 60 & 22 & 40 & 20 & 55 & 50 & 21 & 67 & 37 \\
\hline $\begin{array}{l}\text { Química } \\
\text { Inorgânica }\end{array}$ & 20 & 12 & 0 & 22 & 20 & 30 & 0 & 10 & 7 & 0 & 13 \\
\hline Química Geral & 10 & 0 & 20 & 11 & 0 & 20 & 11 & 0 & 7 & 0 & 8 \\
\hline Bioquímica & 10 & 0 & 0 & 0 & 0 & 0 & 0 & 0 & 29 & 17 & 7 \\
\hline Meio Ambiente & 0 & 0 & 0 & 11 & 0 & 0 & 0 & 0 & 0 & 0 & 1 \\
\hline Química Nuclear & 10 & 0 & 0 & 11 & 0 & 0 & 0 & 0 & 7 & 17 & 5 \\
\hline \multicolumn{12}{|c|}{$\begin{array}{l}\text { Notas: } \\
n=\text { números totais de assuntos químicos abordados nas questões. } \\
{ }^{1} \text { CG: Questões de conteúdos gerais (primeira fase do exame) } \\
{ }^{2} \text { ES: Questões de conteúdos especificos (segunda fase do exame) } \\
\text { Uma questão pode apresentar mais de um assunto químico. }\end{array}$} \\
\hline
\end{tabular}

Diante dos resultados analisados para as provas da FUVEST/USP, salienta-se que:

- de modo geral, os assuntos químicos mais frequentes foram "química orgânica" e "físico-química".

- os assuntos químicos menos frequentes foram "meio ambiente" e "química nuclear".

- o assunto de "bioquímica" apresentou ocorrência somente no ano de 2007 na prova de conhecimentos gerais, e em 2010 e 2011 nas provas de conhecimentos específicos. 
Tabela 63 - Resultado para os assuntos químicos encontrados na primeira fase (CG) e segunda fase (ES) dos exames vestibulares da COMVEST/UNICAMP de 2007 a 2011.

\begin{tabular}{|c|c|c|c|c|c|c|c|c|c|c|}
\hline \multirow{3}{*}{$\begin{array}{l}\text { Assuntos } \\
\text { Químicos }\end{array}$} & \multicolumn{10}{|c|}{ Ocorrência dos assuntos químicos para cada ano, para cada prova, $\%$} \\
\hline & \multicolumn{4}{|c|}{$\mathbf{C G}^{\mathbf{1}}$} & \multicolumn{5}{|c|}{ ES $^{2}$} & \multirow[b]{2}{*}{$\begin{array}{l}\text { Total } \\
n=43\end{array}$} \\
\hline & $\begin{array}{c}2007 \\
n=1\end{array}$ & $\begin{array}{c}2008 \\
n=2\end{array}$ & $\begin{array}{c}2009 \\
n=2\end{array}$ & $\begin{array}{c}2010 \\
n=1\end{array}$ & $\begin{array}{c}2007 \\
n=8\end{array}$ & $\begin{array}{c}2008 \\
n=4\end{array}$ & $\begin{array}{c}2009 \\
n=9\end{array}$ & $\begin{array}{c}2010 \\
n=8\end{array}$ & $\begin{array}{c}2011 \\
n=8\end{array}$ & \\
\hline Físico-química & 100 & 0 & 50 & 0 & 12 & 25 & 33 & 25 & 0 & 9 \\
\hline Química Orgânica & 0 & 50 & 0 & 100 & 25 & 0 & 22 & 25 & 25 & 10 \\
\hline Química Inorgânica & 0 & 0 & 50 & 0 & 25 & 0 & 0 & 12 & 25 & 6 \\
\hline Química Geral & 0 & 50 & 0 & 0 & 25 & 50 & 33 & 12 & 25 & 11 \\
\hline Bioquímica & 0 & 0 & 0 & 0 & 12 & 25 & 11 & 0 & 25 & 4 \\
\hline Meio Ambiente & 0 & 0 & 0 & 0 & 0 & 0 & 0 & 12 & 0 & 2 \\
\hline Química Nuclear & 0 & 0 & 0 & 0 & 0 & 0 & 0 & 12 & 0 & 1 \\
\hline \multicolumn{11}{|c|}{$\begin{array}{l}\text { Notas: } \\
n=\text { números totais de assuntos quimicos abordados nas questões. } \\
{ }^{1} \text { CG: Questões de conteúdos gerais (primeira fase do exame) } \\
{ }^{2} \text { ES: Questões de conteúdos específicos (segunda fase do exame) } \\
\text { Uma questão pode apresentar mais de um assunto químico. }\end{array}$} \\
\hline
\end{tabular}

Os resultados para as provas da COMVEST/UNICAMP mostram que:

- os assuntos de "química orgânica" e "química geral" foram os mais frequentes durante o período analisado.

- os assuntos menos frequentes foram "meio ambiente" e " química nuclear" onde apresentaram ocorrências (12\%) somente na prova de conhecimentos específicos do ano 2010. 
Tabela 64 - Resultado para os assuntos químicos encontrados na primeira fase (CG) e segunda fase (ES) dos exames vestibulares da VUNESP/UFSCAR de 2007 a 2011.

\begin{tabular}{|c|c|c|c|c|c|}
\hline \multirow{3}{*}{ Assuntos Químicos } & \multicolumn{5}{|c|}{ Ocorrência dos assuntos químicos para cada ano, para cada prova, \% } \\
\hline & \multicolumn{3}{|c|}{$\mathrm{CG}^{1}$} & \multirow{2}{*}{$\begin{array}{c}\mathbf{E S}^{\mathbf{2}} \\
\mathbf{2 0 1 0} \\
n=3\end{array}$} & \multirow[b]{2}{*}{$\begin{array}{l}\text { Total } \\
n=13\end{array}$} \\
\hline & $\begin{array}{c}2007 \\
n=3\end{array}$ & $\begin{array}{l}\mathbf{2 0 0 8} \\
N=5\end{array}$ & $\begin{array}{c}2009 \\
n=2\end{array}$ & & \\
\hline Físico-química & 33 & 20 & 50 & 0 & 23 \\
\hline Química Orgânica & 66 & 40 & 50 & 33 & 46 \\
\hline Química Inorgânica & 0 & 0 & 0 & 0 & 0 \\
\hline Química Geral & 0 & 20 & 0 & 33 & 15 \\
\hline Bioquímica & 0 & 0 & 0 & 0 & 0 \\
\hline Meio Ambiente & 0 & 20 & 0 & 33 & 15 \\
\hline Química Nuclear & 0 & 0 & 0 & 0 & 0 \\
\hline \multicolumn{6}{|c|}{$\begin{array}{l}\text { Notas: } \\
n=\text { números totais de assuntos químicos abordados nas questões. } \\
{ }^{1} \text { CG: Questões de conteúdos gerais (primeira fase do exame) } \\
{ }^{2} \text { ES: Questões de conteúdos especificos (segunda fase do exame) } \\
\text { Uma questão pode apresentar mais de um assunto quimico. }\end{array}$} \\
\hline
\end{tabular}

Os resultados para os assuntos químicos indicam que:

- os assuntos mais frequentes nas questões com ilustrações do vestibular da VUNESP/UFSCAR foram "química orgânica" e "físico-química".

- os assuntos "química inorgânica", "bioquímica" e "química nuclear" não apresentaram ocorrências durantes os anos analisados. 


\section{VUNESP/UNESP}

Tabela 65 - Resultado para os assuntos químicos encontrados na primeira fase (CG) e segunda fase (ES) dos exames vestibulares da VUNESP/UNESP de 2007 a 2011.

\begin{tabular}{|c|c|c|c|c|c|c|c|c|c|c|c|}
\hline \multirow{3}{*}{$\begin{array}{l}\text { Assuntos } \\
\text { Químicos }\end{array}$} & \multicolumn{11}{|c|}{ Ocorrência dos assuntos químicos para cada ano, para cada prova, $\%$} \\
\hline & \multicolumn{5}{|c|}{$\mathrm{CG}^{1}$} & \multicolumn{5}{|c|}{$\mathbf{E S}^{2}$} & \multirow[b]{2}{*}{$\begin{array}{l}\text { Total } \\
n=84\end{array}$} \\
\hline & $\begin{array}{l}2007 \\
n=11\end{array}$ & $\begin{array}{c}2008 \\
n=9\end{array}$ & $\begin{array}{l}\mathbf{2 0 0 9} \\
n=12\end{array}$ & $\begin{array}{l}\mathbf{2 0 1 0} \\
n=21\end{array}$ & $\begin{array}{l}2011 \\
n=9\end{array}$ & $\begin{array}{l}2007 \\
n=5\end{array}$ & $\begin{array}{c}2008 \\
n=5\end{array}$ & $\begin{array}{c}2009 \\
n=5\end{array}$ & $\begin{array}{c}2010 \\
n=4\end{array}$ & $\begin{array}{l}2011 \\
n=3\end{array}$ & \\
\hline Físico-química & 9 & 33 & 42 & 62 & 44 & 40 & 40 & 60 & 50 & 0 & 42 \\
\hline Química Orgânica & 54 & 22 & 8 & 5 & 22 & 40 & 40 & 0 & 25 & 67 & 23 \\
\hline $\begin{array}{l}\text { Química } \\
\text { Inorgânica }\end{array}$ & 18 & 11 & 8 & 9 & 0 & 0 & 0 & 20 & 0 & 33 & 9 \\
\hline Química Geral & 0 & 11 & 25 & 9 & 0 & 20 & 20 & 20 & 25 & 0 & 12 \\
\hline Bioquímica & 9 & 22 & 0 & 9 & 22 & 0 & 0 & 0 & 0 & 0 & 8 \\
\hline Meio Ambiente & 0 & 0 & 8 & 5 & 11 & 0 & 0 & 0 & 0 & 0 & 4 \\
\hline Química Nuclear & 9 & 0 & 8 & 0 & 0 & 0 & 0 & 0 & 0 & 0 & 2 \\
\hline \multicolumn{12}{|c|}{$\begin{array}{l}\text { Notas: } \\
n=\text { número total de assuntos quimicos abordados nas questões. } \\
{ }^{1} \text { CG: Questôes de conteúdos gerais (primeira fase do exame) } \\
{ }^{2} \text { ES: Questões de conteúdos especificos (segunda fase do exame) } \\
\text { Uma questão pode apresentar mais de um assunto químico. }\end{array}$} \\
\hline
\end{tabular}

Os resultados apresentados na tabela 65 para os vestibulares da VUNESP/UNESP indicam que:

- o assunto de "físico-química" foi o mais frequente entre os demais, havendo um aumento significativo nas provas de conhecimentos gerais $(\mathrm{CG})$ no decorrer dos anos de 2007 a 2010.

- os assuntos de "química nuclear", "meio ambiente" e "bioquímica" apresentaram ocorrências somente nas provas de conhecimentos gerais.

- o assunto menos frequente foi "química nuclear", apresentando ocorrências somente nas provas de primeira fase nos anos 2007 e 2009.

- a prova de conhecimentos gerais do ano de 2010 apresentou maior número de questões com ilustrações e $62 \%$ destas trataram sobre o assunto de "físico-química". Os assuntos de "química geral”, "química inorgânica" e "bioquímica" apresentaram 9\% das ocorrências, e "meio ambiente" e "química orgânica", 5\%. O assunto de “química nuclear" não apresentou ocorrências para este ano. 


\section{VUNESP/UNIFESP}

Tabela 66 - Resultado para os assuntos químicos encontrados na primeira fase (CG) e segunda fase (ES) dos exames vestibulares da VUNESP/UNIFESP de 2007 a 2011.

\begin{tabular}{|c|c|c|c|c|c|c|c|c|c|}
\hline \multirow{3}{*}{$\begin{array}{l}\text { Assuntos } \\
\text { Químicos }\end{array}$} & \multicolumn{9}{|c|}{ Ocorrência dos assuntos químicos para cada ano, para cada prova, $\%$} \\
\hline & \multicolumn{3}{|c|}{$\mathbf{C G}^{\mathbf{1}}$} & \multicolumn{5}{|c|}{ ES $^{2}$} & \multirow[b]{2}{*}{$\begin{array}{l}\text { Total } \\
n=68\end{array}$} \\
\hline & $\begin{array}{l}2007 \\
n=11\end{array}$ & $\begin{array}{l}\mathbf{2 0 0 8} \\
n=10\end{array}$ & $\begin{array}{l}\mathbf{2 0 0 9} \\
n=12\end{array}$ & $\begin{array}{c}2007 \\
n=8\end{array}$ & $\begin{array}{l}2008 \\
n=10\end{array}$ & $\begin{array}{c}2009 \\
n=5\end{array}$ & $\begin{array}{c}2010 \\
n=6\end{array}$ & $\begin{array}{c}2011 \\
n=6\end{array}$ & \\
\hline Físico-química & 27 & 30 & 17 & 50 & 30 & 40 & 33 & 67 & 34 \\
\hline Química Orgânica & 27 & 30 & 25 & 25 & 30 & 40 & 33 & 0 & 26 \\
\hline Química Inorgânica & 18 & 20 & 33 & 12 & 10 & 0 & 0 & 17 & 16 \\
\hline Química Geral & 9 & 10 & 25 & 12 & 30 & 20 & 17 & 17 & 18 \\
\hline Bioquímica & 18 & 0 & 0 & 0 & 0 & 0 & 0 & 0 & 3 \\
\hline Meio Ambiente & 0 & 0 & 0 & 0 & 0 & 0 & 0 & 0 & 0 \\
\hline Química Nuclear & 0 & 10 & 0 & 0 & 0 & 0 & 17 & 0 & 3 \\
\hline \multicolumn{10}{|c|}{$\begin{array}{l}\text { Notas: } \\
n=\text { número total de assuntos químicos abordados nas questões. } \\
{ }^{2} \text { CG: Questões de conteúdos gerais (primeira fase do exame) } \\
{ }^{2} \text { ES: Questões de conteúdos especificos (segunda fase do exame) } \\
\text { Uma questão pode apresentar mais de um assunto químico. }\end{array}$} \\
\hline
\end{tabular}

Os resultados para os vestibulares da VUNESP/UNIFESP indicam que:

- de modo geral, o assunto mais frequente foi "físico-química". Porém, em alguns anos, o assunto de "química orgânica" apresentou as mesmas ocorrências que "físicoquímica".

- houve uma diminuição das questões que envolvem o assunto de "físico-química" nos anos de 2007 a 2009.

- o assunto de "química nuclear" foi evidenciado em duas provas, com ocorrência de $10 \%$ na prova de conhecimentos gerais em 2008 e $17 \%$ na prova de conhecimentos específicos em 2010.

- o assunto "meio ambiente" não foi trabalhado nas questões contendo ilustrações durante o período analisado. 
Tabela 67 - Resultado para os assuntos químicos encontrado no exame do ENEM nos anos 2010 e 2011.

\begin{tabular}{lcc|c}
\hline & \multicolumn{3}{c}{ Ocorrência dos assuntos químicos } \\
para cada ano, para cada prova, \%
\end{tabular}

Os resultados obtidos das provas do ENEM mostram que:

- o assunto mais frequente em ambos os anos analisados foi "físico-química".

- os assuntos de "bioquímica" e "química nuclear" foram os menos frequentes.

- as provas possuem uma melhor distribuição dos assuntos químicos em relação aos demais exames vestibulares.

De forma geral entre os assuntos categorizados, "físico-química", “orgânica", "inorgânica" e "geral" foram os mais frequentes. Por outro lado os assuntos de "bioquímica", "meio ambiente" e "química nuclear" tiveram poucas ocorrências nas questões com ilustrações analisadas.

Desta forma, verifica-se que os organizadores dos exames vestibulares analisados abordam em suas provas determinados assuntos constantemente, enquanto que outros são esporadicamente empregados.

O exame que não apresentou ocorrências de questões contendo ilustrações com o assunto de "bioquímica" foi a VUNESP/UNESP, para o assunto de "química nuclear" foi a VUNESP/UFSCAR e para "meio ambiente" a VUNESP/UNIFESP. Os demais exames vestibulares das instituições USP, UNICAMP e o exame do ENEM trabalharam com todos os assuntos químicos categorizados dentro do período estudado, porém alguns foram 
distribuídos de forma mais equilibrada durante o ano do que outros.

Pode-se destacar neste estudo o exame da COMVEST/UNICAMP, pois suas provas apresentam questões que abordam assuntos com caráter amplo e generalista dos conhecimentos solicitados nas provas de química, neste caso as que contêm ilustrações.

\section{Habilidades cognitivas requisitadas}

A tabela 68 indica os resultados analisados para todos os exames vestibulares analisados em relação às habilidades cognitivas solicitadas nas questões, segundo Zoller: LOCS (habilidades cognitivas de baixa ordem) e HOCS (habilidades cognitivas de alta ordem).

Tabela 68 - Ocorrência para as questões que demandam HOCS e LOCS da primeira e segunda fase dos exames vestibulares das cinco universidades paulistas e ENEM nos anos de 2007 a 2011.

\begin{tabular}{|c|c|c|c|}
\hline \multirow[t]{2}{*}{ Ordem } & \multicolumn{3}{|c|}{ Ocorrência nas Questões, \% } \\
\hline & $\begin{array}{c}\mathbf{C G}^{\mathbf{1}} \\
n=147\end{array}$ & $\begin{array}{c}\mathbf{E S}^{\mathbf{2}} \\
n=105\end{array}$ & $\begin{array}{c}\text { Total } \\
n=252\end{array}$ \\
\hline $\mathrm{HOCS}^{3}$ & 29 & 76 & 49 \\
\hline LOCS $^{4}$ & 71 & 24 & 51 \\
\hline \multicolumn{4}{|c|}{$\begin{array}{l}\text { Notas: } \\
n=\text { número de questões. } \\
{ }^{1} \text { CG: Questões de conteúdos gerais (primeira fase do exame) } \\
{ }^{2} \text { ES: Questões de conteúdos especificos (segunda fase do exame) } \\
\text { As questões do ENEM (2010 e 2011) foram contabilizadas na primeira fase de } \\
\text { conhecimentos gerais. } \\
{ }^{3} \text { HOCS: habilidades cognitivas de alta ordem. }\end{array}$} \\
\hline
\end{tabular}

Pode-se observar que, de forma geral, tem-se uma inversão nos resultados na comparação entre as duas fases de provas, ou seja, na fase de conhecimentos gerais predominam questões que mobilizam habilidades cognitivas de baixa ordem (LOCS), e, na fase de conhecimentos específicos, questões que mobilizam habilidades cognitivas de alta ordem (HOCS).

As tabelas 69 e 70 indicam os resultados da análise individual para cada vestibular 
em cada fase de exame.

Tabela 69 - Ocorrência para as questões que demandam HOCS e LOCS encontradas em questões de conhecimentos gerais (primeira fase) dos exames vestibulares de cada universidade e ENEM nos anos de 2007 a 2011.

\begin{tabular}{|c|c|c|c|c|c|c|c|}
\hline \multirow[b]{2}{*}{ Ordem } & \multicolumn{7}{|c|}{ Ocorrência nas Questões, \% } \\
\hline & $\begin{array}{c}\text { FUVEST } \\
\text { (USP) } \\
n=34\end{array}$ & $\begin{array}{c}\text { COMVEST } \\
\text { (UNICAMP) } \\
n=5\end{array}$ & $\begin{array}{c}\text { VUNESP } \\
\text { (UNESP) } \\
n=50\end{array}$ & $\begin{array}{c}\text { VUNESP } \\
\text { (UFSCAR) } \\
n=9\end{array}$ & $\begin{array}{c}\text { VUNESP } \\
\text { (UNIFESP) } \\
n=28\end{array}$ & $\begin{array}{c}\text { ENEM } \\
n=21\end{array}$ & $\begin{array}{c}\text { Total } \\
n=147\end{array}$ \\
\hline $\mathrm{HOCS}^{1}$ & 21 & 80 & 40 & 33 & 7 & 33 & 29 \\
\hline $\mathrm{LOCS}^{2}$ & 79 & 20 & 60 & 67 & 93 & 67 & 71 \\
\hline
\end{tabular}

Tabela 70 - Ocorrência para as questões que demandam HOCS e LOCS encontradas em questões de conhecimentos específicos (segunda fase) dos exames vestibulares de cada universidade nos anos de 2007 a 2011.

\begin{tabular}{|c|c|c|c|c|c|c|}
\hline \multirow[b]{2}{*}{ Ordem } & \multicolumn{5}{|c|}{ Ocorrência nas Questões, \% } & \multirow[b]{2}{*}{$\begin{array}{c}\text { Total } \\
n=105\end{array}$} \\
\hline & $\begin{array}{c}\text { FUVEST } \\
\text { (USP) } \\
n=37\end{array}$ & $\begin{array}{c}\text { COMVEST } \\
\text { (UNICAMP) } \\
n=23\end{array}$ & $\begin{array}{c}\text { VUNESP } \\
\text { (UNESP) } \\
n=20\end{array}$ & $\begin{array}{c}\text { VUNESP } \\
\text { (UFSCAR) } \\
n=2\end{array}$ & $\begin{array}{c}\text { VUNESP } \\
\text { (UNIFESP) } \\
n=23\end{array}$ & \\
\hline $\mathrm{HOCS}^{1}$ & 78 & 91 & 55 & 100 & 74 & 76 \\
\hline $\mathrm{LOCS}^{2}$ & 22 & 9 & 45 & 0 & 26 & 24 \\
\hline $\begin{array}{l}n=\text { núme } \\
{ }^{n} \text { HOCS: } \\
{ }^{2} \text { LOCS: }\end{array}$ & $\begin{array}{l}\text { le questões. } \\
\text { ilidades cog } \\
\text { ilidades cogr }\end{array}$ & $\begin{array}{l}\text { de alta orden } \\
\text { de baixa orde }\end{array}$ & & & & \\
\hline
\end{tabular}

Os resultados das tabelas 69 e 70 mostram que:

- o exame da FUVEST/USP e da VUNESP/UNIFESP apresentaram questões que demandam LOCS na primeira fase do exame (79\% e 93\% respectivamente). Já na segunda fase, houve a predominância de questões que demandam HOCS com $78 \%$ para a FUVEST/USP e 74\% para a VUNESP/UNIFESP, ressaltando os resultados obtidos na tabela 68 dos resultados gerais.

- o vestibular da VUNESP/UFSCAR, assim como a análise anterior, obteve maiores ocorrências em questões que demandam LOCS na primeira fase com 67\%. Já na segunda fase suas questões mobilizam HOCS, totalizando $100 \%$.

- o destaque dos resultados para esta categoria foram as provas da 
COMVEST/UNICAMP, que nas duas fases de conhecimentos predominaram as questões que mobilizam HOCS, com $80 \%$ das ocorrências na primeira fase e $91 \%$ na segunda fase. Este resultado significativo demonstra diferenças de orientação no desenvolvimento e elaboração de questões para o vestibular da UNICAMP. De suas questões ressalta-se a interpretação de textos e respostas argumentativas a cerca dos assuntos abordados.

- na análise das questões no exame do ENEM, questões que demandam habilidades cognitivas de baixa ordem (LOCS) são mais frequentes, totalizando 67\% das ocorrências.

As tabelas $71,72,73,74,75$ e 76 indicam os resultados individuais para cada exame referente a análise de questões que mobilizam HOCS e LOCS encontrados nas provas entre os anos 2007 e 2011.

\section{FUVEST/USP}

Tabela 71 - Ocorrência para as questões que demandam HOCS e LOCS encontrada na primeira fase (CG) e segunda fase (ES) dos exames vestibulares da FUVEST/USP de 2007 a 2011.

\begin{tabular}{|c|c|c|c|c|c|c|c|c|c|c|c|}
\hline \multirow[b]{3}{*}{ Ordem } & \multicolumn{11}{|c|}{ Ocorrência de questões HOCS e LOCS para cada ano, para cada prova, $\%$} \\
\hline & \multicolumn{5}{|c|}{ CG $^{1}$} & \multicolumn{5}{|c|}{ ES $^{2}$} & \multirow[b]{2}{*}{$\begin{array}{l}\text { Total } \\
n=71\end{array}$} \\
\hline & $\begin{array}{c}2007 \\
n=9\end{array}$ & $\begin{array}{c}2008 \\
n=8\end{array}$ & $\begin{array}{l}2009 \\
n=5\end{array}$ & $\begin{array}{c}2010 \\
n=7\end{array}$ & $\begin{array}{l}2011 \\
n=5\end{array}$ & $\begin{array}{l}2007 \\
n=7\end{array}$ & $\begin{array}{c}\mathbf{2 0 0 8} \\
n=7\end{array}$ & $\begin{array}{c}2009 \\
n=8\end{array}$ & $\begin{array}{c}2010 \\
n=9\end{array}$ & $\begin{array}{l}2011 \\
n=6\end{array}$ & \\
\hline $\mathrm{HOCS}^{3}$ & 11 & 50 & 0 & 14 & 20 & 43 & 86 & 100 & 78 & 83 & 51 \\
\hline $\mathrm{LOCS}^{4}$ & 89 & 50 & 100 & 86 & 80 & 57 & 14 & 0 & 22 & 17 & 49 \\
\hline \multicolumn{12}{|c|}{$\begin{array}{l}\text { Notas: } \\
n=\text { número de questões. } \\
{ }^{1} \text { CG: Questões de conteúdos gerais (primeira fase do exame) } \\
{ }^{2} \text { ES: Questôes de conteúdos especificos (segunda fase do exame) } \\
{ }^{3} \text { HOCS: habilidades cognitivas de alta ordem. } \\
{ }^{4} \text { LOCS: habilidades cognitivas de baixa ordem. }\end{array}$} \\
\hline
\end{tabular}

Os resultados para os exames vestibulares da FUVEST/USP mostram que:

- assim como observado nos resultados gerais, questões que mobilizam habilidades cognitivas de alta ordem (HOCS) são mais frequentes em provas de conhecimentos específicos e questões que mobilizam habilidades cognitivas de baixa ordem (LOCS) mais frequentes em provas de conhecimentos gerais. 
- no ano de 2009, a prova de conhecimentos gerais apresentou a totalidade das ocorrências para questões que demandam LOCS, e na prova de conhecimentos específicos a totalidade para questões que demandam HOCS, sendo, portanto, um ano em que a tendência se mostrou polarizada nas duas fases da seleção.

- nas provas de conhecimentos gerais de 2008, metade das ocorrências são para questões que demandam HOCS e outra para LOCS.

- das provas de conhecimentos específicos, somente o ano de 2007 apresentou maior ocorrência para questões que demandam LOCS (57\%). 
Tabela 72 - Ocorrência para as questões que demandam HOCS e LOCS encontrada na primeira fase (CG) e segunda fase (ES) dos exames vestibulares da COMVEST/UNICAMP de 2007 a 2011.

\begin{tabular}{|c|c|c|c|c|c|c|c|c|c|c|}
\hline \multirow[b]{3}{*}{ Ordem } & \multicolumn{10}{|c|}{ Ocorrência de questões HOCS e LOCS para cada ano, para cada prova, $\%$} \\
\hline & \multicolumn{4}{|c|}{$\mathrm{CG}^{\mathbf{1}}$} & \multicolumn{5}{|c|}{$\mathbf{E S}^{2}$} & \multirow[b]{2}{*}{$\begin{array}{l}\text { Total } \\
n=28\end{array}$} \\
\hline & $\begin{array}{l}2007 \\
n=1\end{array}$ & $\begin{array}{c}2008 \\
n=2\end{array}$ & $\begin{array}{c}2009 \\
n=1\end{array}$ & $\begin{array}{c}2010 \\
n=1\end{array}$ & $\begin{array}{l}\mathbf{2 0 0 7} \\
n=5\end{array}$ & $\begin{array}{c}\mathbf{2 0 0 8} \\
n=3\end{array}$ & $\begin{array}{c}2009 \\
n=6\end{array}$ & $\begin{array}{c}\mathbf{2 0 1 0} \\
n=5\end{array}$ & $\begin{array}{l}2011 \\
n=4\end{array}$ & \\
\hline $\mathrm{HOCS}^{3}$ & 100 & 100 & 100 & 0 & 100 & 100 & 67 & 100 & 100 & 89 \\
\hline $\mathrm{LOCS}^{4}$ & 0 & 0 & 0 & 100 & 0 & 0 & 33 & 0 & 0 & 11 \\
\hline \multicolumn{11}{|c|}{$\begin{array}{l}\text { Notas: } \\
n=\text { número de questões. } \\
{ }^{1} \text { CG: Questões de conteúdos gerais (primeira fase do exame) } \\
{ }^{2} \text { ES: Questóes de conteúdos especificos (segunda fase do exame) } \\
{ }^{3} \text { HOCS: habilidades cognitivas de alta ordem. } \\
{ }^{4} \text { LOCS: habilidades cognitivas de baixa ordem. }\end{array}$} \\
\hline
\end{tabular}

Os resultados para o vestibular da COMVEST/UNICAMP indicam que:

- $\quad$ os exames se diferenciam das demais instituições analisadas por apresentar maiores ocorrências de questões com ilustrações que demandam habilidades cognitivas de alta ordem (HOCS), em ambas as provas, não somente em provas de conhecimentos específicos.

- $\quad$ somente duas provas apresentaram questões que mobilizam LOCS, na prova de conhecimentos gerais em 2010 e na de conhecimentos específicos em 2009. 
Tabela 73 - Ocorrência para as questões que demandam HOCS e LOCS encontrada na primeira fase (CG) e segunda fase (ES) dos exames vestibulares da VUNESP/UFSCAR de 2007 a 2011.

\begin{tabular}{|c|c|c|c|c|c|}
\hline \multirow[b]{3}{*}{ Ordem } & \multicolumn{5}{|c|}{ Ocorrência de questões HOCS e LOCS para cada ano, para cada prova, $\%$} \\
\hline & \multicolumn{3}{|c|}{ CG $^{1}$} & \multirow{2}{*}{$\begin{array}{c}\text { ES }^{\mathbf{2}} \\
\mathbf{2 0 0 7} \\
n=2\end{array}$} & \multirow[b]{2}{*}{$\begin{array}{l}\text { Total } \\
n=11\end{array}$} \\
\hline & $\begin{array}{c}2007 \\
n=3\end{array}$ & $\begin{array}{c}\mathbf{2 0 0 8} \\
n=4\end{array}$ & $\begin{array}{c}2009 \\
n=2\end{array}$ & & \\
\hline $\mathrm{HOCS}^{3}$ & 0 & 25 & 100 & 100 & 45 \\
\hline $\mathrm{LOCS}^{4}$ & 100 & 75 & 0 & 0 & 55 \\
\hline \multicolumn{6}{|c|}{$\begin{array}{l}\text { Notas: } \\
n=\text { número de questões. } \\
{ }^{1} \text { CG: Questões de conteúdos gerais (primeira fase do exame) } \\
{ }^{2} \text { ES: Questôes de conteúdos especificos (segunda fase do exame) } \\
{ }^{3} \text { HOCS: habilidades cognitivas de alta ordem. } \\
{ }^{4} \text { LOCS: habilidades cognitivas de baixa ordem. }\end{array}$} \\
\hline
\end{tabular}

Os resultados para o vestibular da VUNESP/UFSCAR indicam que:

- houve predominância de questões que demandam LOCS nas provas de conhecimentos gerais em 2007 e 2008.

- as questões que demandam HOCS apresentaram 100\% das ocorrências na prova de conhecimentos específicos no ano de 2007. 


\section{VUNESP/UNESP}

Tabela 74 - Ocorrência para as questões que demandam HOCS e LOCS encontrada na primeira fase (CG) e segunda fase (ES) dos exames vestibulares da VUNESP/UNESP de 2007 a 2011.

\begin{tabular}{|c|c|c|c|c|c|c|c|c|c|c|c|}
\hline \multirow{3}{*}{ Ordem } & \multicolumn{11}{|c|}{ Ocorrência de questões HOCS e LOCS para cada ano, para cada prova, $\%$} \\
\hline & \multicolumn{5}{|c|}{$\mathbf{C G}^{\mathbf{1}}$} & \multicolumn{5}{|c|}{ ES $^{2}$} & \multirow[b]{2}{*}{$\begin{array}{l}\text { Total } \\
n=70\end{array}$} \\
\hline & $\begin{array}{c}2007 \\
n=8\end{array}$ & $\begin{array}{c}\mathbf{2 0 0 8} \\
n=7\end{array}$ & $\begin{array}{l}\mathbf{2 0 0 9} \\
n=12\end{array}$ & $\begin{array}{l}\mathbf{2 0 1 0} \\
n=16\end{array}$ & $\begin{array}{l}2011 \\
n=7\end{array}$ & $\begin{array}{c}2007 \\
n=5\end{array}$ & $\begin{array}{c}2008 \\
n=4\end{array}$ & $\begin{array}{c}2009 \\
n=4\end{array}$ & $\begin{array}{c}\mathbf{2 0 1 0} \\
n=4\end{array}$ & $\begin{array}{l}2011 \\
n=3\end{array}$ & \\
\hline $\mathrm{HOCS}^{3}$ & 25 & 28 & 17 & 69 & 43 & 80 & 25 & 50 & 100 & 0 & 44 \\
\hline LOCS $^{4}$ & 75 & 71 & 83 & 31 & 57 & 20 & 75 & 50 & 0 & 100 & 56 \\
\hline \multicolumn{12}{|c|}{$\begin{array}{l}\text { Notas: } \\
n=\text { número de questões. } \\
{ }^{1} \text { CG: Questões de conteúdos gerais (primeira fase do exame) } \\
2 \text { ES: Questões de conteúdos especificos (segunda fase do exame) } \\
3 \text { HOCS: habilidades cognitivas de alta ordem. } \\
{ }^{4} \text { LOCS: habilidades cognitivas de baixa ordem. }\end{array}$} \\
\hline
\end{tabular}

Os resultados apresentados para os exames vestibulares da VUNESP/UNESP indicam que:

- $\quad$ em provas de conhecimentos gerais prevaleceram questões que demandam LOCS nos anos 2007, 2008, 2009 e 2011. Porém no ano de 2010, as questões que demandam HOCS foram mais frequentes na prova de conhecimentos gerais (CG).

- nas provas de conhecimentos específicos (ES) prevaleceram as questões que demandam HOCS nos anos 2007 e 2010. No ano de 2008, a prova de conhecimentos específicos apresentou $75 \%$ de ocorrência para questões que mobilizam LOCS e $25 \%$ para HOCS. Em 2011, as questões que demandam LOCS apresentaram 100\% das ocorrências. 


\section{VUNESP/UNIFESP}

Tabela 75 - Ocorrência para as questões que demandam HOCS e LOCS encontrada na primeira fase (CG) e segunda fase (ES) dos exames vestibulares da VUNESP/UNIFESP de 2007 a 2011.

\begin{tabular}{|c|c|c|c|c|c|c|c|c|c|}
\hline \multirow[b]{3}{*}{ Ordem } & \multicolumn{9}{|c|}{ Ocorrência de questões HOCS e LOCS para cada ano, para cada prova, \% } \\
\hline & \multicolumn{3}{|c|}{$\mathbf{C G}^{\mathbf{1}}$} & \multicolumn{5}{|c|}{$\mathbf{E S}^{2}$} & \multirow[b]{2}{*}{$\begin{array}{l}\text { Total } \\
n=51\end{array}$} \\
\hline & $\begin{array}{c}2007 \\
n=9\end{array}$ & $\begin{array}{c}\mathbf{2 0 0 8} \\
n=10\end{array}$ & $\begin{array}{c}2009 \\
n=9\end{array}$ & $\begin{array}{r}2007 \\
n=5\end{array}$ & $\begin{array}{c}2008 \\
n=5\end{array}$ & $\begin{array}{l}2009 \\
n=4\end{array}$ & $\begin{array}{c}2010 \\
n=5\end{array}$ & $\begin{array}{l}2011 \\
n=4 \\
\end{array}$ & \\
\hline $\mathrm{HOCS}^{3}$ & 11 & 10 & 0 & 80 & 80 & 50 & 80 & 75 & 37 \\
\hline $\mathrm{LOCS}^{4}$ & 89 & 90 & 100 & 20 & 20 & 50 & 20 & 25 & 63 \\
\hline \multicolumn{10}{|c|}{$\begin{array}{l}\text { Notas: } \\
n=\text { número de questões. } \\
{ }^{1} \text { CG: Questões de conteúdos gerais (primeira fase do exame) } \\
{ }^{2} \text { ES: Questões de conteúdos especificos (segunda fase do exame) } \\
{ }^{3} \text { HOCS: habilidades cognitivas de alta ordem. } \\
{ }^{4} \text { LOCS: habilidades cognitivas de baixa ordem. }\end{array}$} \\
\hline
\end{tabular}

Os resultados para os exames da VUNESP/UNIFESP indicam que:

- as provas de conhecimentos gerais (CG) apresentaram maiores ocorrências para questões que demandam LOCS.

- já as questões das provas de conhecimentos específicos (ES), a categoria HOCS obteve a maior ocorrência dos resultados.

- a prova de conhecimentos gerais de 2009 apresentou 100\% de ocorrência para questões que demandam LOCS. 
Tabela 76 - Ocorrência para as questões que demandam HOCS e LOCS encontrada no exame do ENEM nos anos 2010 e 2011.

\begin{tabular}{lcc|c}
\hline \multirow{2}{*}{ Ordem } & \multicolumn{3}{c}{ Ocorrência para cada ano, para cada prova, \% } \\
\cline { 2 - 4 } & $\begin{array}{c}\mathbf{2 0 1 0} \\
n=9\end{array}$ & $\begin{array}{c}\mathbf{2 0 1 1} \\
n=12\end{array}$ & $\begin{array}{c}\text { Total } \\
n=21\end{array}$ \\
\hline HOCS $^{1}$ & 56 & 17 & 33 \\
LOCS $^{2}$ & 44 & 83 & 67 \\
\hline Notas: & \\
$n=$ número de questões. \\
${ }^{1}$ HOCS: habilidades cognitivas de alta ordem. \\
${ }^{2}$ LOCS: habilidades cognitivas de baixa ordem. \\
\hline
\end{tabular}

A tabela 76 para os resultados das provas do ENEM salientam que:

- $\quad$ no ano de $2010,56 \%$ das questões demandam HOCS e $44 \%$ LOCS.

- no ano de 2011 apenas 17\% das questões demandam HOCS, apresentando um aumento nas questões que demandam habilidades cognitivas de baixa ordem (LOCS) para resolução de suas questões $(83 \%)$.

Os resultados analisados mostram que cada exame vestibular possui uma característica particular em relação à mobilização de habilidades cognitivas. Alguns exames apresentaram ocorrências muito diferenciadas entre as ordens. A partir dos resultados gerais para cada exame, pode-se salientar que os exames vestibulares da UNICAMP apresentaram maiores ocorrências para questões que demandam HOCS, e os exames da UNIFESP e do ENEM apresentaram maiores ocorrências para questões que demandam LOCS. Já os exames da USP, da UFSCAR e da UNESP tiveram o número de ocorrências aproximadas para cada ordem.

O vestibular da UNICAMP apresentou altas ocorrências para a categoria de questões que demandam HOCS, até mesmo para as provas de conhecimentos gerais, diferentemente dos outros exames.

$\mathrm{Na}$ análise das provas do ENEM, questões que demandam habilidades cognitivas de baixa ordem (LOCS) são mais frequentes, totalizando 67\%. A matriz de referência para o 
ENEM (BRASIL, 2009) divulga a sua organização de conteúdos curriculares baseados em uma ação de competências e habilidades a ser adquirida pelo aluno, para a integração do conhecimento, inclusão social, ingresso no mercado de trabalho e relevância social. Desta forma, Maceno et al. (2011, p.153) complementam:

Além disso, há a valorização da articulação entre a ciência, a tecnologia e as questões sociais, visando formar um cidadão pensante, crítico e, sobretudo, capaz de intervir na realidade e de ser um agente de transformação de seu meio.

Mas percebe-se através dos resultados que existe um descompasso entre a prova e o discurso, pois apenas 33\% destas demandam HOCS. Assim, as questões que mobilizam LOCS acabam favorecendo a possibilidade de estudantes resolverem as questões apoiados no uso da memorização de conteúdos, fórmulas, equações e teorias.

De acordo com Primi et al. (2001, p. 153), as provas do ENEM no ano de 1999 já priorizavam que o aluno resolvesse as questões de maneira diferente da tradicional memorização de conteúdos e conceitos:

\begin{abstract}
Uma questão tradicional centrada na memória requer, para resolvê-la, que o aluno aplique conhecimentos e procedimentos previamente adquiridos. Ele só conseguirá responder se tiver aprendido e conseguir lembrá-los no momento da avaliação (fórmulas, definições, fatos, etc.). Por outro lado, uma questão centrada mais no raciocínio, requer a interpretação e relacionamento das informações disponíveis nas questões. A resposta do aluno a uma questão deste tipo depende menos da recordação de conhecimentos prévios e mais da recombinação de conhecimentos já existentes de maneira nova.
\end{abstract}

A matriz de referência para o ENEM (BRASIL, 2009) salienta os eixos cognitivos comuns para todas as áreas do conhecimento, que são: dominar linguagens, compreender fenômenos, enfrentar situações-problemas, construir argumentações, sem abandonar a contextualização, que exige dos candidatos outros tipos de habilidades diminuindo a possibilidade do uso da memorização de informações.

Os resultados apresentados para a prova do ENEM mostram que no ano de 2010, $56 \%$ das ocorrências foram para questões que mobilizam HOCS e 44\% para LOCS. No ano de 2011, apenas 17\% demandam HOCS, apresentando um aumento significativo nas questões que mobilizam habilidades cognitivas de baixa ordem (LOCS) para resolução de suas questões. 


\section{Características gerais e individuais dos exames vestibulares analisados}

Para cada eixo de análise construiu-se uma 'prova típica', representando uma prova que reúne as principais características de todos os exames analisados, através da indicação das categorias mais frequentes. Esta prova típica torna-se um referencial para comparações individuais com os exames vestibulares analisados.

\section{Eixo 1 - A representação visual em si}

As provas de conhecimentos gerais e conhecimento específicos para o eixo 1 apresentaram os mesmos resultados para as categorias mais frequentes.

Portanto, a tabela 77 indica as categorias mais frequentes apontadas nas questões contendo imagens das provas vestibulares analisadas para ambas as fases de conhecimentos.

Tabela 77 - Prova típica Eixo 1 - a representação visual em si: Categorias mais frequentes para as provas de conhecimentos gerais (CG) e conhecimentos específicos (ES).

Tipos de ilustração

Equações

Moléculas 2D mista

\begin{tabular}{cc}
\hline Funcionalidade das ilustrações & Sintáticas \\
\hline Grau de iconicidade & Desenhos esquemáticos mais signos \\
& $\begin{array}{c}\text { Desenhos esquemáticos mais signos } \\
\text { normalizadas }\end{array}$ \\
\hline Presença e tipo de etiquetas verbais & Nominativas \\
\hline
\end{tabular}

A tabela 77 representa a 'prova típica' para o eixo 1, contendo as características de questões contendo ilustrações de uma prova vestibular, com base nos tipos de ilustração, funcionalidade, grau de iconicidade e etiquetas verbais, a partir dos resultados gerais obtidos da análise de todos os exames estudados. 
Assim, as questões desta 'prova típica', tanto de conhecimentos gerais quanto de conhecimentos específicos, apresentam ilustrações do tipo "equações" e representação molecular "2D misto" contendo letras e palavras que identificam os elementos na ilustração (etiquetas verbais nominativas). As ilustrações possuem menor grau de iconicidade, sendo atribuído à presença de desenhos esquemáticos, representados pelas categorias "desenho esquemático com signos" e "desenho esquemático com signos normalizados", havendo a necessidade de interpretação de conceitos químicos para a sua resolução.

A seguir será apresentada uma comparação entre os resultados oriundos para cada exame vestibular estudado e a 'prova típica' construída.

\section{FUVEST/USP}

Os resultados para o eixo 1 dos exames vestibulares da FUVEST/USP correspondem a 'prova típica', pois a partir dos resultados gerais, as questões apresentam os tipos de ilustração mais frequentes as "equação" e representações moleculares "2D misto", necessitando do conhecimento científico para suas interpretações (funcionalidade "sintática"). O grau de iconicidade das ilustrações requer a interpretação dos conceitos químicos, sendo as categorias mais frequentes "desenho esquemático com signos" e "desenho esquemático com signos normalizados" contento etiquetas verbais "nominativas".

\section{COMVEST/UNICAMP}

Diferentemente da 'prova típica', o vestibular da COMVEST/UNICAMP apresenta outras características. Os tipos de ilustração mais frequentes foram os "gráficos", as "figuras" e as representações moleculares "2D misto". Os resultados para a funcionalidade das ilustrações mostrou que as categorias "sintática" e "inoperante" tiveram ocorrências aproximadas, ou seja, praticamente metade das ilustrações presentes nos exames analisados necessita do conhecimento científico para interpretar a ilustração e consequentemente resolver a questão, e outra metade contém função somente de observação.

Em relação ao grau de iconicidade, as categorias "desenho esquemático com 
signos" e "desenho esquemático com signos normalizados" foram as mais frequentes, como na 'prova típica'. As etiquetas verbais "nominativas" tiveram altas ocorrências, assim como as "sem etiquetas", havendo uma grande variação ao longo dos anos.

\section{VUNESP/UFSCAR}

A categoria de tipos de ilustração das provas vestibulares da VUNESP/UFSCAR mais frequente foi "tabelas" se diferenciando da 'prova típica', mas a segunda mais frequente foi estruturas moleculares "2D misto". A categoria com maiores ocorrências para a funcionalidade das ilustrações foi "sintática", assim como o grau de iconicidade, em que todas as ilustrações presentes nas questões foram classificadas nas categorias de desenhos esquemáticos. As categorias "sem etiquetas" e etiquetas verbais "nominativas" tiveram resultados aproximados.

\section{VUNESP/UNESP}

Nas provas da VUNESP/UNESP a categoria de tipos de ilustração mais frequente foi "equação", correspondendo com a "prova típica', porém a segunda categoria mais frequente nas provas foi "figuras". A segunda categoria mais frequente na 'prova típica' foi "2D misto", mas nas provas da UNESP as "tabelas" foram mais frequentes que as estruturas "2D mistas".

A categoria de funcionalidade das ilustrações mais frequente foi a "sintática" e o grau de iconicidade mais frequente foram as categorias "desenho esquemático com signos" e “desenho esquemático com signos normalizados”, assim como na 'prova típica'.

\section{VUNESP/UNIFESP}

O vestibular da VUNESP/UNIFESP difere-se da 'prova típica' somente em um dos tipos de ilustração mais frequentes, sendo as "figuras" como a categoria com maiores ocorrências, seguida das estruturas moleculares "2D misto". As demais análises foram 
similares com a 'prova típica', sendo a categoria mais frequente para a funcionalidade das ilustrações foi a "sintática" e para o grau de iconicidade as categorias "desenho esquemático com signos" e "desenho esquemático com signos normalizados".

\section{ENEM}

O exame do ENEM apresentou características diferentes da 'prova típica' em relação aos tipos de ilustração presentes, sendo a categoria "figura" o mais frequente. As categorias "equação" e "2D misto" tiveram as mesmas ocorrências (18\%).

As questões apresentam ilustrações com funcionalidade "sintática" e grau de iconicidade "desenho esquemático com signos" e "desenho esquemático com signos normalizados", assim como na 'prova típica'.

\section{Eixo 2 - A Relação entre a representação visual e seu entorno na questão}

Dentre as categorias para a relação texto-imagem (sinótica, denotativa e conotativa), a mais frequente de todos os exames foi a "sinótica". Este resultado sugere que a 'prova típica' para a relação entre o texto da questão e a ilustração apresentada, seja de questões que estabelecem uma correspondência entre os conteúdos e assuntos abordados no texto da questão e os elementos presentes na ilustração.

Desta forma, as características ('prova típica') das questões das provas de conhecimentos gerais e conhecimentos específicos para o eixo 2 , são de textos informativos que se relacionam fortemente com a ilustração, de forma indivisível, estabelecendo uma dupla codificação texto-imagem. 


\section{FUVEST/USP}

O exame vestibular da FUVEST/USP, de forma geral, apresentou altas ocorrências para a categoria "sinótica", sendo semelhante à 'prova típica'. Durante os anos analisados, as questões das provas de conhecimentos gerais apresentaram-se homogêneas, enquanto houve uma grande variação nas questões das provas de conhecimentos específicos.

\section{COMVEST/UNICAMP}

As provas de conhecimentos gerais da COMVEST/UNICAMP apresentaram 100\% de ocorrências para a categoria "sinótica", mostrando homogeneidade de questões que mantém a relação texto-imagem em suas provas. Já nas provas de conhecimentos específicos existe certa variação no número de ocorrências, porém com menor evidência em relação às provas da FUVEST/USP.

\section{VUNESP/UFSCAR}

Assim como nos exames vestibulares da COMVEST/UNICAMP, os exames vestibulares da primeira fase da VUNESP/UFSCAR também apresentaram 100\% das ocorrências para a categoria "sinótica", para os anos 2007, 2008 e 2009.

\section{VUNESP/UNESP}

O vestibular da VUNESP/UNESP se assemelha com a 'prova típica', pois a categoria "sinótica" foi a mais frequente entre as categorias, sendo muito homogênea a distribuição dos dados nas duas fases de conhecimentos das provas, se diferenciando dos demais exames. 


\section{VUNESP/UNIFESP}

As questões com ilustração das provas vestibulares da VUNESP/UNIFESP mantêm fortemente a relação texto-imagem apresentando resultados semelhantes com a 'prova típica'. A categoria "sinótica" apresentou altas ocorrências nas provas de conhecimentos específicos. Nas provas de conhecimentos gerais, com o passar dos anos houve uma diminuição das ocorrências nesta categoria.

\section{ENEM}

O exame do ENEM mantém as características da 'prova típica', sendo 50\% das ocorrências para a categoria "sinótica", porém a categoria "denotativa" apresentou $41 \%$ das ocorrências. Mesmo assim, a categoria "denotativa" representa a relação do texto com a imagem, porém não de uma forma indivisível.

\section{Eixo 3 - A questão de química no vestibular como um todo}

A tabela 78 indica as categorias mais frequentes apontadas no eixo 3 das provas vestibulares analisadas para as fases de conhecimentos gerais (CG) e conhecimentos específicos (ES).

Tabela 78 - Prova típica Eixo 3 - a questão de química no vestibular como um todo: Categorias mais frequentes para as provas de conhecimentos gerais (CG) e conhecimentos específicos (ES).

\section{Conhecimentos Gerais Conhecimentos Específicos}

(CG)

(ES)
Assuntos químicos envolvidos
Físico-química
Físico-química
nas questões
Química Orgânica
Química Orgânica

\section{Habilidades Cognitivas requisitadas}

LOCS

HOCS 
As categorias mais frequentes apresentadas na tabela 78 correspondem à 'prova típica' para o eixo 3 de análise. Deste modo, a 'prova típica' para exames vestibulares de conhecimentos gerais consiste em questões de "físico-química" e "química orgânica" que mobilizam habilidades cognitivas de baixa ordem (LOCS), solicitando informações e conhecimentos memorizados, em que sua resolução baseia-se em uma forma simplificada de aplicação de teorias, fórmulas e equações.

A 'prova típica' para as provas de conhecimentos específicos consiste em questões de "físico-química" e "química orgânica" que mobilizam habilidades cognitivas de alta ordem (HOCS), que requerem para a sua resolução a tomada de decisões, análise, investigação, pensamento crítico e reflexivo.

A seguir, encontram-se as comparações entre a 'prova típica' para cada fase de prova e os exames vestibulares analisados.

\section{FUVEST/USP}

Os exames vestibulares da FUVEST/USP assemelham-se com a 'prova típica' apresentada. As características de suas questões são similares com as categorias mais frequentes da tabela 78. Os assuntos químicos mais abordados nas questões foram "química orgânica" e "físico-química" em ambas as fases de conhecimento. Nas provas de conhecimentos gerais, $79 \%$ das ocorrências são para questões que demandam LOCS, e em provas de conhecimentos específicos, $78 \%$ demandam HOCS. Estes resultados mostram que o vestibular da FUVEST/USP possui as características da 'prova típica' construída a partir dos dados gerais de todos os exames analisados.

\section{COMVEST/UNICAMP}

Em relação aos assuntos químicos abordados nas questões do vestibular da COMVEST/UNICAMP, nas provas de conhecimentos gerais, os assuntos mais frequentes foram "química orgânica" e "físico-química", assim como na "prova típica'. Porém, as provas de conhecimentos gerais demandam HOCS, diferentemente dos resultados dos 
demais exames vestibulares analisados e da 'prova típica'.

Este resultado aponta certa diferença do vestibular da COMVEST/UNICAMP dos demais exames. Nas provas de conhecimentos específicos, os assuntos químicos mais frequentes foram "química geral" e "química orgânica", com ênfase em questões que demandam HOCS, semelhante à 'prova típica'.

\section{VUNESP/UFSCAR}

As provas de conhecimentos gerais da VUNESP/UFSCAR possuem características semelhantes à 'prova típica', sendo os assuntos químicos mais frequentes "química orgânica" e "físico-química", e questões que demandam habilidades cognitivas de baixa ordem. Nas provas de conhecimentos específicos, três assuntos químicos foram os mais frequentes, "química orgânica", "meio ambiente" e "química geral”, todos com as mesmas ocorrências. As questões para esta fase de prova demandam habilidades cognitivas de alta ordem.

\section{VUNESP/UNESP}

As provas da VUNESP/UNESP semelham-se a 'prova típica' em relação aos assuntos químicos nas duas fases de prova. Em relação às habilidades cognitivas requisitadas, tanto nas provas de conhecimentos gerais como nas provas de conhecimentos específicos, houve um equilíbrio nos resultados. As duas fases de conhecimentos apresentaram ocorrências aproximadas entre habilidades cognitivas de alta ordem (HOCS) e habilidades cognitivas de baixa ordem (LOCS). 


\section{VUNESP/UNIFESP}

Assim como o vestibular da FUVEST/USP, os exames da VUNESP/UNIFESP também se assemelham com a 'prova típica' construída. Os assuntos abordados em ambas as fases de conhecimentos das provas foram "química orgânica" e "físico-química". Nas prova de conhecimentos gerais as questões demandam LOCS, e as provas de conhecimentos específicos HOCS.

\section{ENEM}

Os assuntos químicos mais frequentes nas provas do ENEM foram "físico-química" e "meio-ambiente". Por ser uma prova com assuntos de conhecimentos gerais, as questões do ENEM se assemelham com a ordem de habilidade cognitiva apresentada na 'prova típica', apresentando maior ocorrência para questões que demandam LOCS.

Em suma, juntando os três eixos analíticos apresentados na 'prova típica', temos uma prova que contém questões com ilustrações de menor grau de iconicidade, do tipo “equações" e representação molecular "2D misto" que apresentam letras e palavras que identificam os elementos na ilustração, e que necessitam da interpretação de conceitos químicos para a sua resolução. Estas questões abordam assuntos de "físico-química" e "química orgânica", apresentando uma forte relação texto-imagem, que mobilizam habilidades cognitivas de baixa ordem (LOCS) em provas de conhecimentos gerais e habilidades cognitivas de alta ordem (HOCS) em provas de conhecimentos específicos.

Desta forma, identifica-se que o vestibular da USP assemelha-se em todos os resultados com as características apresentadas para a 'prova típica' construída. Já os exames da UFSCAR, da UNESP e da UNIFESP apresentaram resultados compatíveis para os eixos analíticos 2 e 3, mas apresentaram algumas discrepâncias nos resultados para o eixo 1 em referência à 'prova típica'. Nesta mesma comparação, os resultados dos exames da UNICAMP assemelham-se à 'prova típica' apenas para o eixo 2, e o exame do ENEM apenas para o eixo 3 . 
Em conclusão, as análises das características gerais e individuais dos exames vestibulares apresentados nas 'provas típicas' construídas salientam a homogeneidade dos exames analisados em ralação às questões contendo representações visuais. Os cinco exames vestibulares paulistas e as provas do ENEM, nos anos analisados, possuem características semelhantes quanto ao emprego das ilustrações nas questões de química, os assuntos químicos abordados e no tocante às ordens de habilidades cognitivas das questões em ambas as fases de conhecimento. 


\section{CONSIDERAÇÕES FINAIS}

Por meio das análises apresentadas segundo os três eixos deste trabalho, buscou-se classificar e identificar as representações visuais presentes em questões de química dos exames vestibulares de cinco grandes universidades públicas paulistas e as provas do ENEM. Analisou-se um total de 252 questões contendo representações visuais em provas de conhecimentos gerais e conhecimentos específicos.

As fases dos exames vestibulares são distintas em muitos aspectos, mas ainda assim, empregam de forma similar os tipos de representações visuais ilustradas nas questões. De modo geral, os resultados desta pesquisa multifacetada mostram a homogeneidade dos exames vestibulares nos anos analisados, apresentando características semelhantes no tocante à análise das representações visuais em questões de química.

Em relação ao eixo analítico 1 - a ilustração em si - os tipos de ilustração mais frequentes nas questões em ambas as fases de conhecimentos foram as equações (dimensão representacional simbólica) e as representações moleculares bidimensionais (dimensão representacional submicroscópica). Os resultados para a categoria de funcionalidade das ilustrações indicam que os exames, de modo geral, envolvem em suas questões ilustrações que necessitam do conhecimento químico para interpretação e consequente resolução. Isto também pode ser verificado através dos resultados para a categoria de grau de iconicidade, revelando que as maiores ocorrências foram para desenhos esquemáticos com signos e signos normalizados, sendo estes de menor grau de iconicidade (menos realistas), necessitando, para sua compreensão, do conhecimento científico específico associado ao símbolo químico apresentado.

Os resultados para o eixo analítico 2 - a relação entre a representação visual e seu entorno na questão - revelaram a forte relação existente entre o texto da questão (expositivos ou explicativos) e a imagem presente nas provas, sendo evidenciada através dos resultados para a categoria sinótica, salientando que esta relação é útil e necessária para o desenvolvimento do raciocínio, e também a necessidade do conhecimento científico para a possibilidade de resolução das questões.

Nas análises do eixo 3 - a questão de química como um todo - os assuntos químicos mais frequentes nas provas foram química orgânica e físico-química. Tal resultado é especialmente relevante levando-se em conta que, segundo estudos, como de Silva et al. 
(2010), candidatos aos exames vestibulares apresentam dificuldades em exercícios que contemplam temas como equilíbrio químico, velocidade de reação, entalpia e eletroquímica, ou seja, conteúdos de físico-química. Portanto, a ênfase nas provas é justamente nos conteúdos considerados mais difíceis pelos estudantes. Possivelmente, tal ênfase não se deve ao propósito de tornar os exames mais seletivos, mas simplesmente porque tais conteúdos são centrais na química.

Adicionalmente, há de se considerar que os conteúdos programáticos de todas as áreas de conhecimento dos exames vestibulares influenciam diretamente o processo de ensino-aprendizagem das escolas, principalmente no ensino médio, em relação ao currículo e aos conteúdos com os quais os estudantes têm contato durante a vida escolar.

Muitos professores acabam modificando suas aulas a fim de buscar subsídios que fortaleçam o ensino voltado para resoluções de questões de provas vestibulares, focando nos conteúdos presentes nas provas, tornando o vestibular como parâmetro curricular. A lógica competitiva resultante da carência de vagas nas universidades públicas paulistas analisadas neste estudo leva muitos candidatos a recorrer aos cursinhos preparatórios para o ENEM e vestibulares, além das próprias escolas definirem suas aulas com a atenção especial para o exame, fazendo com que este se torne um indicador de êxito e eficiência educacional. Desta forma, as escolas e os cursinhos adotam apostilas e métodos de memorização que implicam na organização curricular.

Além da preparação dos candidatos para o exame, existe a competição entre estes, fazendo com que todo o conteúdo escolar seja "compreendido" o máximo possível. Fica indefinido, por exemplo, se a "boa resposta" resulta da memorização de informações e da aplicação de fórmulas e equações, ou se resulta do processo reflexivo sobre os conceitos apresentados, articulando habilidades como, por exemplo, a interpretação de gráficos.

Com o passar do tempo as questões de química presentes nos exames vestibulares acabam sofrendo algumas modificações como, por exemplo, a implantação da contextualização e vivência dos estudantes. Porém, ainda existem questões baseadas na simples memorização. Os PCNEM+ (BRASIL, 2002) trazem na proposta para o ensino de química que os estudantes compreendam os conteúdos químicos de uma forma integrada e significativa, o que se contrapõem à memorização de termos e informações, como nomes e fórmulas, mas também conceitos trabalhados fora do contexto de realidade dos alunos. 
Assim, utilizando como base as pesquisas de Zoller (1993, 1997, 1999, 2001), sobre a potencialização de questões que demandam habilidades cognitivas de alta ou baixa ordem, temos que os resultados, de modo geral, indicam que questões que demandam habilidades cognitivas de baixa ordem (LOCS) são predominantes nas provas de conhecimentos gerais, e questões que demandam habilidades cognitivas de alta ordem (HOCS) são frequentes nas provas de conhecimentos específicos. Os resultados para a segunda fase de provas indicam que a preparação das questões para os exames vestibulares envolvem o uso de questões que mobilizam a capacidade cognitiva do candidato para a sua resolução, e da importância de requerer a "compreensão dos conceitos" ao invés da memorização de equações e fórmulas ou a aplicação de algoritmos para um determinado conjunto de problemas.

Este resultado é considerado aqui como positivo, pois, em princípio, supõem-se que, quanto mais os organizadores de exames vestibulares elaborarem questões que demandem HOCS, mais os estudantes seriam estimulados a desenvolverem tais habilidades, incluindo a capacidades de elaboração de estratégias, tomada de decisões para resoluções de problemas.

Os conteúdos estudados, principalmente os das áreas de ciências e matemática, quando trabalhados com ênfase na memorização, favorecem o desenvolvimento de habilidades cognitivas de baixa ordem (LOCS). A diminuição na ênfase em questões que demandam LOCS em provas vestibulares e o aumento de questões HOCS poderia, em tese, estimular professores do sistema básico de ensino a modificar elementos importantes da sua prática docente, sobretudo com relação aos métodos de avaliação do desempenho escolar. Adicionalmente, tais mudanças de ênfase quanto às habilidades cognitivas solicitadas nas questões poderiam contribuir para uma mudança na associação tão comum do exame vestibular como algo exclusivamente relacionado à memorização, ou que a capacidade de memorização fosse o principal elemento de seleção nestes exames.

Estas análises sugerem atenção para o processo de elaboração de questões para os exames vestibulares de instituições de ensino superior e provas do ENEM, e como se apresentam para os candidatos. Ou seja, que os organizadores, selecionadores e ilustradores incluam suas imagens com base nos estudos de caracterização e função das representações visuais, como: conectar a relação texto-imagem abordando as demais informações necessárias para a resolução da questão, sem deixar de evidenciar qual a funcionalidade da 
imagem na questão juntamente com seu grau de iconicidade. Estas relações e características identificadas e analisadas nas questões vão além do processo de seleção das provas. Ou seja, os resultados oriundos desta pesquisa podem ser válidos para escolas e sistemas educacionais do país que adotam o vestibular como meta de ensino, os quais que utilizam materiais didáticos baseados nas questões das provas, como livros e apostilas.

Os resultados das provas típicas construídas a partir das categorias mais frequentes mostram como o uso das representações visuais é importante no ensino da química, relevante e presente no processo de ensino-aprendizagem. Porém o exame vestibular é um processo de seleção adotado pelas instituições de ensino superior, cujo método é selecionar estudantes para o preenchimento de determinados números de vagas. Portanto, as características identificadas para as representações visuais nas questões vestibulares podem não ser adequadas para materiais didáticos utilizados dentro da sala de aula.

No entanto, é sabido que o uso da visualização no ensino da química permite que os estudantes desenvolvam habilidades para a compreensão dos códigos e símbolos químicos, e para isso, diversas ferramentas visuais podem ser utilizadas. Porém, poucos professores abordam e trabalham com essas ferramentas em suas aulas. Muitas vezes as representações visuais são usadas como uma metodologia pontual, apenas para ser trabalhada com os estudantes em conteúdos e assuntos químicos mais abstratos. A implementação de recursos visuais no ensino, por parte do professor, pode estar relacionado à sua formação, de tal forma que pouco foi abordado durante a graduação ou foi apresentado de forma superficial, fazendo com que não se sintam preparados para utilizá-los em seus métodos de ensino (FERREIRA e ARROIO, 2009).

Portanto, levando-se em conta que, primeiro, conforme caracterizado neste trabalho, o uso de múltiplos modos de visualização está presente nas questões dos exames vestibulares analisados; segundo, que o vestibular exerce influência, ainda que errônea, no currículo e nas metodologias adotadas pela escola; terceiro, que os exames são elaborados por equipes de docentes das universidades públicas, os quais incluem nos exames conteúdos que consideram importantes no perfil dos ingressantes; quarto, que estudos como o de Ferreira e Arroio (2009) indicam que os professores de química não estão preparados para utilizar o pleno potencial das representações visuais. É plausível supor que há um descompasso entre os exames vestibulares e o ensino de química no sistema básico quanto à questão do uso das representações visuais. Um lado deste desequilíbrio, referente aos 
exames vestibulares, pode ser entendido com estudos como o presente. Indica-se, portanto, que é necessário promover estudos análogos sobre o uso de representações visuais nos materiais didáticos e na forma como são empregados pelos professores e apropriados pelos estudantes.

Finalmente, é esperado que o presente estudo possa contribuir com a ampliação do conhecimento sobre o uso de representações visuais no ensino de química, abarcando também os exames vestibulares. Salienta-se que há relativamente poucos estudos na literatura que se debrucem sobre o uso de representações visuais nos exames vestibulares, sobretudo, no tocante à Química. 


\section{REFERÊNCIAS BIBLIOGRÁFICAS}

ADADAN, E.; IRVING, K. E.; TRUNDLE, K. C. Impacts of multi-representational instruction on high school students' conceptual understandings of the particulate nature of matter. International Journal of Science Education, v. 31, n. 13, p. 1743-1775, 2009.

ALVAREZ, Ana Maria Torres. Produto 1 - Panorama e diagnóstico da oferta e qualidade da Educação Superior brasileira. São Paulo: UNESCO; CNE, 2013. 73f. (Projeto CNE/UNESCO 914BRZ1136.3 Desenvolvimento, aprimoramento e consolidação de uma educação nacional de qualidade. Contrato no. SA-403/2013 e Controle UNESCO 545393). Disponível em: $<$ https://www.google.com.br/url? $\mathrm{sa}=\mathrm{t} \& \mathrm{rct}=\mathrm{j} \& \mathrm{q}=\&$ esrc $=$ s\&source=web\&cd=1\&cad=rja $\underline{\text { \&uact }=8 \& v e d=0 \mathrm{CB} 0 \mathrm{QFjAA} \& u r l=h \mathrm{ttp} \% 3 \mathrm{~A} \% 2 \mathrm{~F} \% 2 \mathrm{Fportal} . \mathrm{mec} . \text { gov.br} \% 2 \mathrm{Findex} . \mathrm{php} \% 3 \mathrm{Fo}}$ ption\%3Dcom_docman\%26task\%3Ddoc_download\%26gid\%3D13944\%26Itemid\%3D\&ei= Y1YHVMXxD4PF8AGU8oGwCA\&usg=AFQjCNG7886wI41JqTDoftUzwuNTtUoyA\&sig2=cpoQ5zY2RPV3vyKZNG_APQ\&bvm=bv.74115972,d.eXY>. Acesso em: ago. 2014.

ALVES, R. Estória de quem gosta de ensinar: o fim dos vestibulares. 11. ed. Campinas: Papirus, 2007. 160 p.

AMAURO, N. Q. Os concursos vestibulares das universidades estaduais paulistas e o ensino de Química no nível médio. 2010. 156f. Tese (Doutorado em Ciências) - Instituto de Química de São Carlos, Universidade de São Paulo, São Paulo, 2010.

BARROS, H. G. C. Alternativas futuras para o vestibular. Educação e Seleção, n. 11, p. 2933,1985 .

BRASIL. Ministério da Educação (MEC). Secretaria de Educação Média e tecnologia (Semtec). PCN+ Ensino médio: orientações educacionais complementares aos Parâmetros Curriculares Nacionais - Ciências da Natureza, Matemática e suas Tecnologias. Brasília: MEC/SEMTEC, p. 141, 2002. 
BRASIL. Ministério da Educação e Instituto Nacional de Estudos Pesquisas Educacionais Anísio Teixeira. Matriz de Referência para o ENEM 2009. Brasília, Distrito Federal, p. 26, 2009.

BRECHER, J. Graphical representation of stereochemical configuration. Pure and Applied Chemistry, v. 78, n. 10, p. 1897-1970, 2006.

CAMPOS, C.; CACHAPUZ, A. Imagens de ciência em manuais de química portugueses. Química Nova na Escola, n. 6, p. 23-29, 1997.

CHANDRASEGARAN, A. L.; TREAGUST, D. F.; MOCERINO, M. Emphasizing multiple levels of representation to enhance students' understandings of the changes occurring during chemical reactions. Journal of Chemical Education, v. 86, n.12, p. 1433-1436, 2009.

CHITTLEBOROUGH, G.; TREAGUST, D. Correct interpretation of chemical diagrams requires transforming from one level of representation to another. Research in Science Education, v. 38, n. 4, p. 463-482, 2008.

Comissão Permanente para o Vestibular (COMVEST). Disponível em:

$<$ http://www.comvest.unicamp.br/> . Acesso em: jun. 2014.

Comissão Permanente para o Vestibular - FAMERP. Disponível em:

$<$ http://www.comvest.unicamp.br/cursos/medicina famerp.html $>$. Acesso em: jun. 2014.

COOK, M. P. Visual Representations in Science Education: The Influence of Prior Knowledge and Cognitive Load Theory on Instructional Design Principles. Science Education, v. 90, n. 6, p. 1073-1091, 2006.

Dia a Dia Educação. Portal da Educação do Paraná. Disponível em: < http://www.quimica.seed.pr.gov.br/modules/galeria/detalhe.php?foto $=1857 \&$ evento $=5>$ Acesso em: 5 ago. 2014.

DIAZ, L.; PANDIELLA, S. Categorización de las ilustraciones presentes em libros de texto de tecnología. Revista Electrônica de Enseñanza de las Ciencias, v. 6, n.2, p. 424-441, 2007. 
FERREIRA, C. R.; ARROIO, A. O uso de visualizações no ensino de química: a formação inicial do professor de química. Revista Brasileira de Ensino de Química, v. 4, n. 2, p.3142, 2009.

Fundação Vunesp. Disponível em: < http://www.vunesp.com.br/internas/quem.html $>$. Acesso em jun.2014.

Fundação Universitária para o Vestibular (FUVEST). Disponível em:

$<\underline{\text { http://www.fuvest.br/> }}$. Acesso em jun. 2014.

GIBIN, G. B.; FERREIRA, L. H. Avaliação dos estudantes sobre o uso de imagens como recurso auxiliar no ensino de conceitos químicos. Química Nova na Escola, v. 35, n. 1, p. 19-26, 2013.

GIBIN, G. B.; KIILL, K. B.; FERREIRA, L. H. Categorização das imagens referentes ao tema equilíbrio químico nos livros aprovados pelo PNLEM. Revista Electrónica de Enseñanza de las Ciencias, Vigo, v. 8, n. 2, p. 711-721, 2009.

GUIMARÃES, Y. A. F.; JUNIOR, M. M. O.; DUARTE, J.; SILVA, D. P.; ABIB, M. L. V. S. A influência da proposta curricular do Estado de São Paulo na prática pedagógica dos professores de química. Anais... Florianópolis: VII ENPEC, 2009.

HAND, B.; CHOI, A. Examining the impact of student use of multiple-mode representations in constructing scientific arguments in organic chemistry laboratory classes. Research in Science Education, v. 40, n. 1, p. 29-44, 2010.

Instituto Nacional de Estudos e Pesquisas Educacionais Anísio Teixeira (INEP). Disponível em: $<$ http://portal.inep.gov.br/web/enem/sobre-o-enem>. Acesso em: jun. 2014.

JOHNSTONE, A. H. The development of chemistry teaching: a changing response to a changing demand. Journal of Chemical Education, v. 70, n. 9, p. 701-705, 1993.

Laboratório de Química Orgânica. Faculdade de Ciências - UdelaR. Disponível em

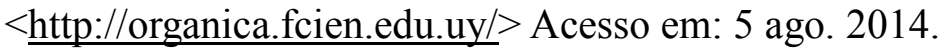


LELIS, I. A. O. M. Evolução histórico-legal do vestibular (1968-1983) do “milagre” à recessão. Revista Educação e Comunicação, v. 1, n. 12, p. 27-45 , 1985.

MACENO, N. G.; RITTER-PEREIRA, J.; MALDANER, O. A.; GUIMARÃES, O. M. A matriz de referência do ENEM 2009 e o desafio de recriar o currículo de química na educação básica. Química Nova na Escola, v. 33, n. 3, p.153-159, 2011.

MARTINS, A. C. P. Ensino superior no Brasil: da descoberta aos dias atuais. Acta Cirúrgica Brasileira, v. 17, (Suplemento 3), p 4-6, 2002.

MARTINS, C. B. A reforma universitária de 1968 e a abertura para o ensino superior privado no Brasil. Educação e Sociedade, Campinas, v. 30, n. 106, p. 15-35, 2009.

Ministério da Educação. Disponível em:

$<$ http://portal.mec.gov.br/index.php?id=12598:publicacoes\&option=com_content\&view=arti cle> Acesso em: maio. 2014.

NETO, P. E. M. Vestibular e exame de ordem: uma análise crítica. Ensaio. Avaliação e

Políticas Públicas em Educação, Rio de Janeiro, v. 3, n. 8, p.317-322, 1995.

NETTO, A. R. O vestibular ao longo do tempo: implicações e implicâncias. Revista Educação e Comunicação, v.1, n.13, p. 41-48, 1986.

NETTO, A. R. O vestibular no sistema educacional brasileiro. Cadernos de Pesquisa, n. 24, p. 47-52, 1978.

OLIM, B. B. Imagens em livros didáticos de história das séries iniciais: uma análise comparativa e avaliadora. Outros Tempos, v. 7, n. 10, p. 93-118, 2010.

PAIVIO, A. (2006). Dual Coding Theory And Education. Disponível em: $<$ http://www.umich.edu/ rdytolrn/pathwaysconference/presentations/paivio.pdf $>$. Acesso em: set. 2013. 
PERALES, F. J.; JIMÉNEZ, J. D. Las ilustraciones en la enseñanza - aprendizaje de las ciencias. Análisis de libros de texto. Enseñanza de las Ciencias, v. 20, n. 3, p. 369-386, 2002.

PERALES, F. J. Uso (y abuso) de la imagen en la enseñanza de las ciencias. Enseñanza de las Ciencias, v. 28, n. 1, p. 13-30, 2006.

PIRES, R.; RAPOSO, P. N.; MÓL, G. S. Adaptação de um livro didático de Química para alunos com deficiência visual. Anais... Florianópolis: VI ENPEC, 2007.

PRIMI, R.; SANTOS, A. A. A.; VENDRAMINI, C. M.; TAXA F.; MULLER, F. A.; LUKJANENKO, M. F.; SAMPAIO, I. S. Competências e Habilidades Cognitivas:

Diferentes Definições dos Mesmos Construtos. Psicologia: Teoria e Pesquisa, v. 17, n.2, p. 151-159, 2001.

Programa de Financiamento Estudantil (FIES). Ministério da Educação. Disponível em:

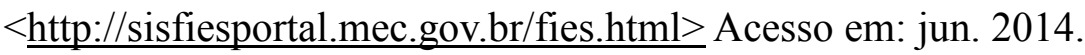

ProUni. Ministério da Educação. Disponível em:

$<$ http://siteprouni.mec.gov.br/o prouni.php $>$ Acesso em: jun. 2014.

RAUPP, D.; SERRANO, A.; MOREIRA, M. A. Desenvolvendo habilidades visuoespaciais: uso de software de construção de modelos moleculares no ensino de isomeria geométrica em química. Experiências em Ensino de Ciências, v. 4, n. 1, p. 65-78, 2009.

SÃO PAULO. Secretaria da Educação. Currículo do Estado de São Paulo: Ciências da Natureza e suas Tecnologias/Secretaria da Educação; coordenação geral, Maria Inês Fini; coordenação de área, Luis Carlos de Menezes. - 1. ed. atual. - São Paulo: SE, 2011. 152 p.

SAVIANI, D. A expansão do ensino superior no Brasil: mudanças e continuidades. Poíesis Pedagógica, v. 8, n. 2, p. 4-17, 2010. 
SCHWARTZMAN, S. “O ensino médio no Brasil é formal, acadêmico, voltado para o vestibular. Não atende jovens com outros interesses”. Revista Ensino Superior Unicamp, v. 1, n. 2 , p. 16-25, 2010.

SILVA, C. S.; MARUYAMA, J. A.; OLIVEIRA, L. A. A.; OLIVEIRA, O. M. M. F. Questões de química no concurso vestibular da Unesp: desempenho dos estudantes e conceitos exigidos nas provas. Química Nova na Escola, v. 32, n. 1, p. 14-21, 2010.

SILVA, G. S.; BRAIBANTE, M. E. F.; PAZINATO, M. S. Os recursos visuais utilizados na abordagem dos modelos atômicos: uma análise nos livros didáticos de química. Revista Brasileira de Pesquisa em Educação em Ciências, v. 13, n. 2, p. 159-182, 2013.

SILVA, H. C.; ZIMMERMAN, E.; CARNEIRO, M. H. S.; GASTAL, M. L; CASSIANO, W. S. Cautela ao usar imagens em aulas de ciências. Ciência \& Educação, v. 12, n. 2, p. 219$233,2006$.

Sistema de seleção Unificada (SISU). Ministério da Educação. Disponível em:

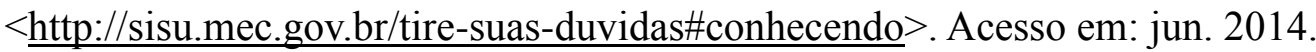

STRUCCHI, N. Educadores defendem formas alternativas ao vestibular. Disponível em: $<$ http://noticias.universia.com.br/destaque/noticia/2006/12/06/428230/educadoresdefendem-formas-alternativas-ao-vestibular.pdf $>$ Acesso em: jun. 2014.

SUART, R. C.; MARCONDES, M. E. R. As habilidades cognitivas manifestadas por alunos do ensino médio de química em uma atividade experimental investigativa. Revista Brasileira de Pesquisa em Educação em Ciências, v. 8, n. 2, 2008. 
TANEGUTI, Luiza Yoko. Produto 2 - Relatório técnico contendo estudo sobre a atual oferta/demanda de cursos de graduação no Brasil... . Brasília: Ministério da Educação Superior, 2013. 48 f. (Projeto CNE/UNESCO, 914BRZ 1136.3. Desenvolvimento, aprimoramento e consolidação de uma educação de qualidade). Disponível em: $<$ https://www.google.com.br/url?sa=t\&rct $=\mathrm{j} \& \mathrm{q}=\&$ esrc $=$ s\&source $=$ web $\& \mathrm{~cd}=2 \& \mathrm{cad}=$ rja\&uac $\underline{\mathrm{t}=8 \& \mathrm{ved}=0 \mathrm{CCUQFjAB} \& u r l=h t t p} \% 3 \mathrm{~A} \% 2 \mathrm{~F} \% 2 \mathrm{Fportal}$.mec.gov.br\%2Findex.php $\% 3$ Foption \%3Dcom_docman\%26task\%3Ddoc_download\%26gid\%3D13948\%26Itemid\%3D\&ei=61U HVOfWBfz8AHisYHYCQ\&usg=AFQjCNFJ04xaQHtVHdXWegYURhwj5kP9RA\&sig2=aOsKiph9 MDBBduSSXfU6 A\&bvm=bv.74115972,d.eXY>. Acesso em: ago. 2014.

TREAGUST, D. F.; CHITTLEBOROUGH, G.; MAMIALA, T. L. The role of submicroscopic and symbolic representations in chemical explanations. International Journal of Science Education, v. 25, n. 11, p. 1353-1368, 2003.

Universidade Estadual Paulista "Júlio de Mesquita filho" (UNESP). Disponível em:

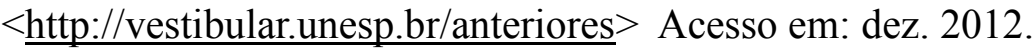

Universidade Estadual de São Carlos (UFSCAR). Disponível em:

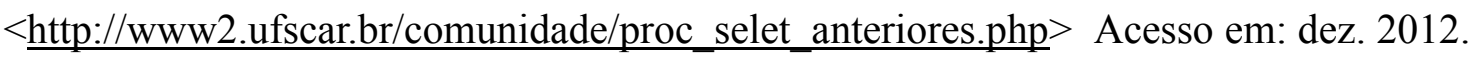

VERGNAUD, G. A classification of cognitive tasks and operations of thought involved in addition and subtraction problems. In CARPENTER, T.; MOSER, J.; ROMBERG, T. Addition and subtraction. A cognitive perspective. Hillsdale: Lawrence Erlbaum, 1982. p. $39-59$.

Vestibular UNIFESP. Disponível em:

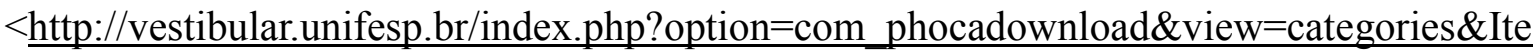
$\underline{\operatorname{mid}=112}>$ Acesso em: dez. 2012.

ZOLLER, U. Alternative assessment as (critical) means of facilitating HOCS-promoting teaching and learning in chemistry education. Chemistry Education: Research and Practice in Europe, v. 2, n. 1, p. 9-17, 2001. 
ZOLLER, U. "Lecture and Learning: are they compatible? Maybe for LOCS; unlikely for HOCS". Journal of Chemical Education, v. 70, n. 3, p. 195- 197, 1993.

ZOLLER, U. "Scaling-up of higher-order cognitive skills-oriented college chemistry teaching: An action-oriented research". Journal of Research in Science Teaching, v. 36, n. 5, p. 583-596, 1999.

ZOLLER, U.; DORI, Y. J.; LUBEZKY, A. Algorithmic, LOCS and HOCS (Chemistry) exam questions: Performance and attitudes of college students. International Journal of Science Education, v. 24, p. 185-203, 2002.

ZOLLER U.; TSAPARLIS G. Higher and lower-order cognitive skills: the case of chemistry. Research in Science Education, v. 27, p. 117-130, 1997. 